Portland State University

PDXScholar

\title{
Limits of limit equilibrium and finite element techniques applied to cracked debris dams on collapsing foundations
}

Stanley Soliday Jr.

Portland State University

Follow this and additional works at: https://pdxscholar.library.pdx.edu/open_access_etds

Part of the Civil Engineering Commons

Let us know how access to this document benefits you.

\section{Recommended Citation}

Soliday, Stanley Jr., "Limits of limit equilibrium and finite element techniques applied to cracked debris dams on collapsing foundations" (1991). Dissertations and Theses. Paper 4428.

https://doi.org/10.15760/etd.6306

This Thesis is brought to you for free and open access. It has been accepted for inclusion in Dissertations and Theses by an authorized administrator of PDXScholar. Please contact us if we can make this document more accessible: pdxscholar@pdx.edu. 
AN ABSTRACT OF THE THESIS OF Stanley Soliday $\mathrm{Jr}$. for the Master of Science in Civil Engineering presented on December 16, 1991.

Title: Limits of Limit Equilibrium and Finite Element Techniques Applied to Cracked Debris Dams on Collapsing Foundations.

APPROVED BY THE MEMBERS OF THE THESIS COMMITTEE:

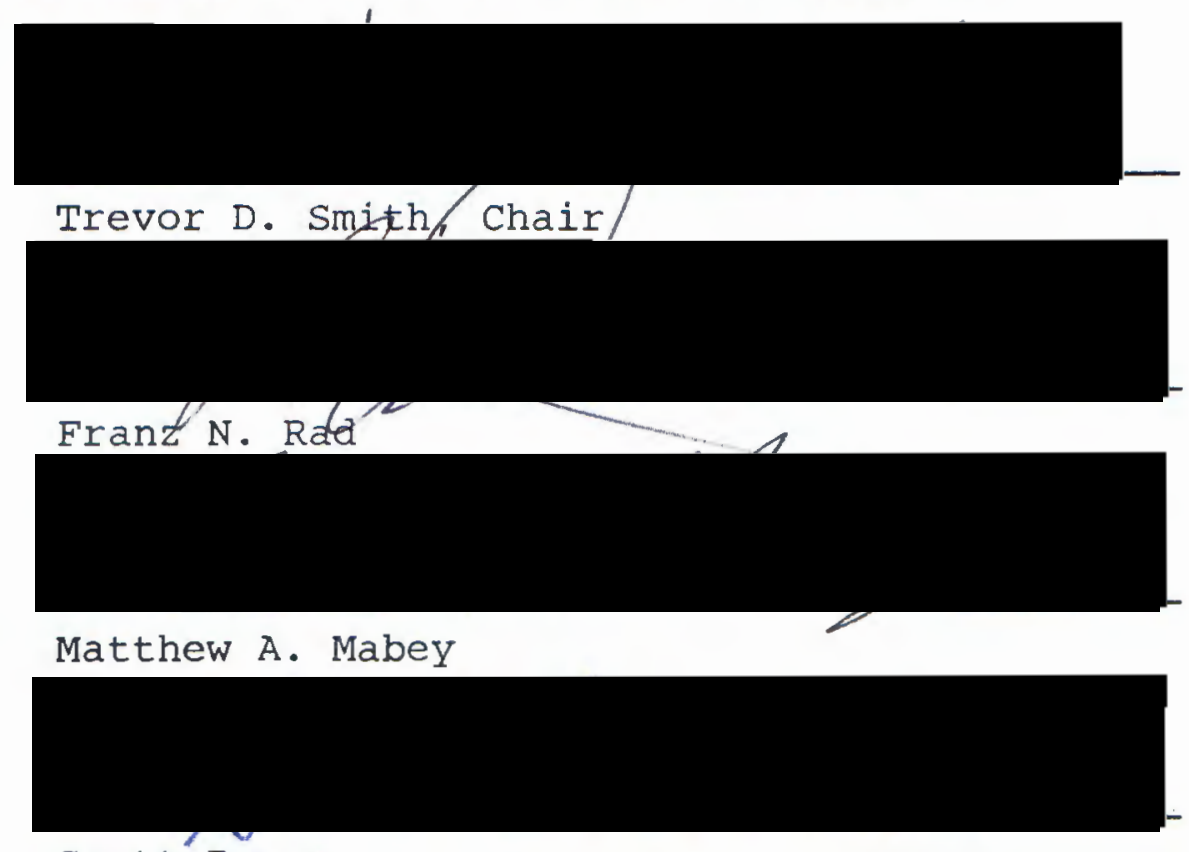

Scott Burns

Limits of slope stability, limit equilibrium methods, and of the finite element code FEADAM are reached in the application of these methods to the problem of cracked dams 
constructed on collapsing soils.

Utilizing a generic dam, various classic slope stability approaches are tested as possible dam slope failure mechanisms. Slope stability methods are rejected as a way to accurately define and quantify the collapse problem. As a result of this work a block rotation mode of collapse is postulated. Then the finite element method (FEM) is used to try to define and quantify the collapse problem. The FEM is applied to four dam sites. Of the sites, one site is collapse prone, three are not. The finite element code FEADAM (Finite Element Analysis of Dams) is used to make the computations.

Results show a possible series of blocks rotating as a saturated front passes under a debris dam. This rotation is somewhat captured by FEADAM. The motion and associated stressed are very complex however, and more work is needed to further map the dynamics of collapse. FEADAM is limited for further research due to limitations of the hyperbolic model and mesh size and shape restrictions.

After analysis of 500 plus runs, it is found that FEADAM is limited to displacement predictions of about $10 \%$ of actual field displacements in most collapse cases. FEADAM does however show a sigma-3 (tension) increase in most collapse cases, indicating a weaker soil state. 


\section{LIMITS OF LIMIT EQUILIBRIUM AND FINITE ELEMENT TECHNIQUES APPLIED TO CRACKED DEBRIS DAMS ON COLLAPSING FOUNDATIONS}

by

STANLEY SOLIDAY JR.

A thesis submitted in partial fulfillment of the requirements for the degree of

MASTER OF SCIENCE

in

CIVIL ENGINEERING

Portland State University

1992 
TO THE OFFICE OF GRADUATE STUDIES:

The members of the committee approve the thesis of Stanley Soliday Jr. presented December 16, 1991.

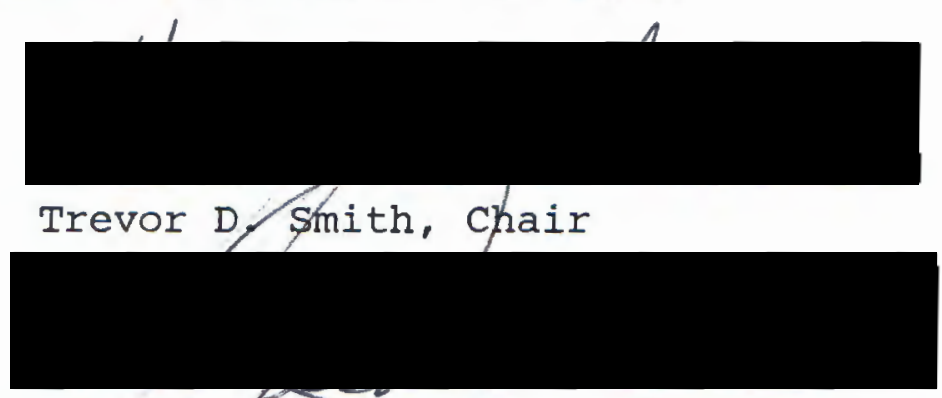

Franz N. Rad

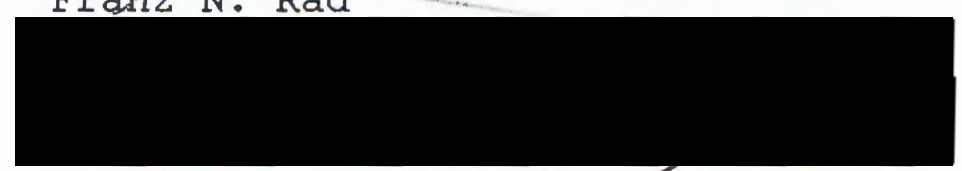

Matthew, A. Mabey

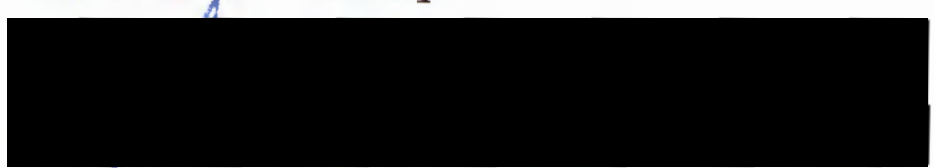

Scott Burns

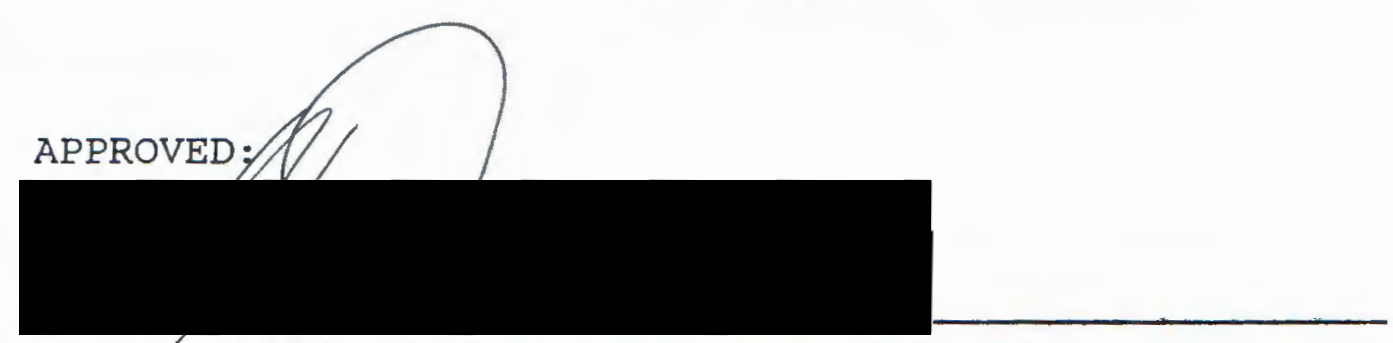

Franz N. Rad, Chair, Department of Civil Engineering

C. William Savery, Interim Vice flovost For Graduate Studies and Research 


\section{DEDICATION}

Here's to the debris dams, large and small

Here's to the rain, wherever it may fall

Here's to the planet, a part of it we are all 


\section{ACKNOWLEDGEMENTS}

Thanks to the USDA Soil Conservation Service, Portland District, for generous sponsorship of this research. Thanks to SCS staff Cliff Deal, Ed Stearns, and Aubrey Sanders for generous amounts of data and discussion.

Thanks to Dr. Trevor D. Smith who has been especially helpful in every aspect of this project, and the author's present education. Bob Slyh has helped with engineering and mathematical concepts, blending with collapse mechanism theories. Thanks to project members Robert Jacobson, Kelly Uhacz, Martha Denham, Elaine Williams, and Tab and Fahim for their help with everything from ABAQUS to the coffee maker.

Thanks to John Harris of the CAD lab for hardware and software aid. Thanks to Dr. Rad for helping to open some doors, and Dr. Gorji for an open door to questions with uncertain answers. Thanks Tom for the use of your thesis.

The author is grateful to geology professors A. Johnson, H.Mills, P. Hammond, J. Graham, L. Palmer, and M.Beeson, for sound geologic and computer principles.

A special thanks to Al, Darlene, Aubrey, Myrtle, 
Barry, the Brown's, Belka's, Krueger's, Ashby's, and others of the community. Thanks to Aikido teachers and friends.

Finally, but foremost, thanks to my wife Johanna, kids Mo and Annie, and F.B for patience with a would-be basement scientist during the last 3 years. Thanks Jo for help with word processing, phones, photos, rides, assorted details, and unconditional love and support. 
TABLE OF CONTENTS

PAGE

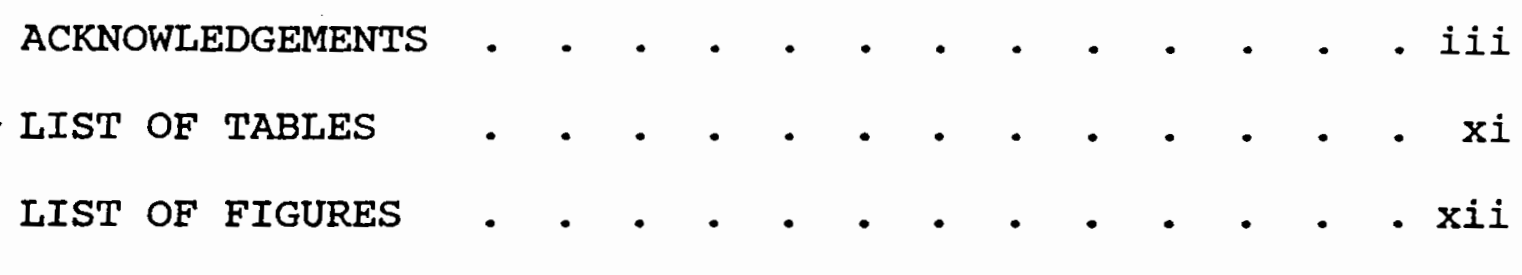

CHAPTER

I INTRODUCTION • • • • • • • • • • • • • • •

Occurrence and Problems with Collapsing Soils . 1

Collapsible soils

Debris Fan Dams

Geologic Setting

Stability Concerns for Cracked Dams • • . 5

The Present State of

Stability Investigation

Research Objective

II SLOPE STABILITY TECHNIQUES FOR

DEBRIS DAM CRACKING • • • • • • • • • 9

Slope Stability Techniques • • • • •

The Generic Dam

Embankment Geometry

Limit Equilibrium Techniques • • • . • . 15

Translational Techniques

Circular Techniques

Limitations of Limit

Equilibrium Techniques

Other Failure Mechanisms . . • . • • • . 27

The Drop Block Mechanism

The Drop Block With Rotation Mechanism 
III APPLICATION OF EINITE ELEMENT METHOD • • • • • 35

Einite Element Modeling • • • • . . . 35

The Hyperbolic Model

The FEADAM Program

Theoretical Problems

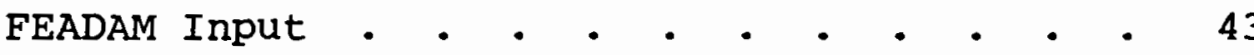

Hyperbolic Parameters

Pressuremeter Data

IV FEADAM TECHNIQUES USED / BASIN CONSIDERATIONS • 46

EEADAM Meshes for Debris Dams. . . . . . 46

The Generic Mesh

Transverse and Longitudinal Meshes

Modeling a Sequence of Events . . . . . 52

Dam Construction

Foundation Collapse

Dam Cracking

V FEADAM MODELING OF THE WHITE TANKS DAM \#3 • • • 57

Dam Structure and Local Geology . • . . 57

White Tanks structure

Local Geology

Transverse Sections • . . . . . . . . 60

FEADAM Input, Model WT9

FEADAM Output, Model WT9

Interpretation

Longitudinal Models, No Soft Zone - . . . 65

FEADAM Input, Model WL14

FEADAM Output, Model WL14

Interpretation 
Longitudinal Models With a Soft zone . . . 66

FEADAM Input, Model WL15

FEADAM Output, Model WL15

Interpretation

Stability Summary • • • • • • • • • 68

Dam Safety

VI FEADAM MODELING OF THE FREDONIA DEBRIS DAM • • • 69

Dam Structure and Local Geology . . . . . 69

The Fredonia structure

Local Geology

Inducing Collapse in the Fredonia Dam . . . 70

Mechanisms Used to Displace Nodes

Hyperbolic Parameters

Transverse Sections, Dry State . . . . . 72

FEADAM Input, Model F79

FEADAM Output, Model F79

Interpretation

Tranverse Sections, Saturated State . . - 80

FEADAM Input, Model F93

FEADAM Output, Model F93

Interpretation

Saturated State with a Load . . . . . . 85

Modeling Mechanisms

FEADAM Input, ModeI F66

FEADAM output, Model F66

Interpretation

FEADAM Input, Model F70

FEADAM Output, Model F70

Interpretation 
Longitudinal Sections • • • • • • • • 98 Longitudinal Meshes

Longitudinal Sections, Dry state . . .

FEADAM Input, Model FL5

FEADAM Output, Model FL5

Interpretation

Longitudinal Sections, Saturated state . . 100

FEADAM Input, Model FL6

FEADAM Output, Model FL6

Interpretation

Miscellaneous Mechanisms . . . . . . 103

Piping Experiment

Depth Experiment

Stability Summary

Dam Safety

VII FEADAM MODELING OF THE GREENS LAKES DAM \#3 • • 115

Dam Structure and Local Geology . . . . 115

Greens Lake Structure

Local Geology

Collapse History

Transverse Sections, Dry State • • . • 118

FEADAM Input, Model GL2

FEADAM Output, Model GL2

Interpretation

Transverse Sections, Saturated State • . . 123

FEADAM Input, Model GL11

FEADAM Output, Model GL11

Interpretation 
Saturated State Halfway Under the Dam . . 127

FEADAM Input, Model GL18

FEADAM Output, Model GL18

Interpretation

Longitudinal Sections . . . . . • . . 128

FEADAM Input, Mode1 GLO6

FEADAM Output, Model GLO6

Interpretation

Stability Summary • • • • • • • • •

Dam Safety

VIII FEADAM MODELING OF THE SOUTH

Dam Structure And Local Geology . . . . 131

Dam Structure

Local Geology
Transverse Sections, Dry Case
FEADAM Input, Model ST1
FEADAM Output, Model ST1
Interpretation

Transverse Case, Saturated State - . - .

FEADAM Input, Model ST2

FEADAM Output, Model ST2

Interpretation

Stability Summary

Dam Safety 
PAGE

IX CONCLUSIONS AND RECOMMENDATIONS • • • • • • • • 144

Stability Conclusions • . . • . . . . 144

Slope stability Summary

FEADAM Summary

FEADAM Accuracy

REFERENCES .

APPENDICES

A REPAIR POSSIBILITIES • • • • • • • • 157

B MINI-DAMS • • • • • • • • • • • • 168 


\section{IIST OF TABLES}

TABLE

PAGE

I White Tanks Model Figure Summary . . . . 61

II White Tanks Hyperbolic Parameters . . . . 62

II Fredonia Model Figure Summary . • • . • 75

IV Fredonia Hyperbolic Parameters . • • • . 76

V Greens Lake Model Figure Summary • • • • . 119

VI Greens Lake Hyperbolic Parameters . • • 120

VII South Straight Hollow Model Figure Summary • 135

VIII South Straight Hollow Hyperbolic Parameters • 136

IX Model Displacement Sigma-3 Summary . • • 152

$\mathrm{X}$ Mini-Dams Moisture Parameters • . . . . . 168 


\section{IIST OF FIGURES}

FIGURE

PAGE

1. Generic Dam . . . . . . • - . • . 11

2. Longitudinal Cracks in Sand H Debris Dam . . 14

3. Infinite Slope Mechanism - • • . . . . 17

4. Sliding Block Mechanism • . . . . . . 19

5. Sliding Block With Slope Mechanism. . . . 22

6. Circular Failure Mechanism . . . . . . 24

7. Basin Sinkhole . . . . . . . . . . 28

8. Drop Block Mechanism • . . . . . . 29

9. Drop Block with Rotation Mechanism. • . . 31

10. Incremental Rotation Mechanism . . . . . 33

11. Crack Map, Downstream Fredonia Dam. • . . 34

12. Hyperbolic Stress-Strain Curves. . . . . 37

13. Pressuremeter Material Property Curves • . 45

14. Geologic Cross Section, Fredonia Debris Basin 47

15. Generalized Debris Basin Cross Section . . . 51

16. Site Location Map . . . . . . . . 56

17. Cross Section, White Tanks Dam . . . . . 59

18. WT9 Displacement Contours . . . . . . 63 
xiii

FIGURE

PAGE

19. WT9 Stress Contours • • • • • • • • 64

20. WL15 Displacement Contours . . • • • . 67

21. Dry Modulus Change with depth . . . . . . 73

22. Wet Modulus Change with depth . . . . . . 74

23. F79 Displacement Contours • • • • • 78

24. F79 Stress Contours • • • • • . . . 79

25. F93 Displacement Contours • • • • • 82

26. F93 Stress Contours • • • • • • • . . 83

27. Collapse Model Mechanisims - • • • . - 86

28. Fredonia Site Map . • • • • • • • • • 89

29. F66 Displacement Contours • • • • • • • 91

30. F66 Stress Contours • • • • • • • • 92

31. F70 Displacement Contours • • • • • • • 94

32. F70 Stress Contours . . . . . . . . 95

33. FL6 Displacement Contours . • . • • • . 101

34. Solution Pipes at Fredonia . • . . . . 104

35. Piping Experiment Displacement Contours • 105

36. Piping Experiment Stress Contours . • • • 106

37. Rotation block . . . . . . . . . . 108

38. Depth Experiment Stress Contours • • • . 110

39. Greens Lake Site Map. • • • • • • • 116

40. GL2 Displacement Contours . . • • • • • 121

41. GL2 Stress Contours • • • • • • • • • $\quad 122$ 
42. GL11 Displacement Contours • • • • . • 125

43. GL11 Stress Contours • . • • • . . . 126

44. South Straight Hollow Site Map . . . . . 133

45. Subsurface Profile . . . . . . . . . 134

46. ST1 stress Contours • . . . . . . . 138

47. ST2 Displacement Contours . . . . . . 140

48. ST2 Stress Contours . . . . . . . . 142

49. Infiltration Enhancers - . . . - . . . 160

50. Poly Liner . . . . . . . • • . • . 162 


\section{CHAPTER I}

\section{INTRODUCTION}

\section{OCCURRENCE AND PROBLEMS WITH COLLAPSING SOILS}

\section{Collapsible Soils}

The term, collapsible soils, as used here means soils that tend to undergo a significant volume loss upon wetting. Earth dams built on collapsible soils may crack badly when collapse occurs due to the absence of tensile strength.

Collapsible soils occur worldwide and in two main categories in the continental united states. In midwestern states there may be a cover of loess, a silty, homogeneous, nonstratified, unindurated deposit of windblown, glacialremnant material. In the arid western states, alluvial deposition of a wide range of particle sizes takes place after a sudden upland rainfall. After drying out, the resultant soil tends to be of a loose structure held together by various salt ions, depending on their source. Once this resultant soil is re-saturated, the ions dissolve, and the soil compacts to a new, lower volume. Rollins (1990, 1991) gives an excellent discussion of collapsible soils in the area of this thesis. This collapse takes place in the debris basin material for the most part. The problem comes when structures such as debris retention dams are 
built on collapsible basin soils. Since collapsible soils may actually collapse of their own weight (Rollins, 1991) the added stress from a dam only increases foundation soil collapse, which also causes the dam to crack. Most earth dams crack to some extent (Talbot, and Ralston, 1981). Debris dam Cracks pose several problems. There is the problem of the debris retention capability of cracked dams, since most of the dams are built to protect cultural features from debris flows. There is also the problem of transverse dam cracking. Longitudinal cracks may be readily apparent in the dams, but the degree of transverse cracking is unknown. Transverse cracks may provide conduits for piping, and subsequent failure.

The dams within themselves are not classified as collapsible except in a few cases where the compacted material in the cutoff trench may show a lowered modulus of elasticity similar to the lowered modulus in basin collapsed material.

Debris dams may crack when an impoundment of several feet or greater accumulates behind the structures. This accumulation may result from summer convective storm induced flash floods. These floods may cause rapid debris accumulation upon alluvial fan areas, which in turn may accumulate to a depth of several feet or more behind the dams. When this happens metastable soils collapse and at 
some point longitudinal cracks on the order of a few inches to a foot wide and hundreds of feet long open up along the dam slopes from the dam toe to about two thirds upslope towards the crest. Cracks do not seem to form much above this height and are thought to form upslope instantly: with soil collapse. Then, downslope cracks are thought to occur as the impoundment behind the dam drains through and under the dam over a period of time. It is not known whether or not transverse cracking is taking place concurrently with longitudinal cracking.

Full impoundment behind dams most certainly causes more damage than the shallow impoundment described above. However, the distinction between partial and full impoundment effects is not well documented except in a few cases, where the full impoundment seems to simply aggravate the amount and magnitude of cracks. The effect of piping due to a full impoundment is probably much greater than the case of a shallow impoundment. This idea is based on the observation of pipes and tunnels present around spillway conduits, on the dam slopes, and in the upstream basin. These pipes appear to be solution features. Similar features are well documented in Southwestern areas as solution induced cavities (Yair and York, 1984; Werle and Stilley, 1991). 
The core of the dams is not classified as collapsible except in a few cases where the compacted material in the cutoff trench may show a lowered modulus of elasticity similar to the lowered modulus in basin collapsed material.

\section{Debris Fan Dams}

Over the past 30 years, the United States Department of Agriculture, Soil Conservation Service (SCS), has constructed or accepted management of as many as 50 earthen dams built on (and of) collapsible soils. These debris dams range from 20 to 30 feet high and from one-quarter to five miles long. Many of these dams have experienced some degree of cracking and settlement after impoundments of several feet or more of debris-fan slurry. Most also show the effects of more minor desiccation cracking in areas where diurnal temperatures may reach 120 degrees Fahrenheit. A detailed crack study at the Sand $\mathrm{H}$, Utah, debris dam shows sinkholes and longitudinal cracks forming as a result of irrigating a football practice field adjacent to the downstream toe of the dam (Smith, Deal, 1988). Crack studies at the Fredonia and Greens Lake dams indicate sinkholes and cracks forming as a result of storm-induced impoundments from several feet or less. 


\section{Geologic setting}

The debris dams analyzed in this thesis are located on the medial to distal portions of alluvial fans. Therefore, the predominant geologic setting is an alluvial environment. For the purposes of this thesis, an alluvial fan is described as a cone-shaped deposit of alluvium made by a stream where it runs out onto a level plain or meets a slower stream. The fans generally form where streams issue from mountains upon the lowland. Most fans are of a low gradient, 1 to 3 degrees. The depth (surface to bedrock) is generally from 30 to 50 feet. Material from cobble to clay-sized particles make up interbedded flows which fill the above basins. Depth of groundwater may vary from -25 to -40 feet. The width of alluvial basins varies from a few thousand feet to several miles or more.

\section{STABILITY CONCERNS FOR CRACKED DAMS}

\section{The Present State of Stability Investigation}

The collapse problem has been studied by SCS workers and independent researchers. SCS workers have done field observation, trenching, drilling, and mapping. Independent researchers have studied the collapse problem from the field and laboratory, with examples in the geotechnical literature. Beckwith and Hansen (1990) describe a collapsing alluvial soil showing its alluvial structure. 
More recent articles (Houston and Spadola, 1988; Houston and El-Ehwany, 1990) cover moisture front movement and settlement in collapsible soils. Rollins $(1990,1991)$ has described collapse testing of Nephi, Utah, silts. This study utilizes pressuremeter data and finite element constitutive modeling to study the collapse problem:

Various limit equilibrium techniques are employed with various standard slope stability techniques, including translational and slip circle methods. These techniques attempt to relate a factor of safety to a particular mechanism. The mechanisms are fit to the dam slopes, with no modification in the various relations to account for 1) the collapse problem, and 2) the crack geometry. As an example of 2), survey data often (although not always) indicate little or no subsidence of dam crests and slopes.

Each technique has its associated problems and limits. For example, survey data often indicate little or no vertical subsidence of dam crests and slopes. In this case, a volume loss and subsequent vertical strain calculation does not work. When there is vertical strain measurable in the basin, the case is simply vertical strain to collapse. This type of strain is commonly one to two feet, creating basin sinkholes. The real problem, however, is to relate this vertical strain to magnitude and direction of: 1) foundation collapse beneath the dam, and 2) subsequent dam 
cracking and offset. Slope stability techniques are not able to properly qualify, or quantify, 1) or 2) above. Foundation soils possess little tensile strength when dry, and much less when saturated. Most classical soil mechanics approaches do not take this into account.

\section{Research Objective}

The object of this research is to explore cracked dams on collapsing soils with presently available techniques. The exploration will be achieved using various slope stability and finite element techniques. Techniques that do an adequate job of representing the collapse phenomenon will be outlined and their validity discussed.

Problems with the finite element methods (FEM) include quality of data input, and quantitative correctness of output. Input to any FEM code is an average of extremely heterogeneous basin conditions as a result of chaotic alluvial deposition. For example, the stiffness parameter $k$ used in the generalized FEM matrix form of Hooke's Law is actually only measured at a few discrete field locations. These measurements are then used to represent basin sections hundreds of feet long. While this value of $\mathrm{K}$ works well to study the marked difference between wet and dry conditions, it does not tell where those conditions are likely to occur in a basin or dam. The approach also uses an average wet-dry condition, The problem now is that impoundments may 
actually form where a particular event channelizes flow to a present topographic low. It is this location that will collapse if collapsible soils are present. The models presented in this thesis are made along lines of reported past collapse damage.

The output from such models should therefore be used with the above facts in mind. The models in this thesis may be used to establish relative differences in dry-wet conditions, patterns of dam stresses, and to some extent, the magnitude of post-collapse dam stresses. The models in this thesis may not be used to exactly reproduce field conditions. This is illustrated by the fact that of over 400 various model runs made, in no case are field cracking conditions duplicated to within a foot or so of actual observed post collapse cracks, using input parameters measured or estimated. Models in this thesis are only able to achieve field crack conditions by lowering input parameters to extremely unrealistic values, and introducing theoretical collapse mechanisms. 
CHAPTER II

SLOPE STABILITY TECHNIQUES FOR DEBRIS DAM CRACKING

SLOPE STABILITY TECHNIQUES

\section{The Generic Dam}

Traditional slope stability techniques seek to identify a mechanism to define a failure plane and quantify a factor of safety along that plane. This factor of safety is a number giving the ratio of average shear strength divided by necessary shear stress for equilibrium. So, it is an indication of how close a particular slope is to moving downhill along a particular plane at some uncertain time when developed shear stress overcomes resisting shear strength. In the case of debris dams there are two slopes along which to consider a factor of safety, upstream and downstream slopes. These slopes range from $2: 1$ to $3: 1$. Debris basins are generally dry, except after storm runoff collects behind the dams.

For the purpose of discussion, a generic dam will be introduced. This dam will be 24 feet from ground surface to crest top. Upstream slope angle will be $3: 1$ in order to represent a worst case scenario, with downstream slopes at $2: 1$. A 10-foot cutoff trench will be used, centered under 
the dam. Of those dams with a cutoff trench, this again is a worst case scenario, since a compacted trench would have higher cohesion values, thus reducing the chance of failure along a defined slide plane. In the worst case an impoundment of 15 feet or more might accumulate behind the dam. An impoundment of this magnitude may occur once in 50 to 100 years.

Thus slope stability calculations based on a total saturated slope state represent a rare, perhaps 100 year or so, event. An event of smaller magnitude would represent a smaller rainfall event more likely to happen. Thus, two cases exist. One case is a totally saturated state from seepage of a large impoundment through the dam. The other case is a shallow impoundment of a few feet or less. In the second case the foundation soils may become saturated or partially saturated to an undetermined depth. Then the foundation soils collapse. In this case the foundation remains dry.

In order to calculate a factor of safety for the two cases above, a generic dam is used (Figure 1) since many debris dams in this study have similar designs and materials. This dam is 24 feet from the ground surface to crest top. The upstream slope angle is $2: 1$ to represent the steepest slope possible. A 10 foot deep cutoff trench is used. The trench is centered under the dam. Typical values 


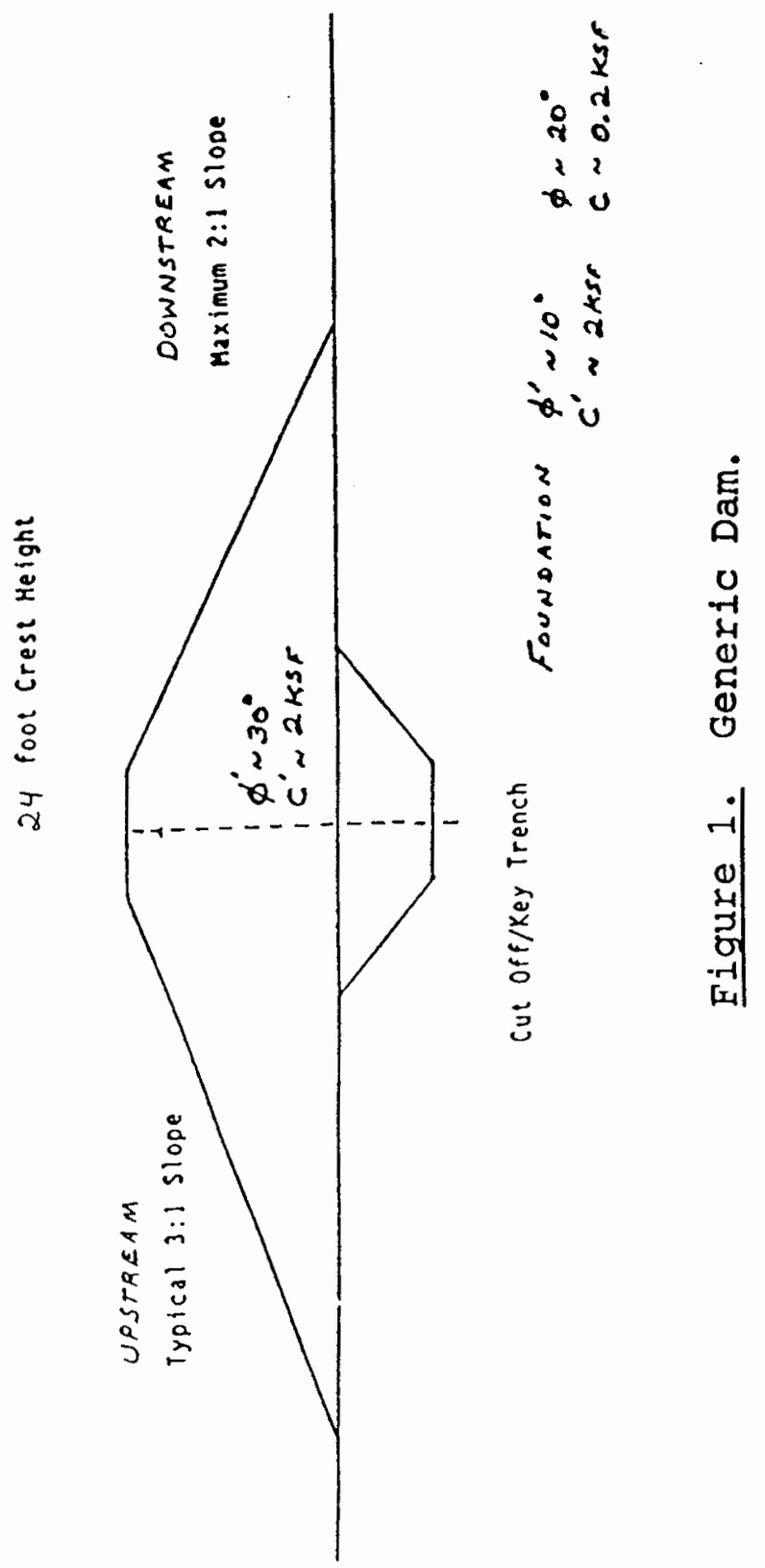


of cohesion are $2.0 \mathrm{ksf}$ basin material dry, $2.0 \mathrm{ksf}$ dam material dry, $0.2 \mathrm{ksf}$ basin material saturated, and $1.5 \mathrm{ksf}$ dam material saturated. Typical values for the internal angle of friction are 10 degrees basin material dry, 20 degrees basin material saturated, 30 degrees dam material dry, and 20 degrees dam material saturated. These values have been determined from pressuremeter test results. Pressuremeter modeling has shown saturated collapsible soils to have a lowest cohesion and friction angle of 0.2 ksf and 20 degrees, respectively. These parameters are achieved by iteratively matching field pressuremeter curves to theoretical curves until a best $f i t$ is achieved. At this point, a suitable cohesion and friction angle may be interpreted for use in slope stability relations. These values are representative of a range of values which may vary by plus or minus $30 \%$ (or more in a few cases).

Values of cohesion and phi angle outside the ranges given (lower) may be used to find the lower limit shear strength to push the factor of safety below 1.0. Note the drop in cohesion of basin materials by a factor of 10 . This is due to ionization of sulfate and carbonate salt bonds during saturation. This factor has the most dramatic effect on dam strength. This change in strength is accounted for by averaging values along a given failure plane in the generic dam. Calculations show that a similar factor of 
safety may be obtained within a range of slope angles of plus or minus 2.5 degrees of the 30-degree generic slope angle.

\section{Embankment Geometry}

Cracked debris dams in the SCS inventory have a variety of geometries. The dams range in length from several thousand feet to over several miles long. Side slopes range from $2: 1$ to $3: 1$. Common slope angles are $3: 1$ upstream and 2.5:1 downstream. Crest height is typically 20 to 30 feet. Cutoff trenches, when present, range from 5 to in excess of 15 feet deep. Dams cut across gently dipping $(1$ to 3 degree) alluvial canyons in most cases, so the structure may pinch out against canyon walls. Damage to these dams varies from barely visible cracking to eighteen inches or so of horizontal separation along longitudinal cracks as observed, for example at the Fredonia and Sand $H$ debris dams shown in Figure 2. Vertical offset is not normally as much as horizontal offset except in a few cases such as a depression on the upstream Fredonia slope, and reported crest subsidence at Greens Lake (Earth Science Associates, 1982). The exact extent of damage to the dams has not been measured in a comprehensive, precise fashion directly before, or after an impoundment. Offsets and crack patterns used here are based on anecdotal data taken from (albeit) excellent field observation some time later, after actual 


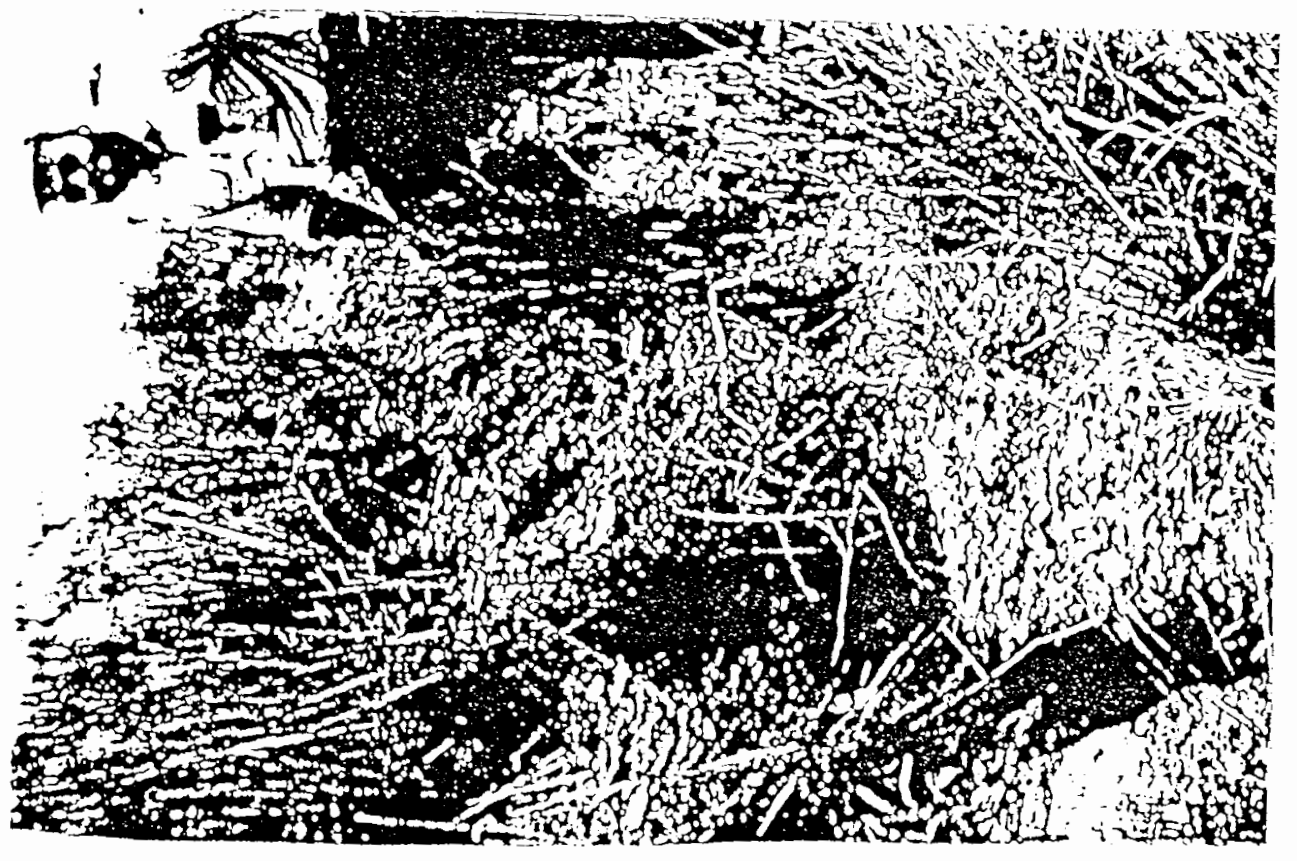

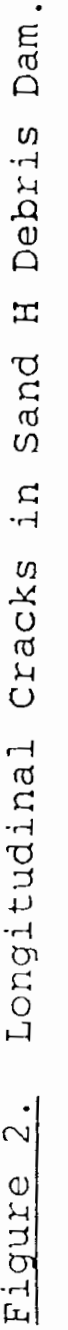

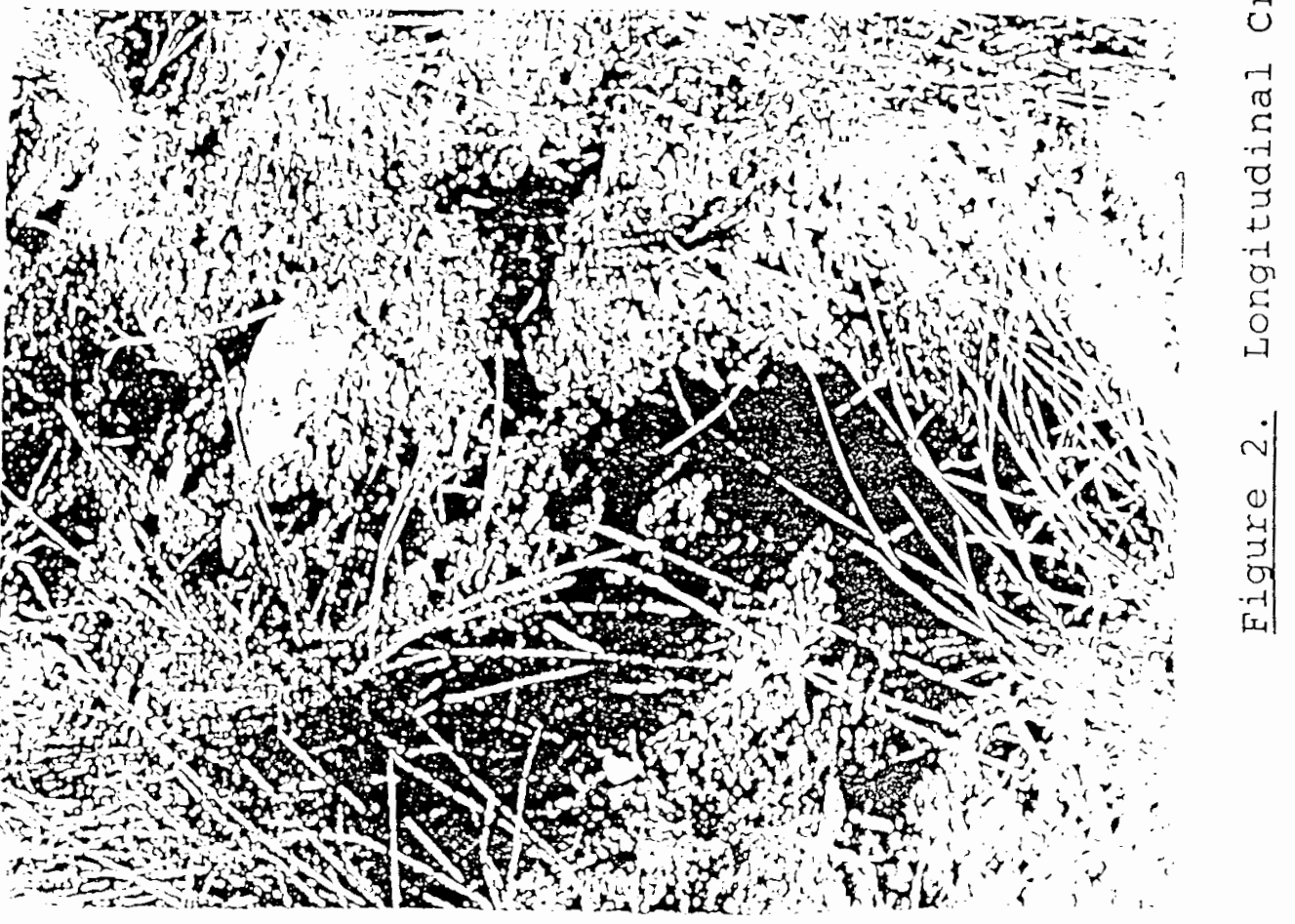


first damage. In this case, the generic dam will serve as a guide in understanding the principles of dam cracking from collapsing foundations.

\section{LIMIT EQUILIBRIUM TECHNIQUES}

Limit equilibrium techniques include many types of slope stability mechanism assumptions to achieve a factor of safety. Generally, the factor of safety along a given surface is defined as the ratio of shear strength to shear stress developed as a result of driving forces along a potential surface (Das, 1985). It had been postulated by SCS and PSU researchers that perhaps the factor of safety calculations could be employed for dam stability along block failure planes. To investigate this hypothesis, translational and circular failure plane techniques were used.

When a debris embankment cracks, the cracks tend to be vertical to slightly inclined from vertical. This makes choosing an appropriate failure plane difficult. In this case, attempts were made to fit the failure surface (cracks) to the method.

\section{Translational Techniques}

Translational techniques include infinite slope and two-wedge methods. The slope stability computer program, UTEXAS2 (Wright, 1987), was also used to generate a factor 
safety. UTEXAS2 has the ability to quickly check a variety of slide plane configurations using a variety of material input figures. For example, using the circular search routine, the program is able to find an optimum circular failure plane given input slope geometry and starting point. The infinite slope relation is the basic slope stability calculation given in equation (1), Ritter, 1978. Figure 3 shows the slide plane configuration.

$$
\begin{aligned}
\text { F.S. }= & -\frac{C}{\gamma h \sin \beta \cos \beta}\left(\frac{\left.m \gamma_{w}\right) \cos ^{2} \beta \operatorname{Tan} \phi h}{c}=\right.\text { soil cohesion } \\
\gamma & =\text { soil unit weight } \\
m & =\text { percent of unit saturated } \\
\gamma_{w} & =\text { unit weight of water } \\
h & =\text { thickness of unit } \\
\beta & =\text { slope angle } \\
\varnothing & =\text { soil friction angle }
\end{aligned}
$$

The first major problem in calculating a factor of safety using the infinite slope relation is lack of a welldefined failure plane. Since the maximum reported slope angle is $2: 1$, this would represent the worst stability case since the driving forces increase with increasing slope angle. The 2:1 angle as mentioned occurs only on the downstream sides however. In reality this slope probably never entirely saturates. However, for calculation a worst 


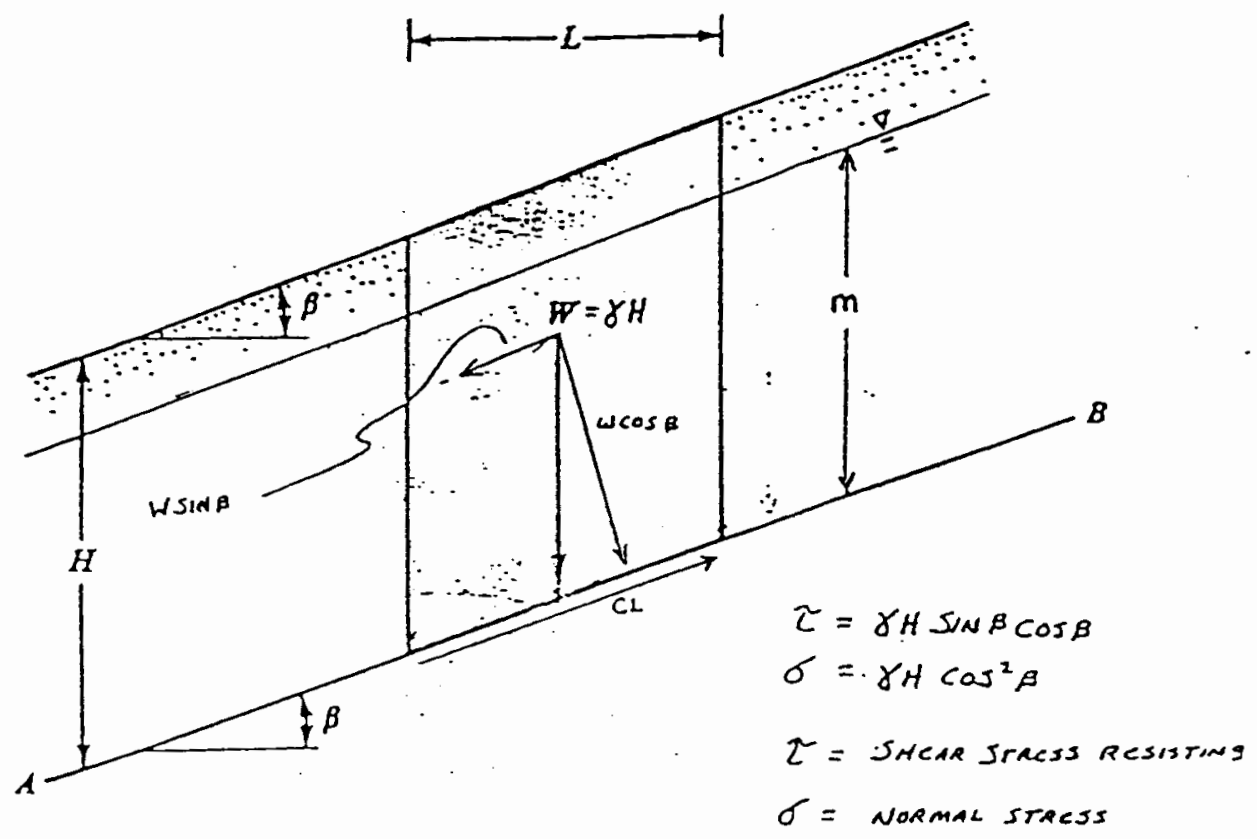

Figure 3. Infinite Slope Mechanism. 
case is assumed where the slope angle is 30 degrees, saturated material. A hypothetical failure surface is assumed to be 30 degrees for the infinite slope calculation. Thickness of the failure block is assumed to range from 4 to 10 feet. A crack is assumed to exist 10 vertical feet up on the slope, quite possible from field observations.

Limits of $\mathrm{C}$ and phi are given above. Unit weight dry ranges from approximately 85 to 95 pcf from lab reports (USDA, 1970). The factor of safety for a block of dam material moving downslope is over 2.0 for any case with thickness from 6 to 10 feet, and $C$ in excess of $0.75 \mathrm{ksf}$. Note that the average cohesion used in this relation is important. An average cohesion of $0.20 \mathrm{ksf}$ or less would allow the factor of safety to dip to below 1.0 for a 10 -foot thick block.

Two relations (Cheney and Chassie, 1982) are given below in equation (2). Equation (2) is a simple planar analysis in which sliding of a wedge of material is determined only by passive-active forces and cohesion along a horizontal slide plane, Figure 4.

$$
\text { F.S. }=\frac{\text { Horizontal Resisting Forces }}{\text { Horizontal Driving Forces }}=\frac{\mathrm{Pp}_{\mathrm{P}}+\mathrm{Cl}}{\mathrm{a}}
$$

$$
\begin{aligned}
& \text { Where } \mathrm{P}_{\mathrm{p}}=\text { passive force, toe of block } \\
& \qquad \begin{aligned}
\mathrm{C}_{\mathrm{L}} & =\text { cohesion along length of slide plane } \\
\mathrm{P}_{\mathrm{a}} & =\text { active force at head of slide block }
\end{aligned}
\end{aligned}
$$



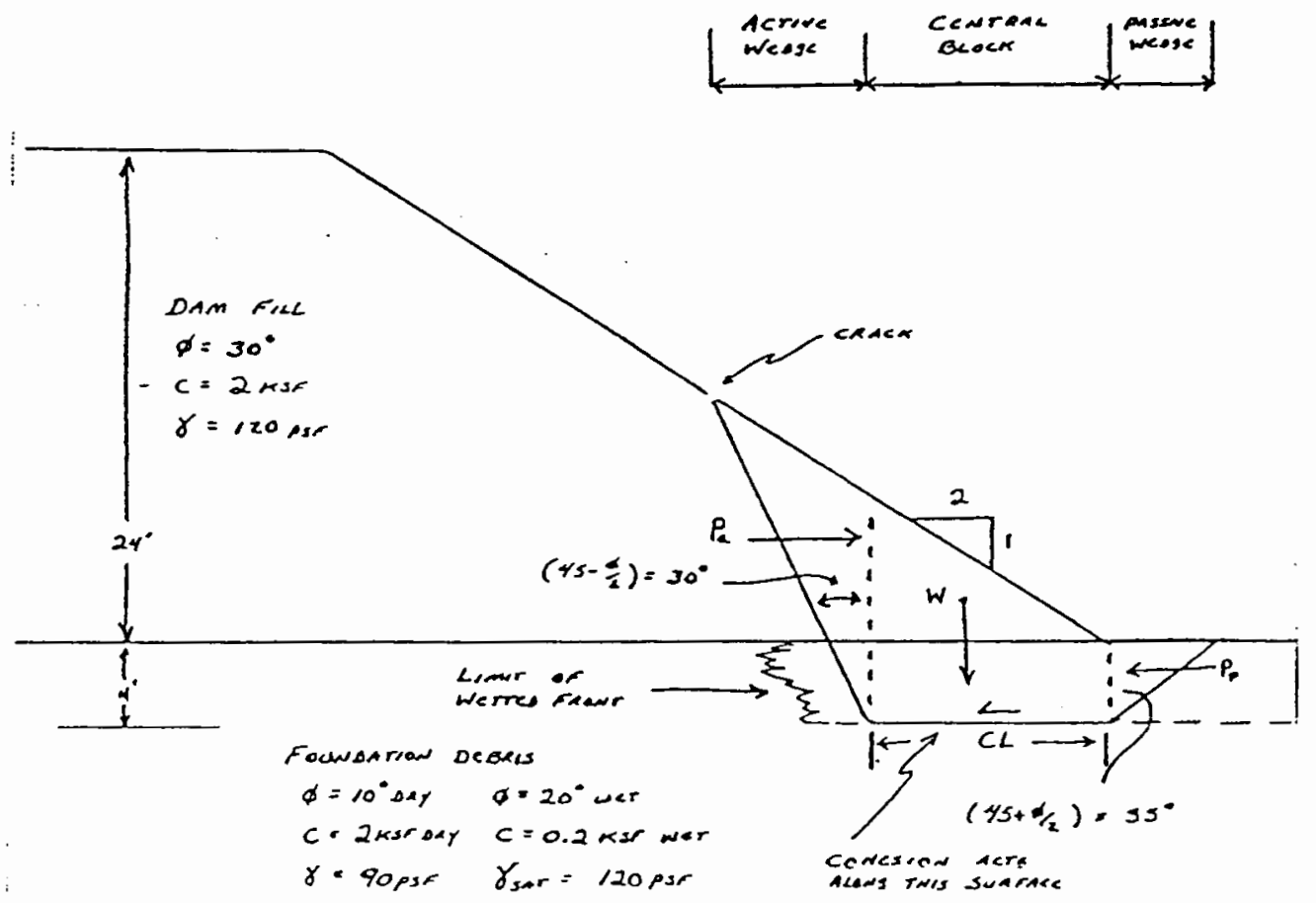

Figure 4. Sliding Block Mechanism. 
Using the geometry and properties in Figure 4, equation (2) gives an F.S. $=2.0$ or more for a sliding block analysis. This is using an average cohesion along a hypothetical 4-foot deep slide plane. Average cohesion in this case is $0.20 \mathrm{ksf}$ along the slide plane. A 12-foot crack height is assumed in order to place the slide plane. As with the infinite slope relation, a 12-foot above basin crack height is consistent with field observations.

When cohesion is reduced to zero, the factor of safety against sliding is reduced to 0.93 . A slight cohesion would make the factor of safety 1.0. As with the infinite slope relation, cohesion is an important variable. A value of cohesion of zero has been measured on a few samples of Fredonia, Arizona, and South Straight Hollow, Utah, material (USDA, 1966, 1970). An average cohesion value of zero along a 35-foot long failure surface 4 feet deep in the basin may or may not be possible. An average value of cohesion along any failure plane, including any part of the dam, of zero, is probably not possible. The above calculations rely on the fact that a crack 12 feet up on the dam slope to 4 feet deep in the basin is present as a failure plane forming at 30 degrees as defined on Figure 4. It may also be seen from this figure the arbitrary placement of a slide plane which may or may not be placed accurately. There is no way to determine correct slide plane piacement.

An extension of the sliding block analysis is the 
sliding block analysis on a slope shown on Figure 5. Similar to the infinite slope relation, the sliding block on a slope analysis also takes into account active and passive forces at the head and toe of the slide block, respectively. The resulting factor of safety is 1.6 saturated, and well over $2.0 \mathrm{dry}$. The saturated calculation may be low since $0.5 \mathrm{ksf}$ is used as a low end dam cohesion value. In the above analysis cohesion is important, as in the infinite and planar slide block mechanisms. The sliding block with a slope mechanism states that when cohesion of the dam drops below about $0.1 \mathrm{ksf}$, the factor of safety against sliding will drop below 1.0. This method also depends to a lesser extent on where the passive force triangle is placed. A larger passive force will increase the factor of safety. Both the active and passive components depend on where one places the failure surface. In the above case, the failure surface is arbitrarily placed parallel to the dam slope, 8 feet deep. This is not necessarily a true failure surface, but a hypothetical surface placed for the sake of calculation. The assumption is made that a surface crack 12 feet upslope descends 8 feet, then intersects a 30 degree sloping failure plane. The assumption is also made that a crack is filled with water. This serves well for calculation. However, in the field cracks may form at an elevation greater than halfway up the downstream slope, at a level above any phreatic surface that might be set up during 


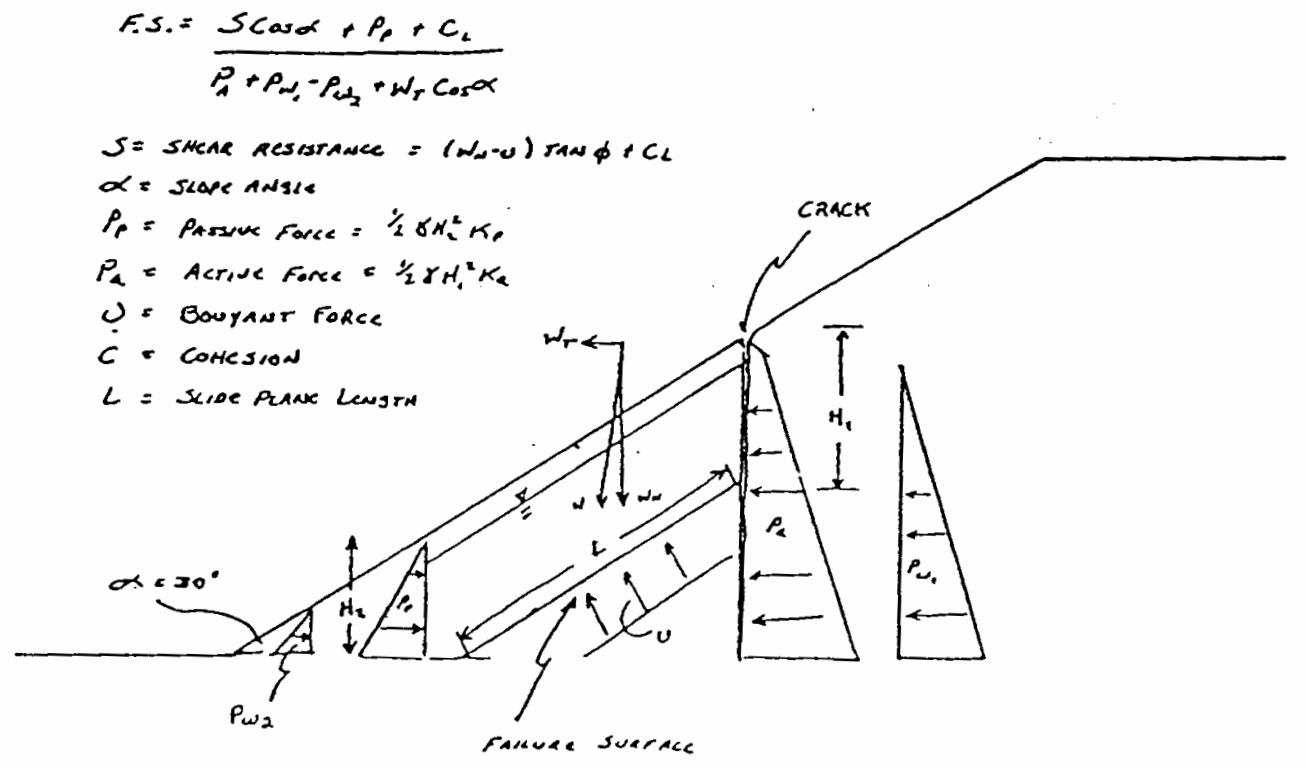

Figure 5. Sliding Block With Slope Mechanism. 
drawdown from a full impoundment. In actuality, a full impoundment may not be necessary to cause cracks (Sanders, 1981). Thus, the block and block analysis with a slope are probably not representative of the collapse mechanism at work in the case of cracked dams on collapsing soils.

\section{Circular Technigues}

Circular failure planes are approached using the method of slices and the UTEXAS2 circular search routine. Figure 6 shows one example of a circular failure plane. The governing equation used (Bishop, 1955) is given below.

$$
\text { F.S. }=\frac{\sum_{i=1}^{n}\left(C L i+w_{i \cos } \beta \tan \phi\right)}{n+\left(w_{\left.i \sin B_{i}\right)}\right)}
$$

Where $\quad \mathrm{C}=$ cohesion

$$
\begin{aligned}
L= & \text { length of slide plane per slice } i \\
W= & \text { weight of block } i \\
\beta= & \text { angle of tangent to slip circle per } \\
& \text { slice } i \\
\phi= & \text { internal angle of friction } \\
\mathrm{n}= & \text { number of slices }
\end{aligned}
$$

The calculated factor of safety is over 2.0 for the saturated case with cohesion at $0.5 \mathrm{ksf}$. When cohesion is reduced below $0.05 \mathrm{ksf}$, the resulting factor of safety drops 


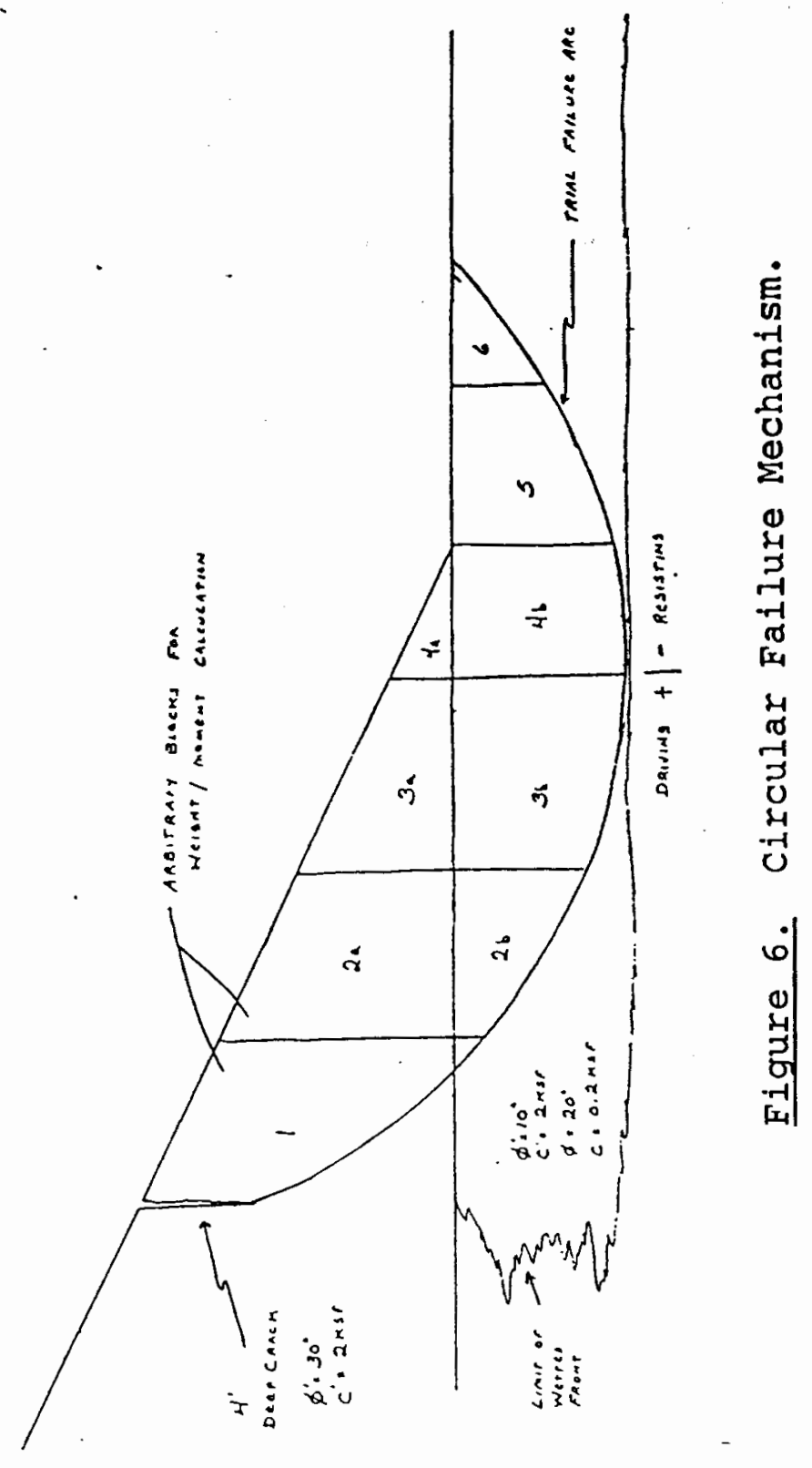


below 1.0 . This result is very similar to results using infinite slope and planar mechanisms. The importance of average cohesion values is repeated in the circular method. Since by definition a circular method must pass through the dam, and since dam cohesion will probably never reach the low value of $0.05 \mathrm{ksf}$, circular mechanisms are probably not valid to describe or quantify slope stability or cracking of debris dams. To check this result, over a hundred runs have been made on the slope stability program, UTEXAS2 (Wright, 1987) using planar and circular mechanisms, dry state, saturated state, with and without cracks. As with hand calculations, dam slope factors of safety remain well above 1.0 unless cohesion is reduced to a value approaching zero. Thus, it appears again that average cohesion value is important in dam factor of safety calculations as used in this thesis.

Other SCS researchers have had similar results trying to apply slope stability calculations. Slope stability calculations do not predict a factor of safety of less than one except under extreme, unlikely conditions such as cohesion equal to zero. Therefore, another mechanism other than a linear failure surface along which average conditions of stress and strength are calculated needs to be tried. 
Limitations of Limit Equilibrium Techniques

There are two main limitations to limit equilibrium methods for predicting slope failure to foundation collapse. By the first limitation, limit techniques assume a predefined slide plane. This is not possible with a collapsing foundation. Figure 4 shows that a wetted front has caused 1.0 feet of vertical collapse. At this point, the motion of the proposed slide plane is not horizontal, but vertical. There are no current relations or field measurements to quantify this motion.

The second limitation is of material properties. Upon some degree of critical saturation, basin foundation materials may undergo a dramatic loss of cohesion and an increase in internal angle of friction as the collapsible material consolidates. So, a simple assignment of the mohrcouloumb parameters to slide block material is not possible. It also is not clear exactly when a slide plane might push through the foundation, during or after collapse. No soil properties are available for a dynamic state during actual collapse.

Thus, it is important to capture the kinematics and material property changes associated with collapsing debris fan soils. Slope stability relations currently in use are not able to do this. In this case another collapse mechanism must be proposed to define collapse and cracking. Then another method, the finite element 
method, may be used to verify the method and to quantify collapse. In this case, we may look for another mechanism to define and quantify collapse and cracking. Here field observation and measurements may be used to hypothesize a mechanism that does not rely on one failure surface but is more linked to the vertical collapse of wetted soil. Then the finite element method may be used to induce collapse in the basin and dam foundation and to observe the effects on the dam.

\section{OTHER FAILURE MECHANISMS}

\section{The Drop Block Mechanism}

To develop a theoretical mechanism to quantify dam cracking several factors need to be considered. Collapse in the basin behind the embankment tends to be vertical as seen in Figure 7. This figure, other similar photographs, and anecdotal field observations support the idea of vertical collapse of basin soils. For theoretical purposes it is assumed that as a wetted front moves under a dam collapse is instant and vertical only. It is also assumed that the block of material above the collapsed zone moves vertically down with the collapsing foundation. This motion defines the drop block mechanism in Figure 8. However. field reports available do not show a large amount of vertical offset of dam slopes. Survey data from the scs has shown little settlement along dam crests, though there may 


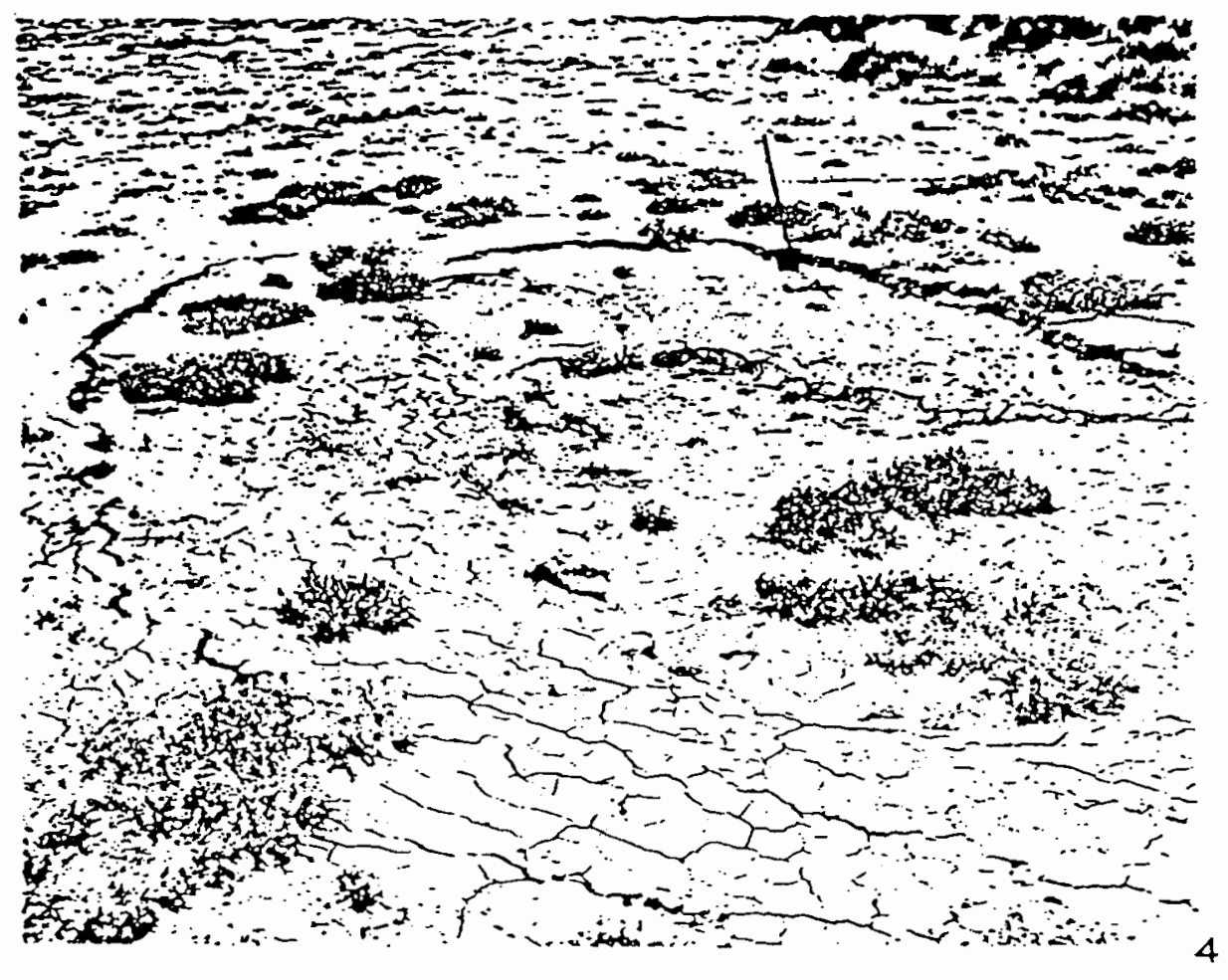

A portion sinkhole Iocated at station $15+30$ on centerline.

Figure 7. Basin Sinkhole. 


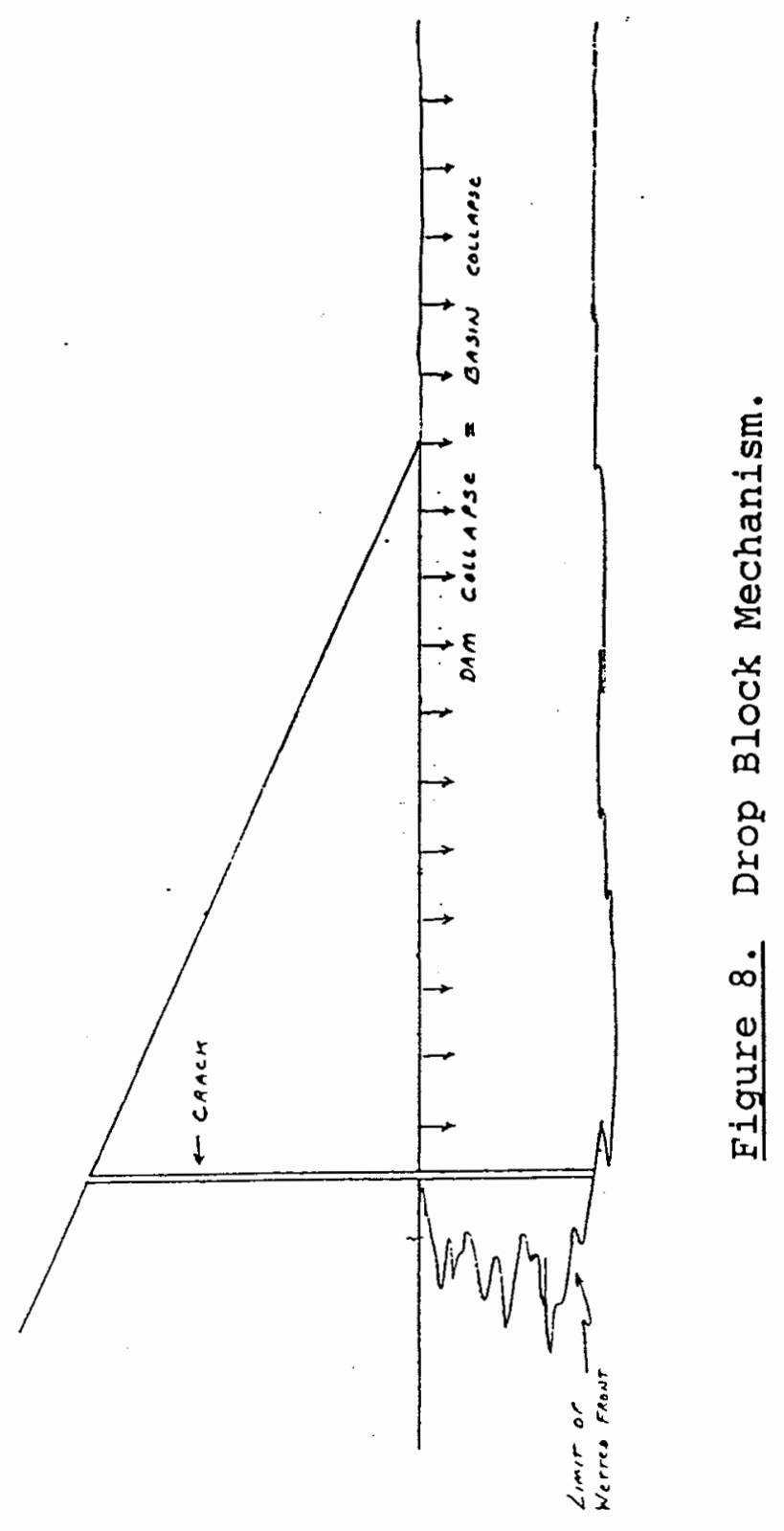


be an accuracy problem here due to missing and damaged survey monuments. Figure 6 shows that most of the longitudinal cracking is in the horizontal direction. This anomalous type of cracking has been observed by others (Turnbull and Hvorslev, 1967). Therefore, a mechanism including rotation is introduced.

\section{The Drop Block With Rotation Mechanism}

The proposed block with rotation mechanism is shown in Figure 9. In the most simple scenario, a wetting front would proceed under the dam, and collapse would then take place. Field observations show that the longitudinal cracks may commonly form at about 10 feet up the dam slope. In this case the moment to prevent block rotation would be on the order of $150 \mathrm{ksf}$. Since soil posesses very little tensile strength, rotation of a soil block above a collapsing foundation zone is postulated to occur. This block would move as shown in Figure 9 about a non-collapsed point. As the wetting front passed this point, another block would rotate at a limiting cohesion value and so on. In the field there is most probably a combination of block rotation with some vertical displacement as a wetted front passes by. Only limited rotation or drop block motion is necessary before support from the foundation is regained, as the wetted front passes by. Then the wetted front may move under the entire dam over an as yet 


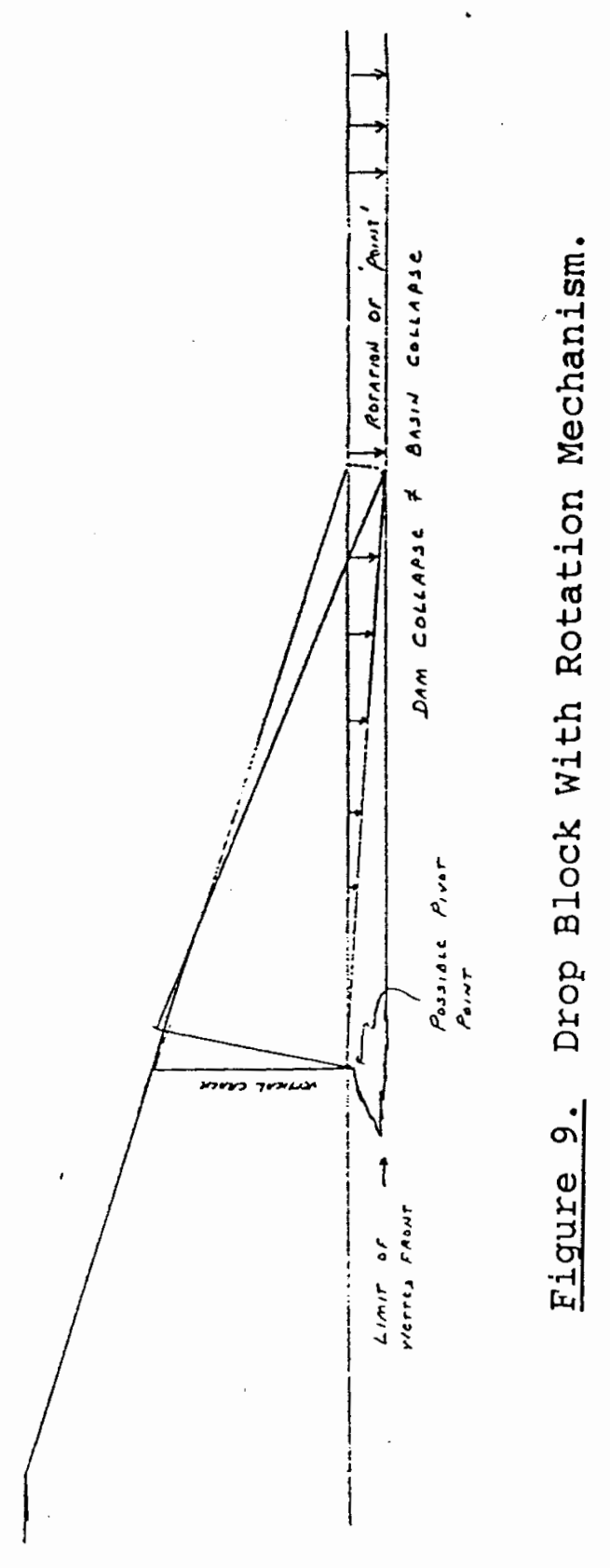


unspecified period of time, with cracks opening and closing as the front passes by, leaving cracked up-and downstream slopes. The validity of the above mechanisms is dependent on actual field measured deformations with time. Such measurements have not yet been made. Thus, the exact amount of vertical and horizontal offset is difficult to quantify at this time. However, enough post collapse cracks exist to model the process in a reconstructed sequence.

In this work, one slope is considered to represent the entire dam. Figure 10 shows the multiple crack possibility on one slope. The blocks in Figure 10 are drawn to fit the crack pattern developed from field mapping at Fredonia, Figure 11. Concurrent studies consider both upstream and downstream slopes in a finite element model. 


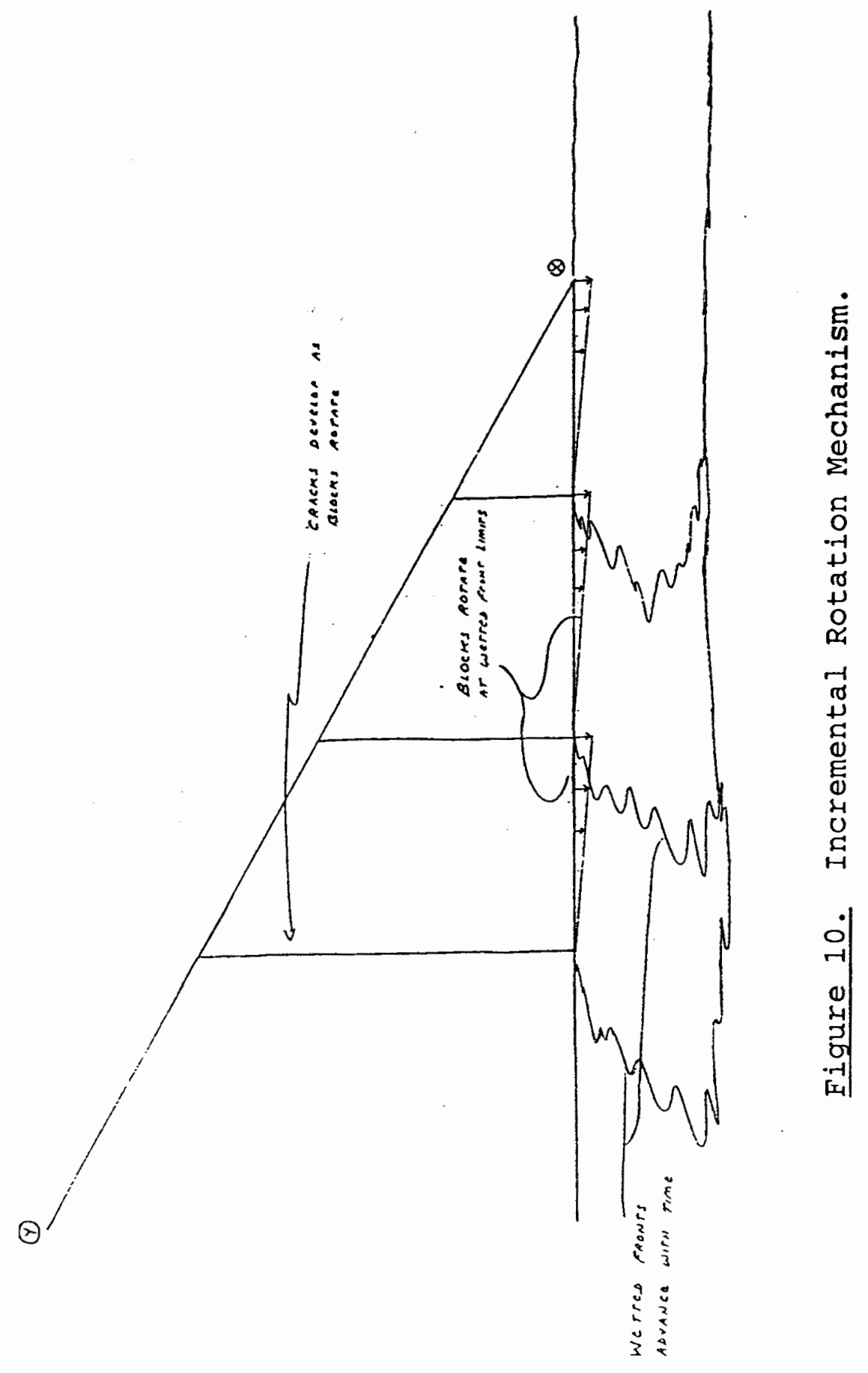




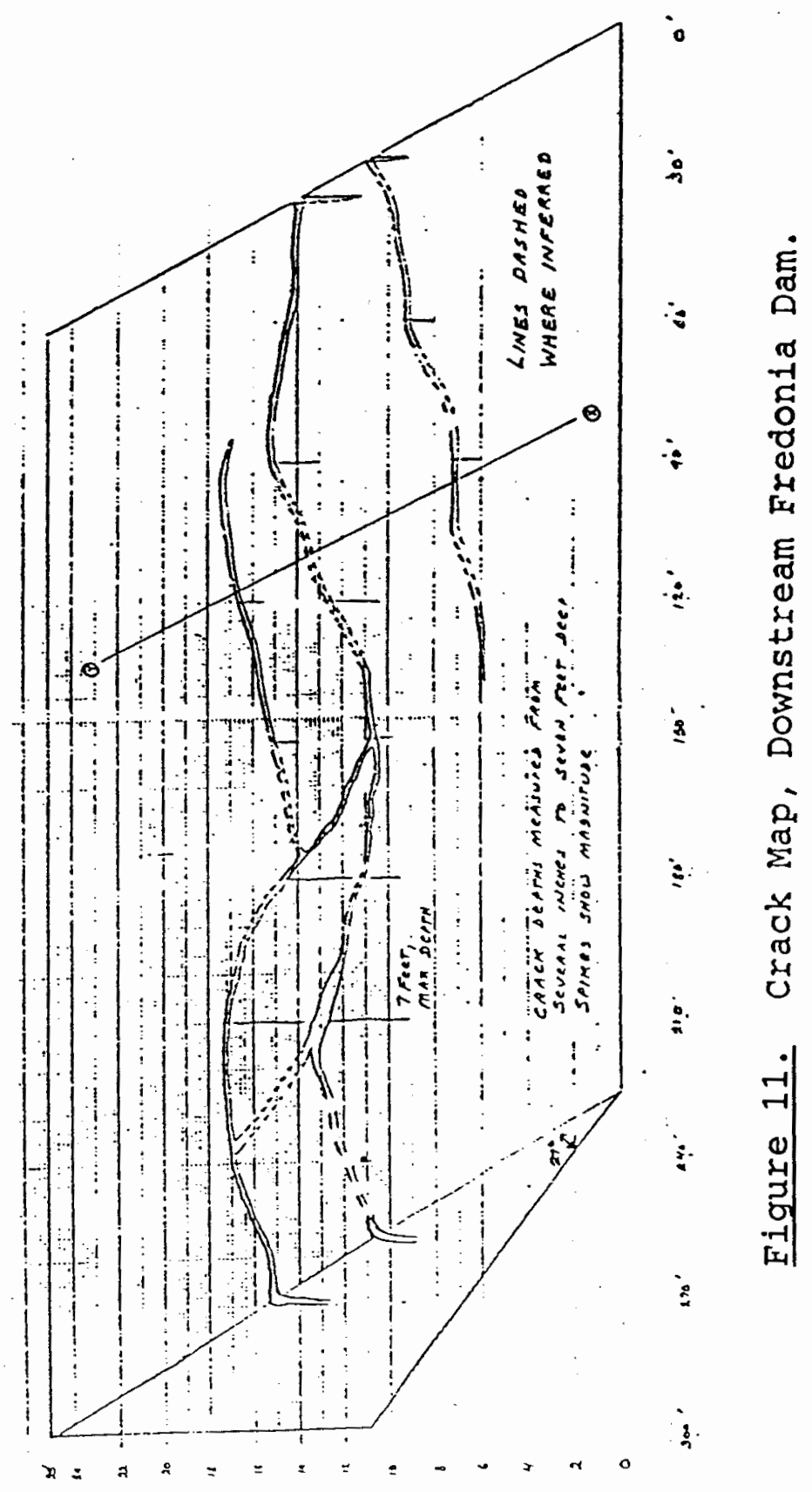


CHAPTER III

APPLICATION OF FINITE ELEMENT METHOD

FINITE ELEMENT MODELING

In developing a model of foundation and dam behavior, stress-strain relation of the collapsible material needs. to be taken into account. In general, soil strain does not respond to stress in a linear fashion. The problem is to adequately represent numerically how soil will deform under a given applied load. The problem for a collapsible soil is made more difficult since deformation is related to two variables, stress and saturation.

Finite element codes in formulation of element stiffness matrices require Young's modulus to be available from input variables. The basic relation used in this thesis is an incremental nonlinear form of Hooke's law that seeks to represent a soil stress-strain curve. Input variables are taken from field measurement of classic soil mechanics parameters including: cohesion, angle of internal friction, and unit weight. The elastic parameter, Young's modulus $K$, and Poisson's Ratio $v$ are also used.

One major problem in the case of collapsible soils is to relate the amount of stress to the amount of collapse, since collapsible soils may actually collapse vertically 
under their own weight when wetted. This phenomenon may be referred to in the literature as hydrocompaction.

Modified soil constitutive laws then have to relate an amount of collapse to saturation and load imposed by debris dams. Saturation is not numerically used in any present model. Saturation effects are simulated by lowering Young's modulus. Load may be measured. A hyperbolic model has been developed that uses soil constitutive parameters to produce a tangent modulus which, when incrementally applied, may approximate a hyperbolic, non-linear soil stress-strain curve (Duncan and Chang,1970).

\section{The Hyperbolic Model}

The hyperbolic model treats soil as a non-linear material. The basic assumption is made that soil shear strength and stiffness increases with confining pressure, represented by a hyperbolic stress strain curve, Figure 12. Experience has shown that the deviatoric stress-strain curves for many soils may well be approximated by such curves. The hyperbola may be represented by equation (5) below (Duncan and Chang, 1970).

$$
\begin{aligned}
\left(\sigma_{1}-\sigma_{3}\right) & =\frac{\varepsilon}{\frac{1}{E_{i}}+\frac{\varepsilon}{\left(\sigma_{1}-\sigma 3\right)}} \\
E_{i} & =\text { initial tangent modulus } \\
\sigma_{1} & =\text { major principal stress }
\end{aligned}
$$



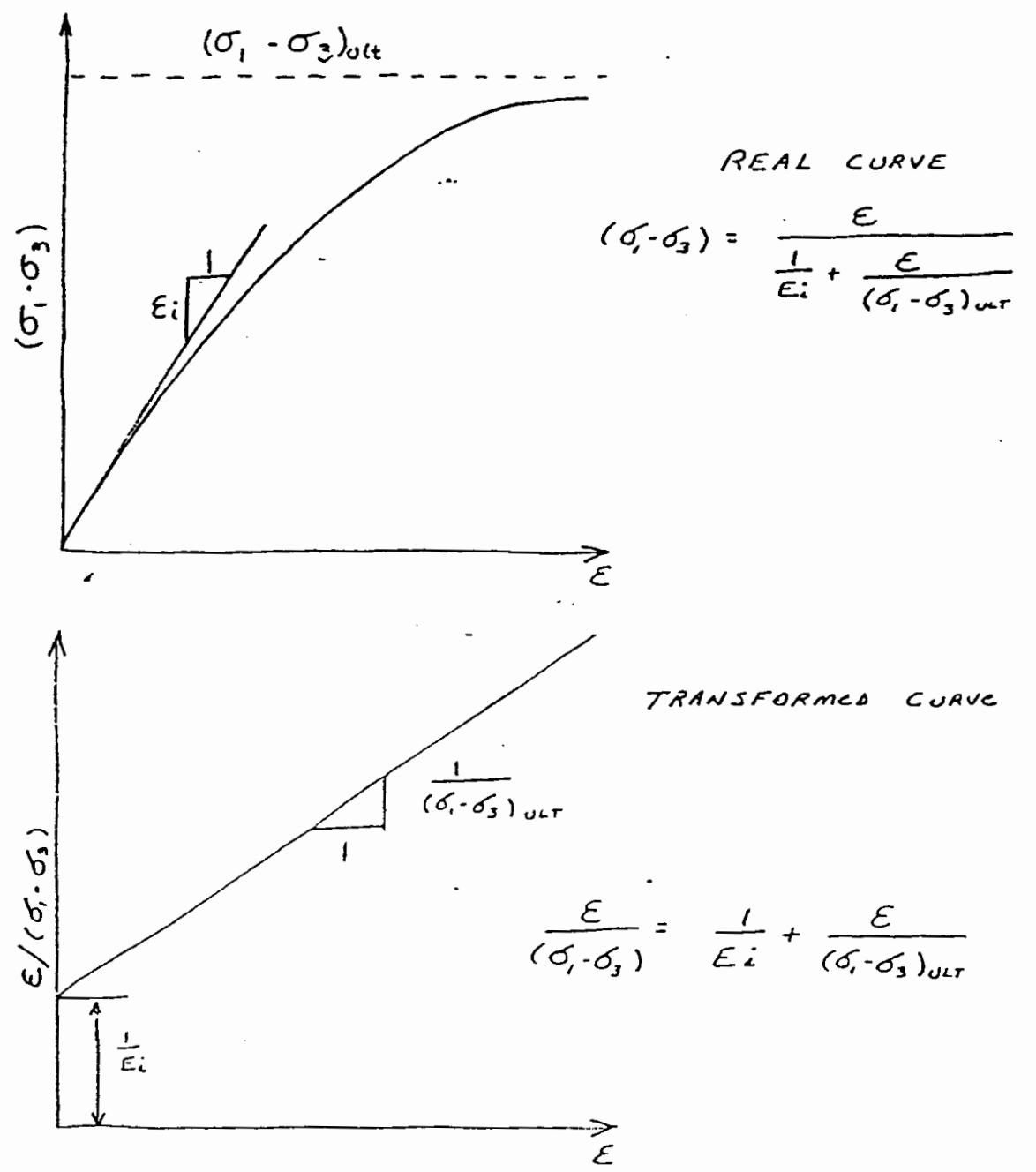

Figure 12. Hyperbolic Stress-Strain Curves. 


$$
\begin{aligned}
\sigma_{3} & =\text { minor principal stress } \\
\varepsilon & =\text { strain } \\
\left(\sigma_{1}-\sigma_{3}\right) \text { ult } & =\text { deviator stress at failure }
\end{aligned}
$$

Also shown in Figure 12 is a transformed hyperbolic curve. This line presents an alternate linear way to show stress-strain data. However, in reality triaxial data do not fit such a straight line. Following the recommendations of Duncan and Chang two points are plotted on the stress strain curve. These two points represent 70 and 95 percent of mobilized shear strength respectively. As shown on figure $12 ; a=1 / E_{i}$, and $b=$ the reciprocal of the ultimate compressive strength (Duncan and Chang, 1970). Note that the initial tangent modulus may be expressed as $E_{i}$ in equation (6), as first proposed by Kondner (Kondner, 1965).

$$
E_{i}=\operatorname{KPa}\left(\sigma_{3} / \mathrm{Pa}\right)^{n}
$$

where $\mathrm{K}=$ constant, established from triaxial test data

$$
\begin{aligned}
\sigma_{3}= & \text { minor principal stress } \\
\mathrm{Pa}= & \text { atmospheric pressure } \\
\mathrm{n}= & \text { exponent determining rate of variation of } \mathrm{E}_{\mathbf{i}} \\
& \text { with } \sigma_{3}
\end{aligned}
$$

This form of expression leaves the soil constants $K$ and $n$ dimensionless. The basic premise for the use of equation 5 is that increases in confining pressure, siama-3, will produce either increases in stiffness, or no change. The soil compressive shear strength may be related in terms of 
the Mohr-Coulomb failure criterion as in (7):

$$
\begin{aligned}
& \left(\sigma_{1}-\sigma_{3}\right)=2 \cos \phi+2 \sigma_{3} \sin \phi \\
& \sin \phi \\
& c=\text { cohesion } \\
& \phi=\text { internal angle of friction }
\end{aligned}
$$

Using relations $(4,5$ and 6$)$ above, non-linear stressstrain behavior may be calculated for each soil element in a debris dam mesh. Thus, at any level of sigma-3 and state of shear stress (or strain) a secant or tangent elastic modulus may be calculated. However, since modulus values and stresses are dependent on each other, repeated calculations must be made. Two techniques may be used to approximate non-linear stress. These methods are the successive iteration and the successive increments method (Duncan and Chang, 1970). The technique used here is the successive iteration method in the computer program FEADAM.

\section{The FEADAM Program}

FEADAM stands for Finite Element Analysis of Dams and was first developed in 1980 by Duncan et.al. (1980). The program has several revisions, the latest being in 1986. The 1984 version is used here because of its compatibility with the Fplot plotting routine developed for SCS. FEADAM uses the hyperbolic model described above where the incremental stress-strain relationship for an element for an isotropic material under plane strain may be shown as in equation ( 8 ): 
$\left\{\begin{array}{c}\Delta \sigma_{X} \\ \Delta \sigma_{Y} \\ \Delta \tau_{X Y}\end{array}\right\}=\frac{3 B}{9 B-E}\left[\begin{array}{ccc}(3 B+E) & (3 B-E) & 0 \\ (3 B-E) & (3 B+E) & 0 \\ 0 & 0, & E\end{array}\right]\left\{\begin{array}{c}\Delta \varepsilon_{x} \\ \Delta \varepsilon_{Y} \\ \Delta Y_{X Y}\end{array}\right\} \ldots(8)$

where $\Delta 6 \mathrm{x}=$ normal stress increment

$\Delta 6 \mathrm{y}=$ normal stress increment

$\Delta \tau \mathrm{xy}=$ shear stress increment

$\Delta E \mathrm{x}=$ normal strain increment

$\Delta \varepsilon \mathrm{y}=$ normal strain increment

$\Delta Y X Y=$ shear strain increment

$\mathrm{E}=$ Young's modulus

$\mathrm{B}=$ bulk modulus

Under primary loading $E=E_{t}=$ tangent modulus as discussed above given by equation (9):

$$
E_{t}=K \quad P a\left(\sigma_{3} / P_{a}\right)^{n}
$$

where $R_{f}=$ failure ratio $=1 /\left(\sigma_{1}-\sigma_{3}\right)$ ult.

The bulk modulus $B$ in ( 8 ) above is given as $(10)$ :

$$
B=\operatorname{KbPa}\left(\sigma_{3} / \mathrm{Pa}\right)^{m}
$$

where $\mathrm{Kb}=$ bulk modulus constant, estimated in the case of collapsible soils; $m=$ bulk modulus exponent, set $=$ 0 in the case of collapsible soils.

FEADAM calculates the stresses, strains and displacements for dams by simulating construction of soil layers. The foundation initialized, stresses are calculated from gravity times unit weight. Layers are then placed on top of one another. At least eight layers are recommended 
for the most accurate calculations. Dam mesh size ranges from 200 to 500 elements.

\section{Theoretical problems}

There are several theoretical problems with the Duncan and Chang hyperbolic model when applied to collapsible soils. Collapsing soils do not increase in shear strength or stiffness with increased confining strength. When wetted and loaded with a normal stress, collapsible soils undergo sudden large strains. The bulk modulus in equation ( 1 ) is undefined for collapsible soils since upon collapse Poisson's ratio may actually be negative and equation (11):

$$
v=\frac{3 B-E}{6 B}
$$

is used by FEADAM to calculate $\mathrm{v}$ based on an input $\mathrm{K}$ is meaningless. Note also that soil properties recommended by Duncan and Chang for input to the FEADAM code are classified as drained or undrained. Collapsing soils are not included in the classification. Collapsing soils may act as drained when dry, but upon some degree of partial saturation change state and are neither strictly drained or undrained.

There are some practical limitations to the FEADAM code. Basically the code is developed to calculate stress, strain, and displacements in dams during the construction 
sequence. The problem of cracked debris dams is post construction failure. Instead, Eailure must be inferred from a set of arbitrary criteria posed to determine if the dam is in a state of primary loading, elastic unloading, tension, or shear failure.

Primary loading moduli are used when the present stress level of an element is 0.95 or less, and sigma-3 is positive. This is generally the case with basic debris dam construction, except one location in the dam core. The dams may be characterized by primary loading using an elastic material.

Elastic unloading occurs when the present stress Ievel drops below $95 \%$ of the previous layer maximum. In the debris dams, an unloading modulus equal to the loading modulus is used in the input file. That is $k=k r$ where $K=$ primary loading modulus and $K r=$ unload-reload modulus. This is done since calculating an average collapsible load modulus accurately is pushing the data far enough at this time. The unload modulus has not thus far been quantified for use in the FEADAM code.

Tension failure occurs when sigma-3 is calculated as negative. By observing sigma-3 plots one may deduce high tension zones indicative of tension failure in elastic material. Actual failure is not indicated.

Shear failure is defined as having occurred when the current stress level of an element exceeds $95 \%$ of its shear 
strength. At this point, modulus values equal to stress level $=0.95$ are used; actual failure levels beyond 0.95 are not calculated.

\section{FEADAM INPUT}

\section{Hyperbolic Parameters}

Equations (9) and (10) describe seven of nine hyperbolic input parameters. They are: $K, \mathrm{~Kb}, \mathrm{C}, \phi, \mathrm{Rf}, \mathrm{n}$, m. The other two input parameters are $\Delta \phi$, and Ko. $\Delta \emptyset, \mathrm{m}$, and $\mathrm{Kb}$ are set equal to zero or fixed at a constant value. Further, there is an unload modulus number Kur which is set equal to the primary modulus $K$ since an unload scenario is not used. Rf is the ratio between actual triaxial tested and theoretical failure stress levels, since actual failure stress levels tend to be somewhat less than the hyperbolic model predicts. The true stress-strain curve stays below the asymptote, the ultimate theoretical compressive soil strength.

\section{Pressuremeter Data}

The hyperbolic approximation has been established from triaxial data to determine values of $K, K b, C, \phi, R f, n$, and m. In an attempt to acquire undisturbed field data, in situ testing has been used with the pre-bored pressuremeter as the standard testing device (Baguelin et. al., 1978). Pressuremeter results directly yield values for $K$, Rf, and 
n, from the procedure given by Neumann (Neumann, 1987). The CAMFE algorithm (Carter, 1978) may be used to generate soil properties. In this procedure, soil properties are manipulated until the resulting computer generated curve closely approximates the field reduced pressuremeter curve. Soil properties at matching may be used as FEADAM input, Figure 13.

In using pressuremeter data to obtain $K, n$, and $R f$, the same procedure has been followed as if triaxial data were used as input data. A comparison of results from pressuremeter-acquired and triaxial-acquired data is not available at this time. 


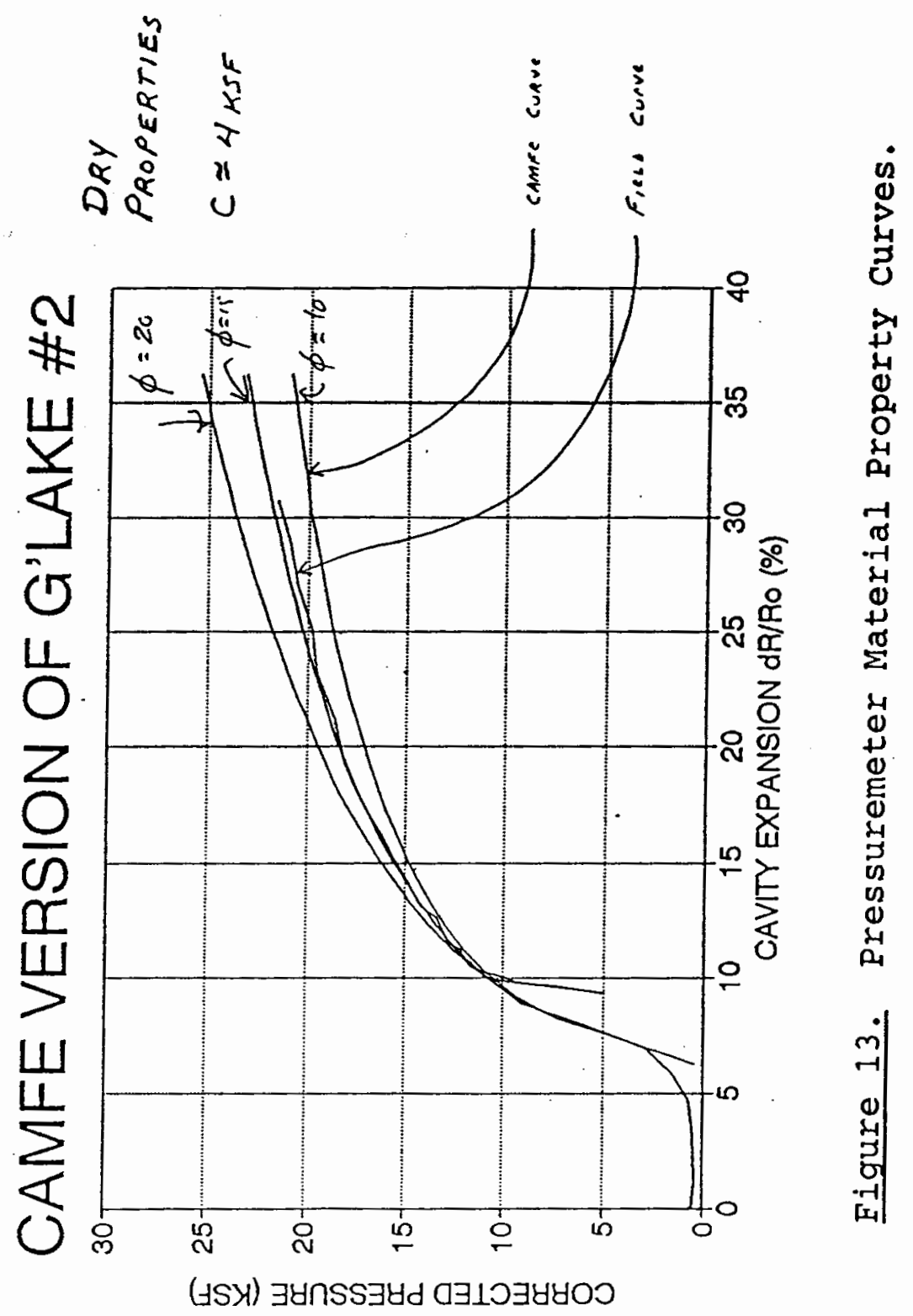


CHAPTER IV

\title{
FEADAM TECHNIQUES USED / BASIN CONSIDERATIONS
}

\author{
FEADAM MESHES FOR DEBRIS DAMS
}

\section{The Generic Mesh}

The FEADAM meshes used here are designed for basin depth, embankment geometry and economy of elements. Basin depths of debris basins modeled ranges from 17 to 29 feet high. Embankment base width varies from 100 to 120 feet. Meshes were designed to go to 30-50 foot possible depth of alluvium. Collapsible soil depth in these basins varies from zero in the case of white Tanks to 15 feet or more in other cases with 15 feet of collapsible material as an average for the sites in this study. Collapsible units may pinch out, or thicken within a few tens of feet across the basin. This change is illustrated in the cross-section, Figure 14 .

The embankment mesh width varies from 100 to 120 feet wide. Meshes are designed with a minimum of eight layers following the recommendations of the FEADAM manual.

After trial and error, a mesh size of between 200 and 300 elements is found to be the most efficient. This size is imposed to reduce computation time and the size of output storage files, without compromising accuracy. 


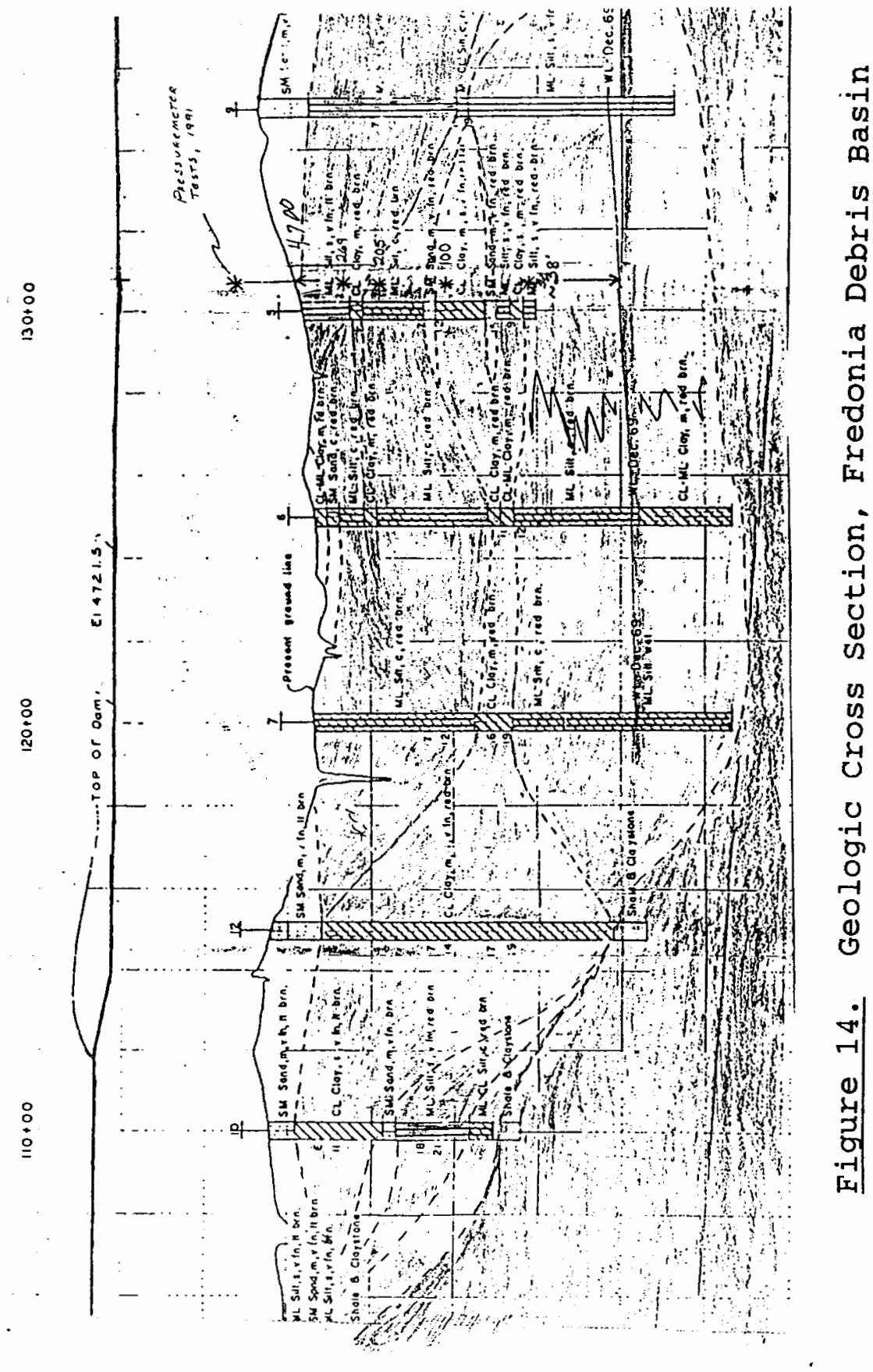


The meshes herein have been designed to represent the debris fan/dam system as accurately as possible. The resulting meshes are similar in their overall geometry, and aspect ratio to other embankment FEM studies (Dekker, 1988; Alberro et. al., 1988). Work now ongoing at PSU using the code MADAM (Metastable Analysis of Dams) uses meshes very similar to meshes developed here (Jacobson,R., 1991). The Sand $H$ study (Smith and Deal, 1988) has been used as a baseline model from which meshes here are derived.

Finally, after a review of past subsurface profiles (USDA, 1966, 1970) it is decided to proceed with a rectangular mesh to represent a section of the debris basins. In reality there may be buried topography and a shallow dipping alluvial fan surface to model. After trial and error it is found that the sloping debris fan surface has little effect on FEADAM output, a constant rectangular mesh represents a deepest alluvium - worst case, and that trying to follow an uncertain subsurface profile with limited subsurface data may not be accurate anyway. There is evidence of a subsurface anomaly at South straight Hollow. Sanders (1981) has reported "subsurface slopes steeper than expected when drilling" at the Fredonia debris dam site.

The resulting meshes are quantitatively accurate with respect to basin/dam configuration, and as accurate as possible with respect to input parameters. The output from 
these meshes, however, needs to be viewed as a qualitative guide to the debris dam cracking problem. This output is as accurate as possible considering the meshes, input, and hyperbolic model used.

Transverse and Longitudinal Meshes

FEADAM modeling may only occur in plane strain. The primary direction is transverse to the dam centerline at or near maximum crest height which also corresponds closely to the area of most cracking. These mesh sections are 370 feet long. The upstream side of the section is about twice the downstream section length. This scale is to best model the water-source effect on the dams.

Longitudinal meshes are 300 feet long and tie into transverse sections about mid-crest. All longitudinal section elements are 10 feet long. One major problem of longitudinal lines is lack of proper geometric representation. There is no accurate way in plane strain to model the third dimension of sloping dam sides using a longitudinal mesh. In an effort to capture the geometry, dam $\mathrm{K}$ values on longitudinal meshes were reduced by $7 \%$ per layer with increasing height from a base level $\mathrm{K}$ of $500 \mathrm{ksf}$ to a crest $\mathrm{K}$ of $100 \mathrm{ksf}$.

There is also a scale problem inherent to any mesh in the longitudinal direction. FEADAM has a size limitation of 550 nodes and 550 elements. In the field, dams are a 
minimum of a few thousand feet long. Given a 3 to 1 aspect ratio, an 8 layer dam, a 30 to 50 foot deep foundation, and 20 to 30 foot high dam, the longitudinal limit is a mesh about 500 feet long. One longitudinal section has been created using 8 layers to represent the entire foundation-dam sequence with 3 foundation layers and 5 dam layers. This mesh is 1800 feet long, 75 feet total height, with 549 nodes and 480 elements.

One other limit of such a large mesh is computer time. It takes a personal computer with an 80286 processor about 3 hours to run the mesh, at $10 \mathrm{mhz}$. A PC with an 80386 processor at 20 or $33 \mathrm{mhz}$ may run the same mesh in about one third the time of the 80286. The cache ability on a PC seems to decrease run time by another $25 \%$ or so. Thus the minimum turnaround time for a 500 element mesh is about 50 minutes. The UNIX based Sun machine may complete a mesh in up to one fifth or less the 386 time.

There is one other longitudinal consideration. The sections modeled are all of a homogeneous material property horizontally along geometrically well defined boundaries. Discretization is necessary in the finite element method. However, the alluvial system is very difficult to discretize. This may be observed from the cross section in Figure 15 (Beckwith and Hansen, 1989). Debris flows move down different pathways with every event (Graf, 1988). The resulting placement of collapse prone pods is not at 


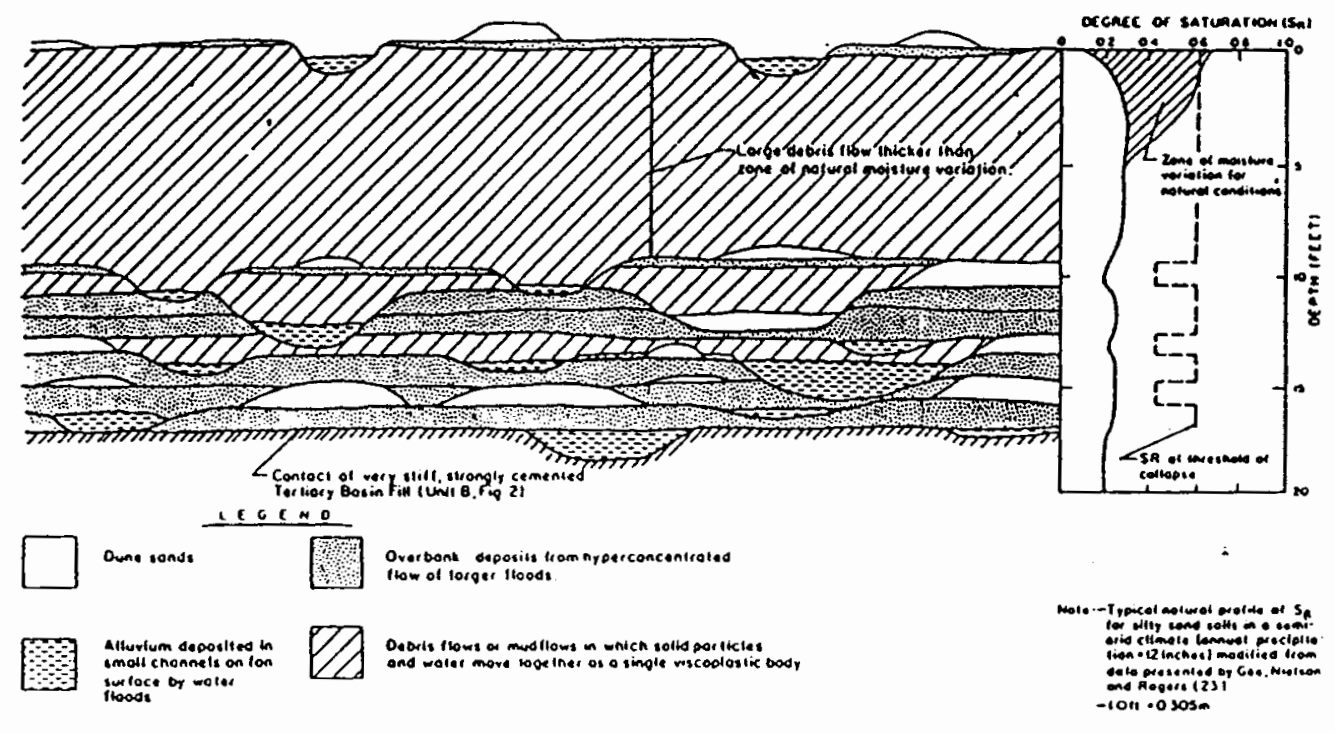

Figute 3. Conceptual depiction of Feacures of collapsing Alluvid Fan - Mudtlou - Dabcls flow Depoltes and Seasonal variaclone of Degree of Saturaction in. Non-infilexacing Geologle Protilo

Figure 15. Generalized Debris Basin Cross Section. 
all evenly spaced. Here, soft zones representing zones of collapse have been placed at the center of the mesh. This is unrealistic as outlined above, but should serve to explore the collapse phenomenon in the most simple case. Time and resource limits prevent detailed analysis here.

\section{MODELING A SEQUENCE OF EVENTS}

\section{Dam Construction}

FEADAM has the ability to simulate three events pertinent to debris dam construction and collapse. Firstly, the foundation part of the mesh is placed and gravity turned on. Then layers are placed and the resulting stresses and strains are calculated one layer at a time. At the end of construction, a distributed or point load may be applied. In the field the dams of course are already built, and then a moisture front initiates collapse. FEADAM can only model stresses and strains as a result of most recent construction. Thus the program is not really able to calculate instantaneous change from changing moduli in a post-construction state. Calculated stresses and strains are a result of accrued layers acting on a zone of predetermined, unchanging strength. In the field, the soil modulus changes during saturation and collapse and is not triggered by collapse. 
Foundation Collapse

Debris dam fan foundations will actually collapse under their own weight. FEADAM is not able to simulate this condition using the construction routine. One way for FEADAM to produce nodal displacements simulating collapse in the basin is to apply a distributed load across the top of elements which are desired to strain vertically. It is then possible to achieve displacements on the order of 1 to 5 feet as field reports indicate. This technique produces stresses below the loaded area that are clearly not realistic. To improve the after-load stress pattern, a distributed load may be buried in the foundation to a depth of 5 to 10 feet with resulting stresses above the load representative of actual foundation conditions.

\section{$\underline{\text { Dam Cracking }}$}

Dam cracking may not be directly calculated by FEADAM. Displacements, stresses and strains calculated by FEADAM maY be used to interpret zones of possible cracking based on field evidence. Other indications of cracking produced by the program include modulus and stress levels used during calculation. For example, a failed element in shear is not allowed by FEADAM. Instead, the program sets failed element moduli to values approaching zero.

In principle, it has been assumed that a wetted front moves under the dam into the cutoff trench, if present. 
This condition represents the worst-case condition, as cutoff trench soils may, or may not, represent similar saturated properties as surrounding soils. However, not all cutoff trenches have been tested under saturated conditions. Thus, the effect of saturation on modulus value change is unknown. The worst, saturated, low modulus value is assumed for all saturated material.

Dams with collapse potential are modeled under a variety of conditions. Firstly, dry soil parameters are used to determine a baseline, after construction stress and strain state. The introduction of a wetted front is simulated by changing modulus values and other properties as described above.

Two other general collapse modeling approaches are taken. In the first, all hyperbolic parameters are set equal to zero except $K$, Kur, and $B$ which are set equal to one. This creates a linear material of very low stiffness in an attempt to simulate a collapse-induced void, letting the weight of the above material induce stress and strain. Cohesion and phi angle are also zero in this case, since by definition FEADAM does not recognize these parameters in a linear material.

In the second modeling approach, node displacements are induced to simulate collapse in an assumed saturated collapse zone. Node displacements may be induced using a point or distributed load. A variety of displacement 
collapse zone. Node displacements may be induced using a point or distributed load. A variety of displacement methods have been attempted.

Modeling approaches are then used to evaluate stresses and displacements at four sites. Two collapse sites are located in Utah with one collapsible, and one noncollapsible site in Arizona as shown on the map, Figure 16. 


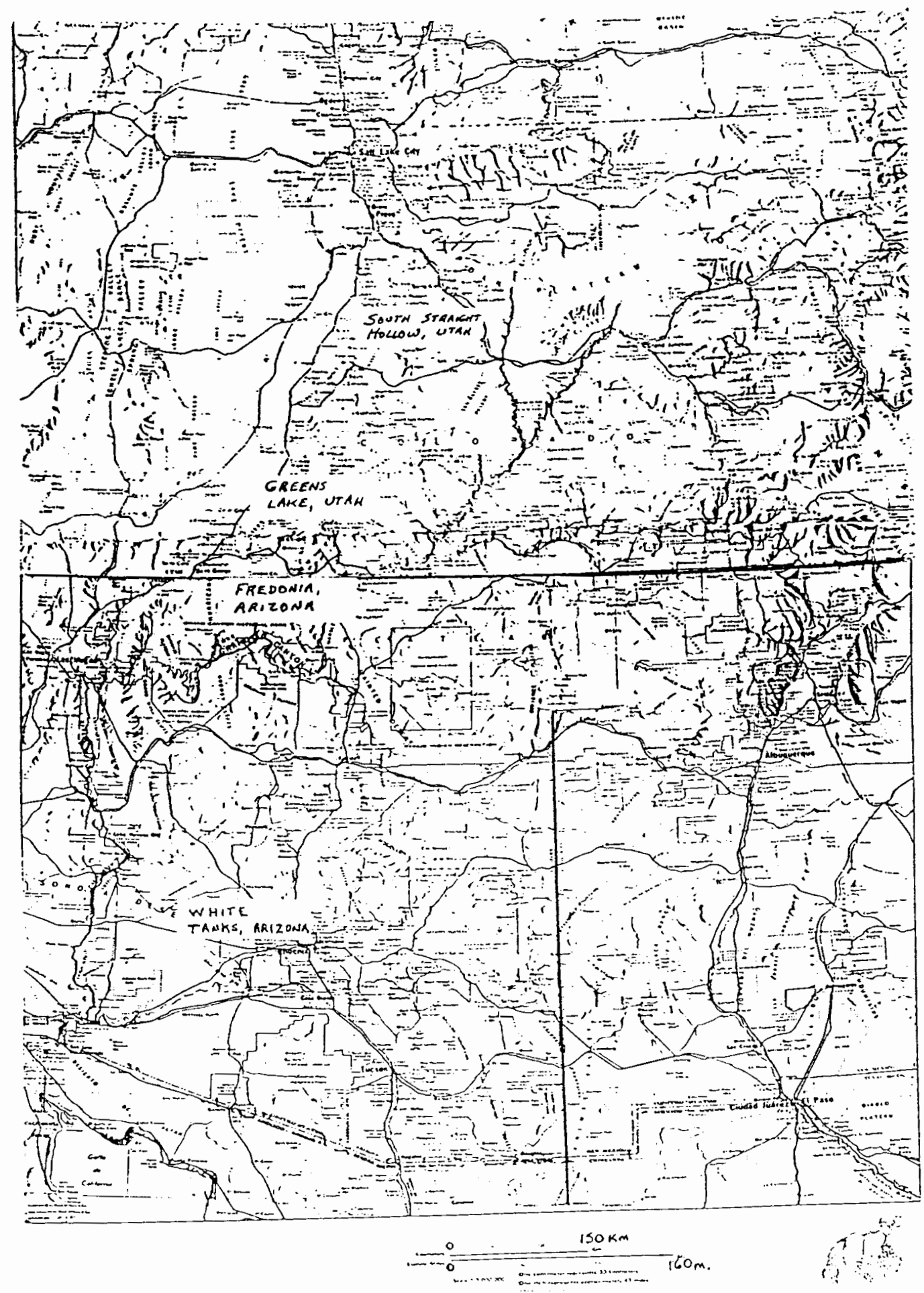

Eigure 16. Site Location Map 
CHAPTER V

FEADAM MODELING OF THE WHITE TANKS DAM \#3

DAM STRUCTURE AND LOCAL GEOLOGY

\section{White Tanks structure}

There are four white Tanks debris dams under SCS control, located at the base of the white Tank Mountains in southwestern Arizona. Dam number 3 is the subject of the most recent site investigation and is reported here. This structure, started in 1952, stands 28.8 feet high at its highest point. Dam slopes are 2:1 upstream and downstream. The dam is approximately 7500 feet long. Note that the structure is not straight but curved, following the local topography. There is no cutoff trench.

\section{Local Geology}

The dams rest on a broad southwest dipping alluvial plain cut by numerous small stream channels. Source material for the alluvial fill at the White Tanks site is mostly of igneous and metamorphic origin. The sediments covering the surface are derivations of granites, diorites, and massive schists. Sand grains are mostly quartz and unweathered feldspars. Much of the fine fraction are of low plasticity silts (cl-ml) with some clays from the 
feldspars, and mafic rock constituents. Calcium carbonate is present, markedly so in the sandy soils. The carbonate may manifest itself as caliche. Therefore, the carbonates at White Tanks are not metastable like the carbonates and sulfates at the other sites reported herein. The white Tanks dam is not affected by foundation collapse of metastable soils. The White Tanks dam, however, may be affected by differential settlement of the silt fraction of soil under the dam. This soil may be observed in hand specimen as a sandy silt with some gravel. This soil is in contrast to the caliche found at the same stratigraphic horizon only a few hundred feet away. The idea geologically is that a continuous caliche unit as shown on Figure 17 has a silt zone approximately 50 feet wide in the middle. One problem encountered is that the modulus value of the caliche has a similar modulus value to a much less consolidated gravel unit. This similarity of values may make the caliche horizon appear continuous, when in fact there appears to be a break in the caliche. The 50 foot or so wide zone filling in the break is a softer sandy silt, with some gravel. This infilling material, softer than the caliche, could cause the dam to settle differentially. 


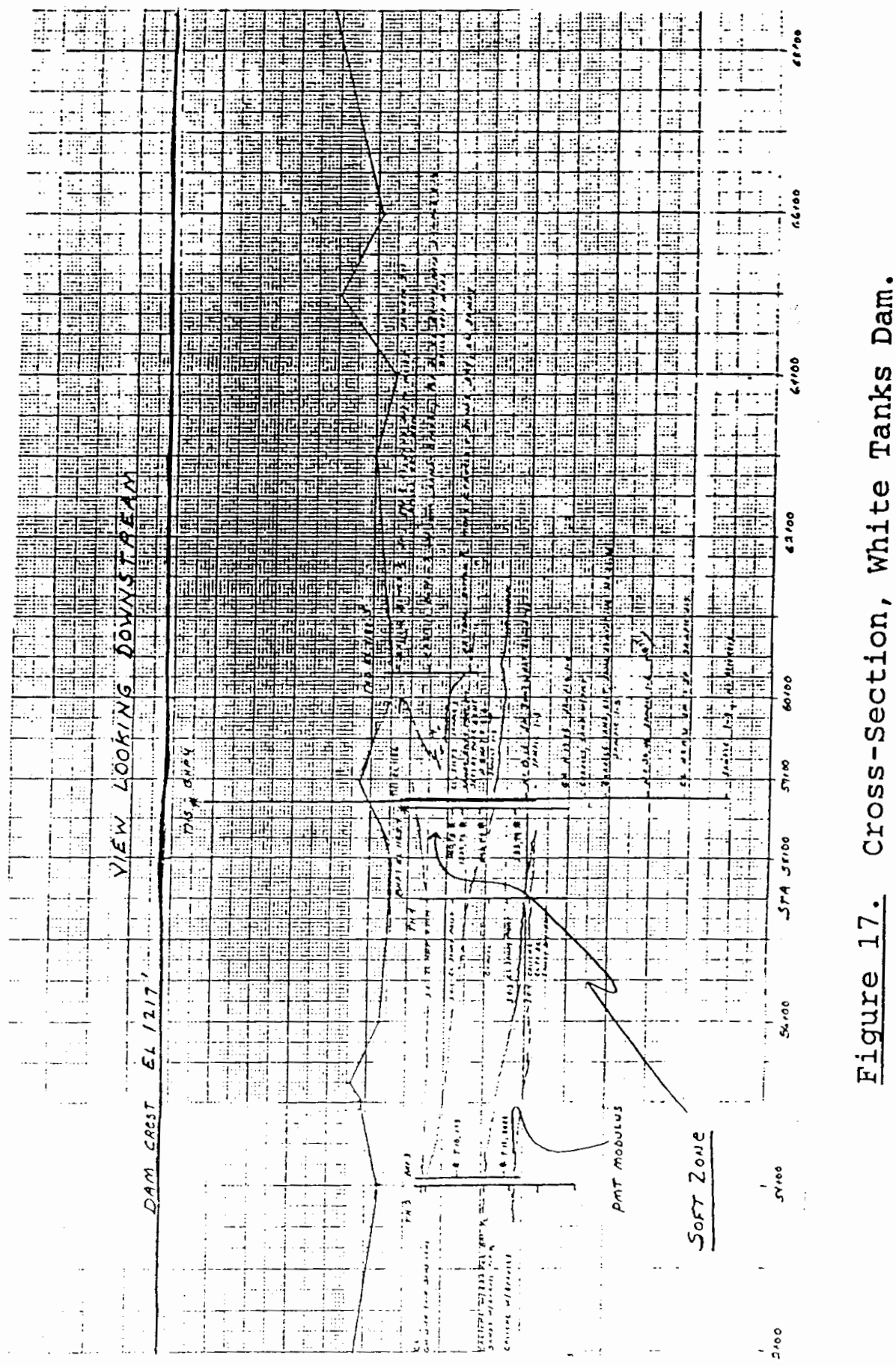




\section{TRANSVERSE SECTIONS}

\section{FEADAM Input, Model WT9}

A summary of White Tanks Models run is shown in Table I. Two cases are compared, with and without a soft zone. For the soft zone, the modulus values are lowered and other hyperbolic values changed as shown on Table II. The transverse section is not as well measured as the longitudinal section in terms of modulus values in the subsurface. Thus the soft zone in the transverse direction must be inferred. An arbitrary (subsurface) soft zone length of 60 feet has been assigned.

FEADAM Output, Model WT9

Horizontal and vertical displacements for the case with no soft zone are shown on Figure 18. Sigma-3 stress ranges from -0.12 (tension) to $3.8 \mathrm{ksf}$, Figure 19. Tau-max varies from 0.1 to $2.1 \mathrm{ksf}$.

\section{Interpretation}

Model WT9 shows no signifigant difference in displacement over the model with a soft zone, model WT10. In model WT9 However, sigma-3 stress is lower by one fifth the WT10 sigma-3 stress. So, soft zone transverse models may show increased stresses over no soft zone models, but not associated displacements. 
TABLE I

WHITE TANKS MODEL FIGURE SUMMARY

Mode1 Figure

Display

WT9A 18

WT9B 18

WT9C 19

WT10C 19

WL14 Not

Shown

WL15A 20

WL15B 20
Horizontal displacement

Vertical displacement

Sigma-3 stress

Sigma-3 stress

Horizontal Displacement

Vertical

Displacement
Conditions

Continuous layer cake profile with 1 zone dam

Continuous layer cake 1 zone dam

Continuous layer cake 1 zone dam

Continuous layer cake, add a $60 \mathrm{ft}$. long soft zone

Longitudinal Line, no Soft Zone

Longitudinal Line with Soft Zone

Longitudinal Line with Soft Zone 
TABLE II

\section{WHITE TANKS HYPERBOLIC PARAMETERS}

\begin{tabular}{|c|c|c|c|c|c|c|c|c|c|c|c|c|}
\hline \multirow[b]{2}{*}{ MATERIAL } & \multicolumn{12}{|c|}{ HYPERBOLIC INPUT MODEL WT 9} \\
\hline & c & $\boldsymbol{\gamma}$ & $\phi$ & $\mathrm{K}$ & $\Delta \phi$ & Kur & $\mathrm{K}_{\mathrm{\sigma}}$ & n & $\mathbf{R}_{f}$ & $K_{b}$ & m & NOTES \\
\hline 1 & 6 & .115 & 20 & 200 & 0 & 200 & .5 & .65 & .9 & 130 & .4 & \\
\hline 2 & .6 & .114 & 20 & 225 & 0 & 225 & .5 & .65 & .9 & 150 & .4 & \\
\hline 3 & 5.0 & .125 & 35 & 1050 & 0 & 1050 & .8 & .1 & .7 & 700 & .5 & CUCHE UNIT \\
\hline 4 & .6 & .112 & 30 & 390 & 0 & 390 & .5 & .5 & .7 & 275 & .4 & \\
\hline 5 & 2.0 & .125 & 0 & 600 & 0 & 600 & .8 & 0 & 0 & 400 & 0 & \\
\hline
\end{tabular}

\section{HYPERBOLLC INPUT MODEL WT 10}

$\begin{array}{ccccccccccccc}\text { MATERIAL } & c & \gamma & \phi & K & \Delta \phi & K u r & K_{b} & n & \mathrm{~F}_{\gamma} & K_{b} & \mathrm{~m} & \text { NOTES } \\ 1 & .6 & .115 & 20 & 200 & 0 & 200 & .5 & .65 & .9 & 130 & .4 & \\ 2 & .6 & .114 & 20 & 225 & 0 & 225 & .5 & .65 & .9 & 150 & .4 & \\ 3 & 5.0 & .125 & 35 & 1050 & 0 & 1050 & .8 & .1 & .7 & 700 & .5 & \\ 4 & .6 & .112 & 20 & 390 & 0 & 390 & .5 & .5 & .7 & 275 & .4 & \\ 5 & 2.0 & .125 & 30 & 600 & 0 & 600 & .8 & 0 & 0 & 400 & 0 & \\ 6 & .5 & .110 & 20 & 210 & 0 & 210 & .5 & .5 & .9 & 140 & .4 & \text { SOFT ZONE }\end{array}$




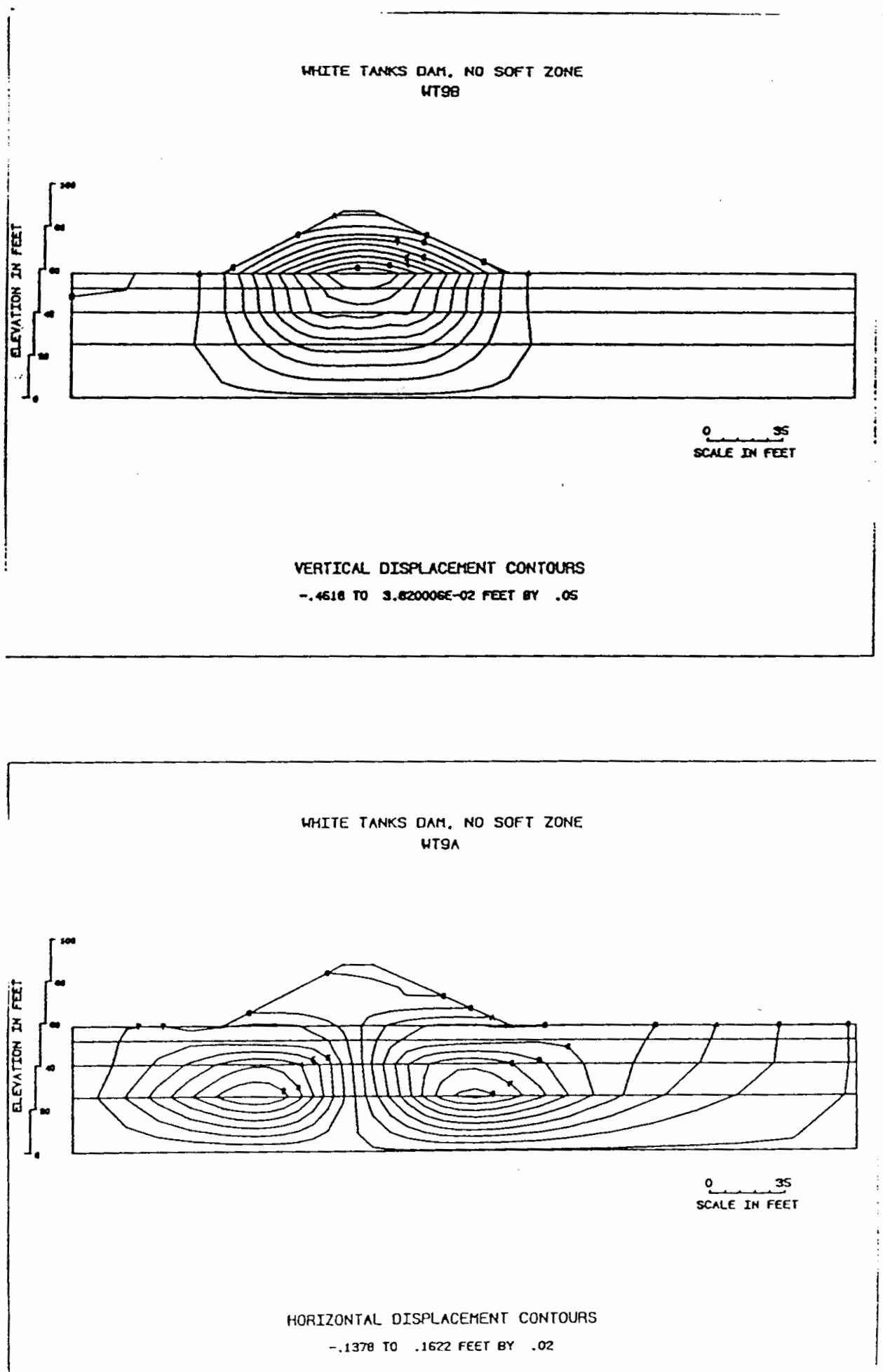

Figure 18. WT9 Displacement Contours. 


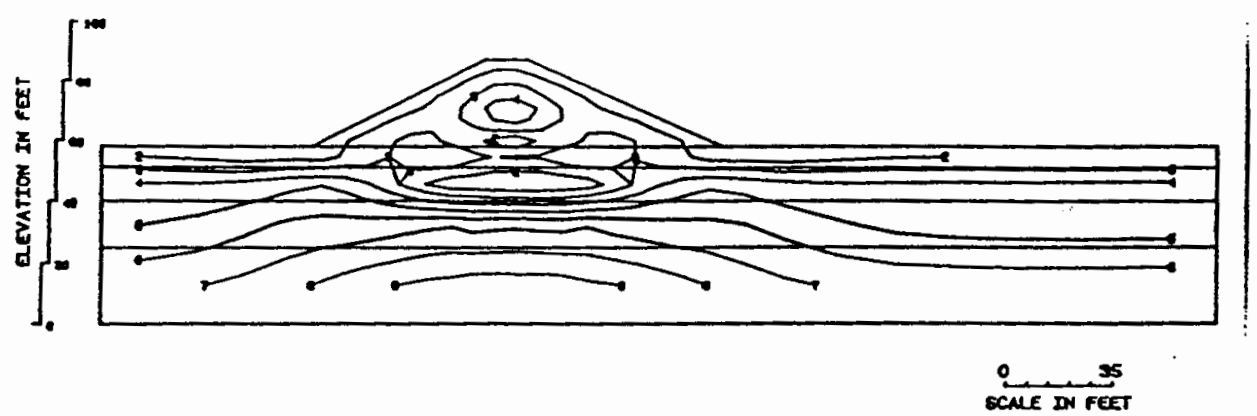

SIGMA-3 STAESS CONTOURS

-.1160 to $3.8042 \mathrm{kBF}$ or .6

HMTE TANKS DAM, SOFT ZONE HTIOC

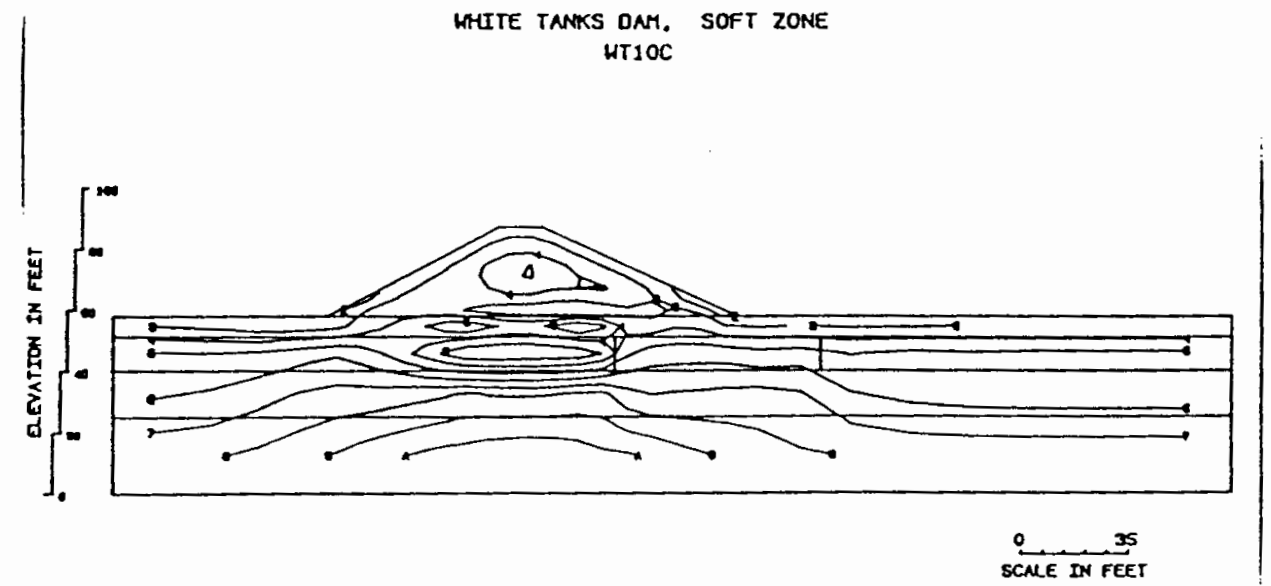

SIGMA-3 STRESS CONTQURS

-.6275 to 3.0825 KSF oY .6

Figure 19. WT9 stress Contours 
This seems to indicate that the hyperbolic parameters introduced were not low enough to induce significant horizontal or vertical displacement, but were low enough to lower stresses, an indication of a weaker soil state.

LONGITUDINAL MODELS, NO SOFT ZONE

\section{FEADAM Input, Model WLI4}

Hyperbolic parameters are the same as transverse input parameters. The longitudinal mesh used is 300 feet long by 87 feet vertical.

\section{FEADAM Output, Model WL14}

The section with no soft zone shows zero horizontal displacement, 0.35 feet of downward vertical displacement, and sigma-3 stress of from 0.1752 to $4.65 \mathrm{ksf}$. Longitudinal contour lines follow material horizon breaks with no dips, bends, or other anomalies noticeable.

\section{Interpretation}

It appears that simply placing layers of various material properties in a mesh with fixed (horizontal) boundaries produces a set of evenly spaced, predictable set of displacements and stresses, according to depth in the mesh. The magnitudes of displacement and stress are consistent with conventional soil mechanics. 
LONGITUDINAL MODELS WITH A SOFT ZONE

EEADAM Input, Model WL15

A 40 foot wide, 11 foot thick soft zone is placed in the longitudinal mesh to simulate the silt zone described above. The hyperbolic parameters of the soft zone are changed such that element stiffness is $210 \mathrm{ksf}, c=$ $0.50 \mathrm{ksf}, \mathrm{phi}=20$ degrees, $n=0.5$, and $\mathrm{Rf}=0.9$.

\section{EEADAM Output, Mode1 WL15}

Horizontal displacements are about one tenth of a foot, over and above the no soft zone case. Sigma-3 and tall:

Tau-max stresses change little also. Figure 20 shows resulting displacement contours.

\section{Interpretation}

The output is very conservative compared to field reports of possible differential settlements of over a foot. In the longitudinal direction, model wL15 shows the greatest offset of close to half a foot, with differential settlement of about one tenth of a foot, compared to model WL14. Some problems arise. The mesh used is probably not long enough, the dam geometry is not well represented, as discussed in Chapter IV, and the boundary condition of Eixed $\mathrm{x}$-direction nodes over such a short distance may be artificially restricting the nodes. Given the above, and the hyperbolic model's insensitivity to parametric changes, a conservative displacement and stress output is obtained. 
WHITE TANKS LONG. LINE, soft zONe LL.1SB

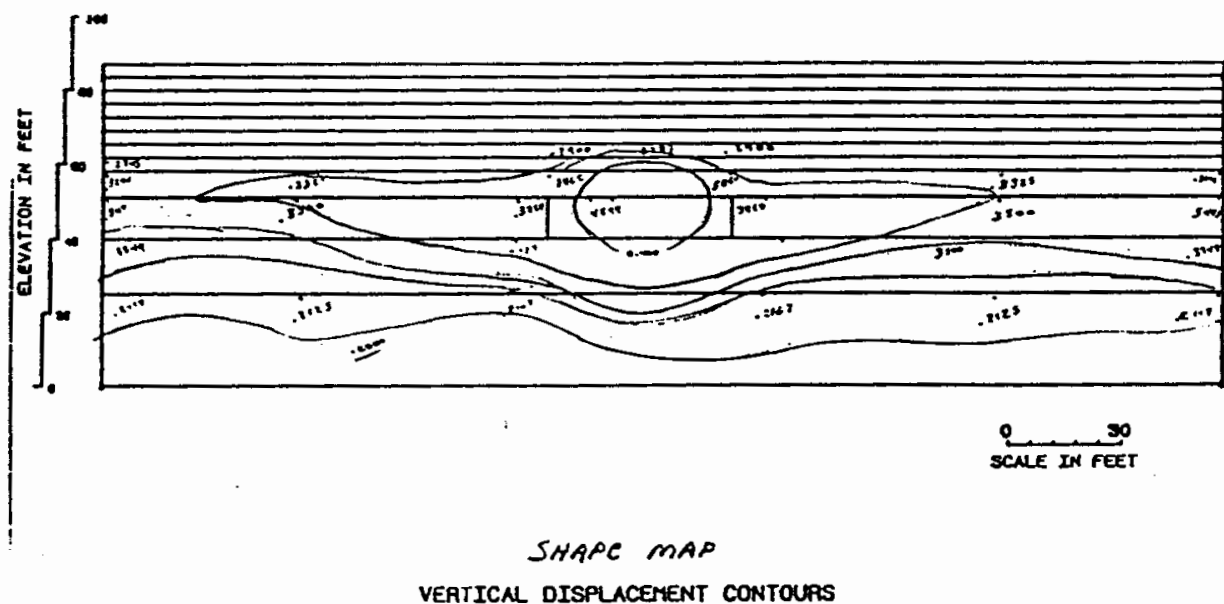

0 ro $-0.4399 \mathrm{Fr}$

WHITE TANKS LONG. LINE, soft zone WL15A

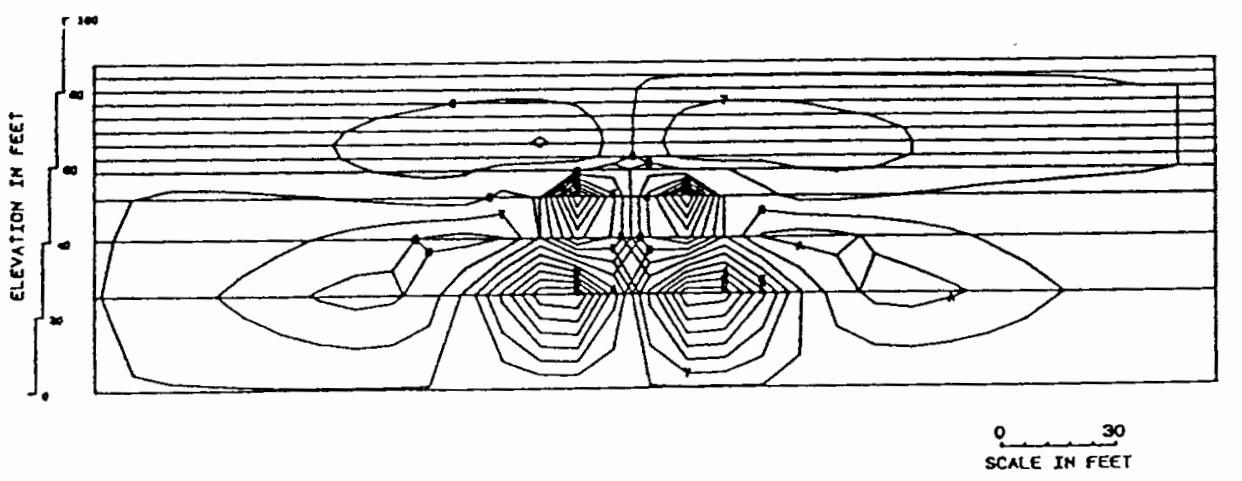

MORIZONTAL DISPLACEMENT CONTOURS

-.0141 YO .0139 FEET QY .002

Eigure 20. WL15 Displacement Contours. 
STABILITY SUMMARY

\section{Dam Safety}

At this point it is difficult to use the FEADAM model to make accurate predictions. A percent difference approach may be useful. Including the soft zone causes an absolute change in vertical displacement of 30 percent. Where the no soft zone displacement is about 4 inches, the soft zone settlements go to about 6 inches. Therefore, depending on the initial field settlement, additional soft zone caused settlements of 30 percent or so may be expected, according to these FEADAM output records. This estimate is conservative, where actual settlements may go as high as 150 percent, or greater, of post construction settlements, assuming construction settlement of 6 inches or so, and differential settlements of 1.5 feet or so.

So, FEADAM shows a 30 percent change in vertical displacements, (dry-construction to soft-post construction simulation), while actual field conditions show vertical offsets of perhaps 300 percent, from construction to differential settlement. Sigma-3 stresses may be a better indicator of dam settlement in the transverse direction, according to FEADAM output. Although longitudinal stresses did not decrease much from no soft zone (WL14) to soft zone (WL15), transverse soft zone (WT10) stresses drop to one fifth the no soft zone (WT9) stresses. This output suggests a weaker soil state with a soft zone. 
CHAPTER VI

FEADAM MODELING OF THE FREDONIA DEBRIS DAM.

\section{DAM STRUCTURE AND LOCAL GEOLOGY}

\section{The Fredonia Structure}

The Fredonia debris dam is located near Fredonia, Arizona, in far north central Coconino County and was built between 1972 and 1973 to protect local structures, farms and roads from debris flows. The dam is over $2 \mathrm{miles}$ long, and about 24 feet high at its highest point which also coincides with the area of most cracking and damage, sta $130+00$ to sta 140+00. Upstream side slopes are 3:1 with downstream slopes at $2: 1$. The dam is not zoned, but built entirely of upstream basin compacted borrow material. The cutoff trench is extensive with $1: 1$ side slopes at each toe to a maximum 20-foot depth near sta 131+00. The trench has been built of recompacted fill in an effort to stem cracking from collapse. This has worked to some extent as noted in the Fredonia crack investigation (Sanders, 1981).

\section{Local Geology}

The Fredonia debris dam crosses a wide, low-angle alluvial fan issuing from cliffs at the fan apex. The soils are sandy silts, silty sands, clayey silts, and silts. The 
soil is quite gypsiferous with small blades of gypsum visible in a hand specimen. Some gypsum cobbles may be found in the basin and on the dam. The northern end of the dam site is reported to have a lower soluble salt content and less damage than to the south. The triassic Moenkopi formation of shale, claystone, and siltstone with gypsum underlies basin soils above a depth of approximately 50 feet, sta 130+00. This also coincides with an area of extensive damage. The Fredonia crack investigation makes mention of curved, longitudinal cracks. This type of crack pattern fits well into the drop block model proposed in Chapter II. A similar crack pattern has been noted in a California test canal (Gibbs and Bara, 1967).

\section{INDUCING COLLAPSE IN THE FREDONIA DAM}

\section{Mechanisms Used to Displace Nodes}

of the mechanisms mentioned in Chapter $\mathrm{V}$, two proved most successful for inducing nodal displacement at Fredonia. They are the distributed load technique, and $K=1$ ( $K=e$ lement stiffness) technique, In some cases, the two techniques have been combined, a distributed load applied across the top of elements of $\mathrm{K}=1$ stiffness. Table III shows the models used as they relate to the mechanisms. The idea behind these mechanisms is to cause nodal displacements equal to: 1) observed field collapse, and 2) equal to laboratorycontrolled collapse on a generic soil. Note that laboratory 
test results on collapse soil samples from the Fredonia site are presently being conducted at Scs Labs, Lincoln, Nebraska. Field observations and lab tests indicate collapse on the order of 5 to $15 \%$. The above mechanisms are compared to two baseline states.

\section{Hyperbolic Parameters}

In the dry state, an upper collapsible zone of various thicknesses is given with hyperbolic parameters corresponding to a dry soil state as defined by pressuremeter testing and field observation. These parameters are shown in Table IV for two Fredonia models.

In the dry state, the soil possesses a high Young's modulus, cohesive strength, and a lower angle of friction and $K$ than in the saturated state. The dry state is the most common in the arid Fredonia area. However, after a storm event creates ponding on the order of one foot or so, or there is a rise in the water table, the formerly dry state soils saturate, collapse and their properties may change significantly. The dry surface material (down to -15.0 feet) has a dry pressuremeter Young's modulus on the order of 250 ksf. Upon saturation, the modulus drops to $75 \mathrm{ksf}$. Dry cohesion is computed using the pressuremeter algorithm CAMFE (Carter, 1978) to be $3.0 \mathrm{ksf}$. Saturated cohesion drops to $0.2 \mathrm{ksf}$. Dry friction angle is 5 degrees, saturated friction angle is 2 degrees. Unit weight increases upon saturation. 
One important assumption of the hyperbolic model is that of a stress-dependent soil stiffness. This is clearly not the case with collapsible soils and is well illustrated by Figures 21 and 22. In Figure 21 the change of modulus value with depth, $\mathrm{n}$, is 0.94 upstream and 0.24 downstream, dry case. The difference in slope is attributed in this case to upstream soils having experienced more cycles of saturation/collapse/ drying than downstream due to ponding behind the dam. From Figure 22, saturated modulus changes with depth; however, this shows no change of soil modulus with increasing depth thus, $n=0$. Collapse potential is then independent of depth if the saturation state is similar. The last parameter change is the coefficient of earth pressure at rest, $K_{O}$. Ko is set lower to try and account for a lower confining pressure in the collapse zone after collapse and volume reduction. For the dams model used here, all material units, except the collapsible units, are assigned linear material properties.

TRANSVERSE SECTIONS, DRY STATE

EEADAM Input, Model 79

A dry state is run to capture a baseline state of stress and strain. Input parameters are shown on Table IV, with model summaries given in Table III. All horizons are linear, homogeneous material except for the hyperbolic dry 


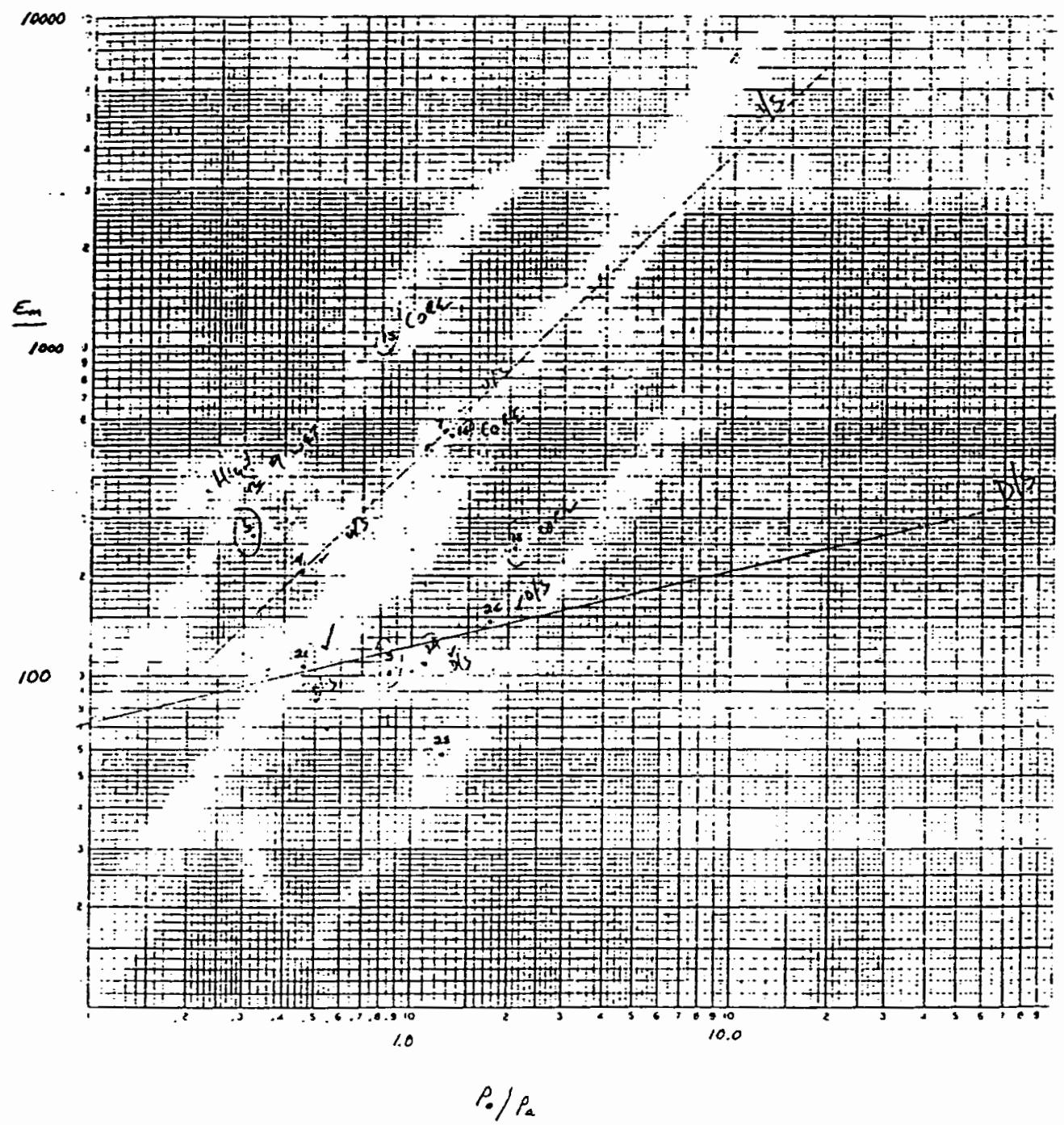

Figure 21. Dry Modulus Change with Depth. 


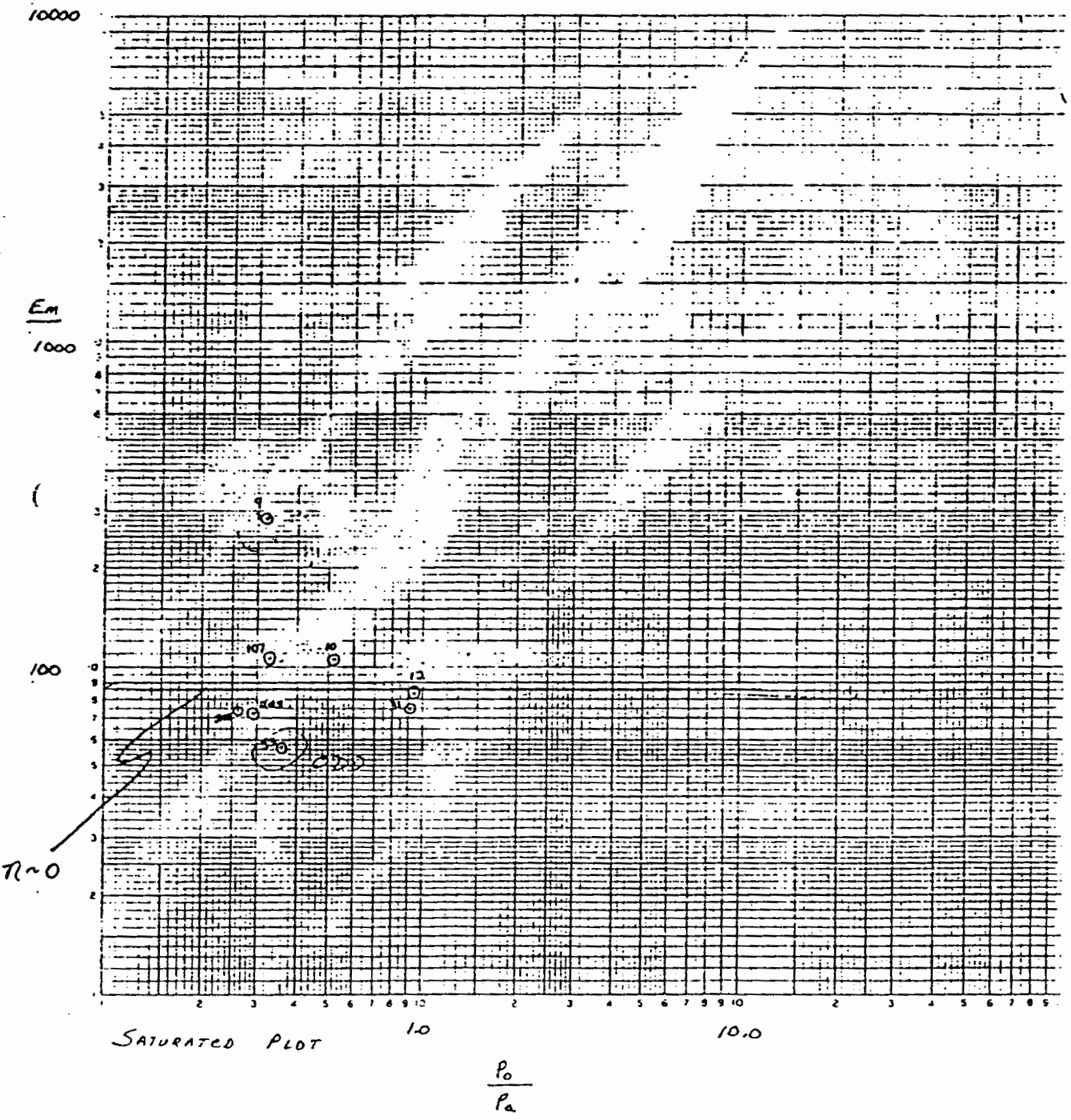

Fiqure 22. Wet Modulus Change with Depth. 
TABLE III

FFEDONIA MODEL FIGURE SUMMARY

Model Figure Display Conditions

\begin{tabular}{|c|c|c|c|}
\hline F79A, B & 23 & $\begin{array}{l}\text { Displacement } \\
\text { Contours }\end{array}$ & $\begin{array}{l}\text { Dry state } 3 \text { layer } \\
\text { Foundation }\end{array}$ \\
\hline F79C & 24 & $\begin{array}{l}\text { Stress } \\
\text { Contours }\end{array}$ & Dry state \\
\hline F93A, B & 25 & $\begin{array}{l}\text { Displacement } \\
\text { Contours }\end{array}$ & $\begin{array}{l}\text { Sat. zone one quarter } \\
\text { under dam } \mathrm{K}=35 \mathrm{ksf}\end{array}$ \\
\hline F93C & 26 & $\begin{array}{l}\text { Stress } \\
\text { Contours }\end{array}$ & $\begin{array}{l}\text { Sat. zone one quarter } \\
\text { under dam }\end{array}$ \\
\hline FL6 & 33 & $\begin{array}{l}\text { Displacement } \\
\text { Contours }\end{array}$ & $\begin{array}{l}\text { Longitudinal section } \\
\text { soft zone in middle }\end{array}$ \\
\hline $\mathrm{F} 20 \mathrm{~A}, \mathrm{~B}$ & 35 & $\begin{array}{l}\text { Displacement } \\
\text { Contours }\end{array}$ & $\begin{array}{l}\mathrm{K}=1 \text { piping } \\
\text { Experiment }\end{array}$ \\
\hline F20C & 37 & $\begin{array}{l}\text { Stress } \\
\text { Contours } \\
\text { Displacement } \\
\text { Vectors }\end{array}$ & $\begin{array}{l}\mathrm{K}=1 \text { piping } \\
\text { Experiment }\end{array}$ \\
\hline$F 66 A, B$ & 29 & $\begin{array}{l}\text { Displacement } \\
\text { Contours }\end{array}$ & $\begin{array}{l}\mathrm{K}=1 \text { soft zone } \\
\text { Load }\end{array}$ \\
\hline F66C & 30 & $\begin{array}{l}\text { Stress } \\
\text { Contours }\end{array}$ & $\begin{array}{l}\mathrm{K}=1 \text { soft zone } \\
\text { Load }\end{array}$ \\
\hline F70A, B & 31 & $\begin{array}{l}\text { Displacement } \\
\text { Contours }\end{array}$ & $\begin{array}{l}K=25 \text { soft zone } \\
\text { Load }\end{array}$ \\
\hline F70C & 32 & $\begin{array}{l}\text { Stress } \\
\text { Contours }\end{array}$ & $\begin{array}{l}\mathrm{K}=25 \text { soft zone } \\
\text { Load }\end{array}$ \\
\hline F83C & 38 & $\begin{array}{l}\text { Stress } \\
\text { Contours }\end{array}$ & $\begin{array}{l}\text { Depth experiment } \\
25 \mathrm{ft} \text {. soft zone }\end{array}$ \\
\hline
\end{tabular}

Model Figure Display Conditions 
TABLE IV

FREDONIA HYPERBOLIC PARAMETERS

\section{HYPERBOLC INPUT MODEL F79}

$\begin{array}{cccccccccccc}\text { MATERIAL } & c & \gamma & \phi & K & \Delta \phi & K U R & K_{b} & n & R_{f} & K_{b} & m \\ 1 & 0 & .101 & 0 & 260^{*} & 0 & 260 & .5 & 0 & 0 & 2000 & 0 \\ 2 & 0 & .121 & 0 & 75 & 0 & 75 & .5 & 0 & 0 & 1200 & 0 \\ 3 & 3 & .101 & 5 & 120 & 0 & 120 & .5 & .8 & .8 & 75 & .5 \\ 4 & 0 & .121 & 0 & 500 & 0 & 500 & .8 & 0 & 0 & 400 & 0\end{array}$

NOTES

HYPERBOUC INPUT MODEL F93

$\begin{array}{ccccccccccccc}\text { MATERIAL } & c & \gamma & \phi & K & \Delta \phi & K u r & K_{b} & n & R_{f} & K_{b} & m & \text { NOTES } \\ 1 & 0 & .101 & 0 & 40^{*} & 0 & 40 & .5 & 0 & 0 & 1600 & 0 & * \\ 2 & 0 & .121 & 0 & 40 & 0 & 40 & .5 & 0 & 0 & 800 & 0 & \\ 3 & 3 & .101 & 5 & 120 & 0 & 120 & .5 & .7 & .8 & 75 & .5 & \\ 4 & 0 & .121 & 0 & 500 & 0 & 500 & .8 & 0 & 0 & 1250 & 0 & \\ 5 & .2 & .121 & 20 & 35 & 0 & 35 & .3 & 0 & .8 & 35 & 0 & \text { COLLAPSIBLE MATERIAL }\end{array}$

* NOTE K(F79) > K (F93) MATERIAL 1 AND 2. THIS REPRESENTS TWO POSSIBLE EXTREMES, AND MAXIMIZES DEFLECTION IN THE F93 CASE, TRYING TO BEST APPROXIMATE FIELD CONDITIONS.

* BULK MODULUS HIGHER THAN F79 AS PART OF DELIBERATE PARAMETRIC VARIATION. BULK MODULUS IN THIS CASE AFFECTS OUTPUT BUT LITTLE. 
upper 15 feet of basin material. In this case, resulting stress and strain are the result of foundation properties and the dam only. As discused in Chapter IV, this approach does not consider subsurface inhomogeneities.

FEADAM Output, Model 79

Results given on Figure 23 show about one inch of displacement to the 'up-and' downstream directions centered 15 feet deep, nearly exactly on the recompacted foundation and basin foundation. Vertical displacement is also about an inch, centered very near the dam center at ground level. Sigma-3 stress contours show a maximum deep in the foundation directly below the dam crest. Two observations may be made.

There is an arching of contours, concave up, with depth, corresponding to the dam slope profile, with a low stress $(-0.18 \mathrm{ksf}$, tension) anomaly forming on the upstream slope, Figure 24. In the dam foundation a $-0.3 \mathrm{ksf}$ tension zone has developed near the -10 foot depth. Note that the displacement and stress patterns developed in the dry case are similar in models of various hyperbolic parameters.

\section{Interpretation}

Dry state results are established from approximately 200 or so trial runs, and the figures presented here may be somewhat conservative. One series of tests for example decreased Ko from 0.5 (commonly accepted) to 0.4 since 
FREDONIA, no soft zone in oroer to model a baseline state F79A

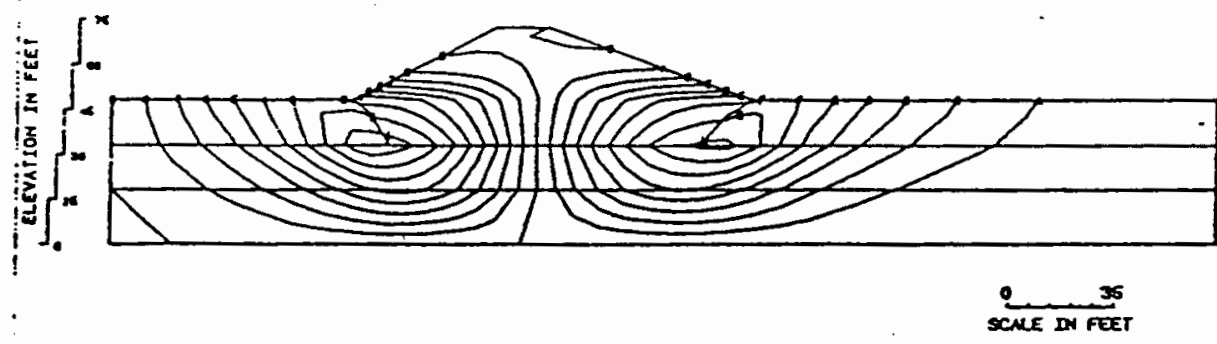

HOAIZONTAL OISPUCEMENT CONTOURS

-.00 to $7.0909006-02$ feet or .01

FREOONIA. no soft zone to madel dry state

1790

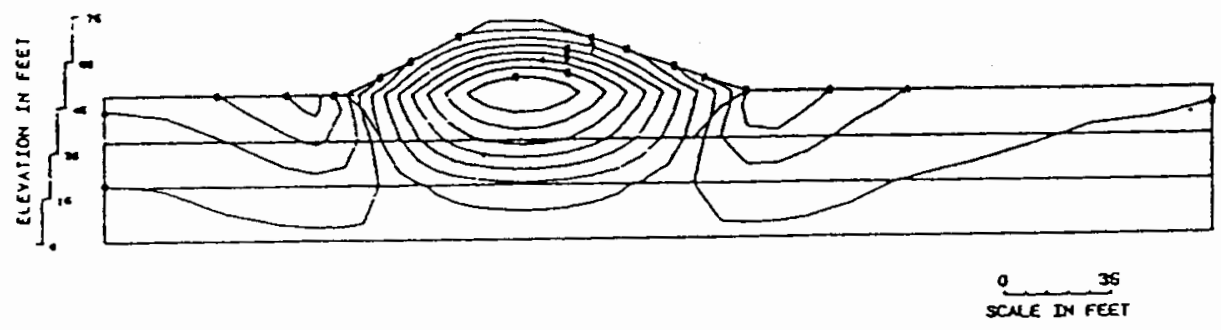

VEATICAL OISPLACEMENT CONTOUAS

-.1175 TO 4.750001E-OR FEET OY .01S

Figure 23. F79 Displacement Contours. 


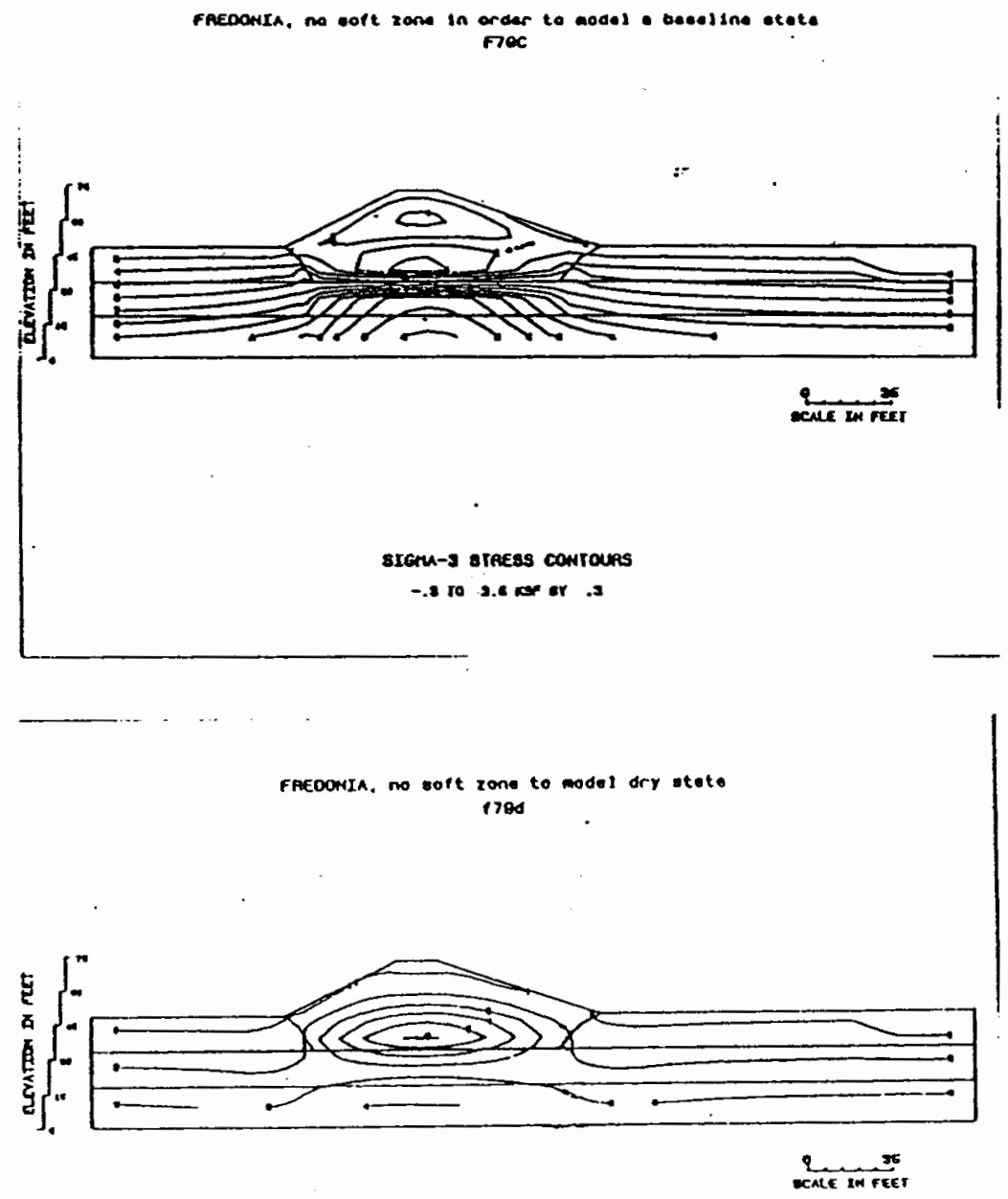

TAU MaX STRESS COHTOURS

$a$ ro $2.1 \mathrm{kr}$ or $A$

Figure 24. F79 Stress Contours. 
the loose basin soils may have a lower than normal confining stress. Lowering Ko by 0.1 almost doubles resulting stresses and strains.

\section{TRANSVERSE SECTIONS, SATURATED STATE}

FEADAM Input, Model F93

The term saturated as used here is defined as a zone of hyperbolic parameters within the FEADAM mesh which simulates a foundation section of saturated, collapsed soil. The hyperbolic properties which change are (dry to saturated) $\mathrm{K}$ from 250 to $35 \mathrm{ksf}$, C from 3.0 to $0.2 \mathrm{ksf}$, phi from 5 to 20 degrees, $\mathrm{n}$ from 0.7 to 0.0 , and unit weight from 0.101 to $0.121 \mathrm{ksf}$. The saturated state is checked at two different locations, simulating the advance of a wetted front. In the first location, the front is assumed to have moved to a point about halfway between the upstream toe and the middle of the crest. At the second location, the front is assumed to have moved to the middle of the crest.

\section{FEADAM Output, Model F93}

Maximum horizontal displacement is 0.3 inches downstream, 0.13 inches upstream. Upstream motion here is about twice the dry value. The Horizontal maximum is very close to the upstream toe in both cases. The vertical displacement between patterns shifts from the dam center to inside the upstream toe at ground level. Magnitude of 
displacement increases from -0.12 to -0.50 inches. A sigma-3 stress anomaly of $-3.6 \mathrm{ksf}$ is produced in the vicinity of the leading edge of the soft zone. The upstream slope near the toe shows a $-0.6 \mathrm{ksf}$ confining stress compared to a $+0.3 \mathrm{ksf}$ confining stress in the dry case. Figures 25 and 26 show displacement and stress plots respectively.

\section{Interpretation}

As in the dry case, displacements are conservative. It seems unlikely that a just constructed dam would settle only 0.12 inches or so. Maximum horizontal displacements are a a quarter of an inch on Figure 25, but are at least an order of magnitude greater in the field as observed by PSU resident staff and many others. The pattern of horizontal displacements shifts closer to the dam slope surface; however, most displacement is concentrated very near the upstream dam toe. This is in contrast to the actual field situation in which up to 3 distinct crack trends have been noted on both the up-and downstream slopes. FEADAM fails to define the trend.

Several observations may be made on this point. As noted above, the chronology of dam cracks is not well defined, so how much cracking occurs right after an impoundment is not certain. Then, FEADAM is modeling a post construction state not a post collapse state. An 


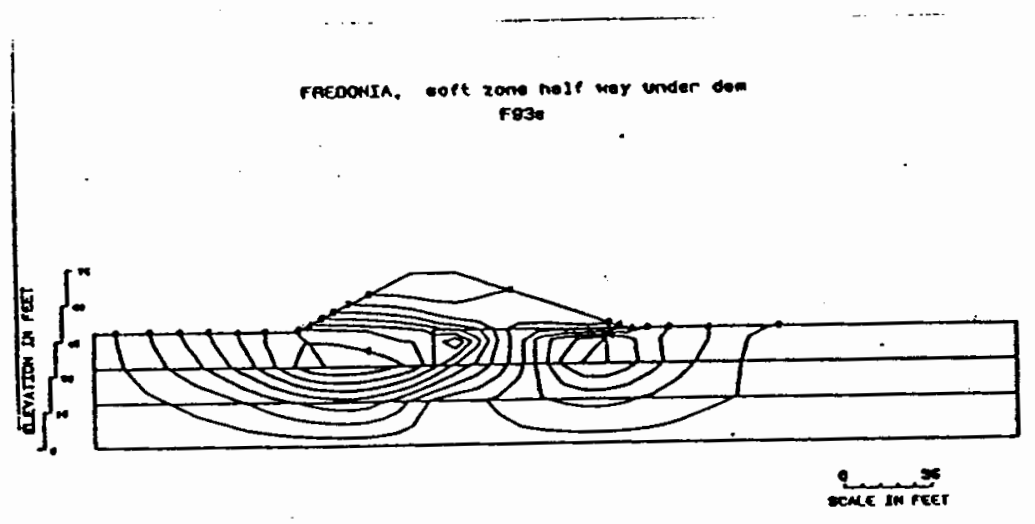

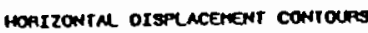
- xzat ro .132 rect or .es

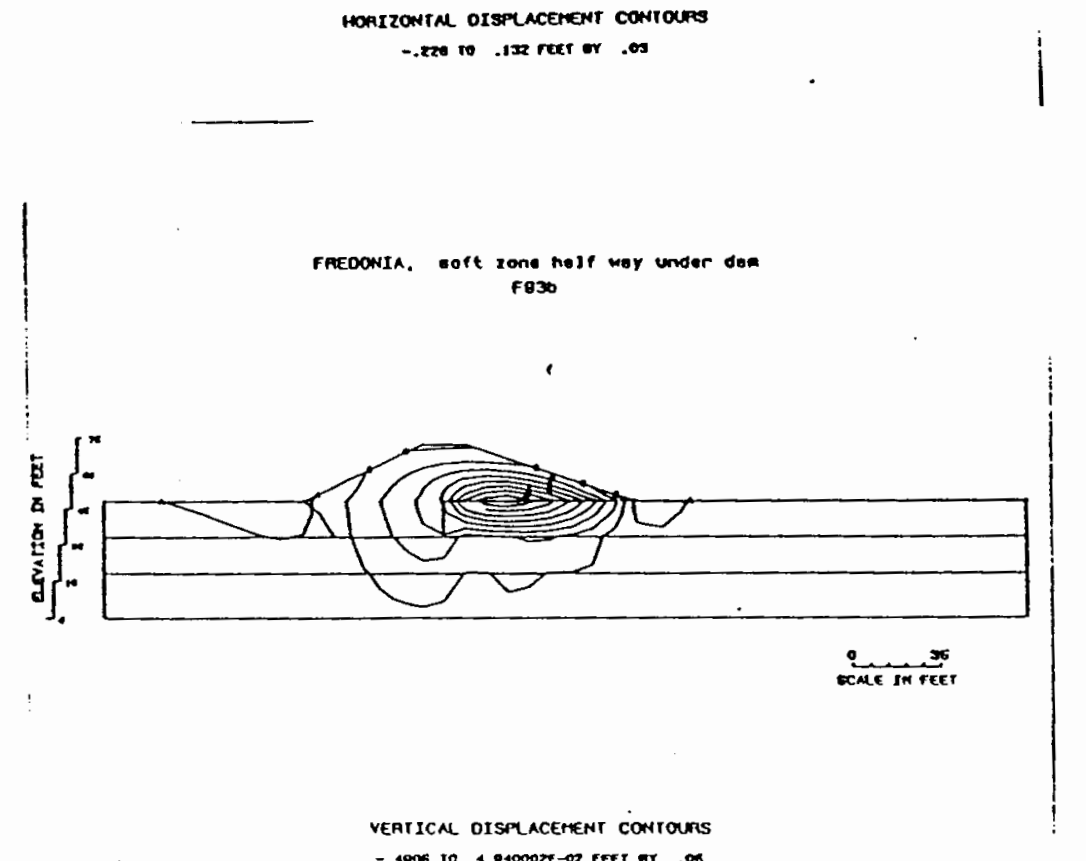

- 4006 to $4000007-00$ reet or

Figure 25. F93 Displacement Contours. 

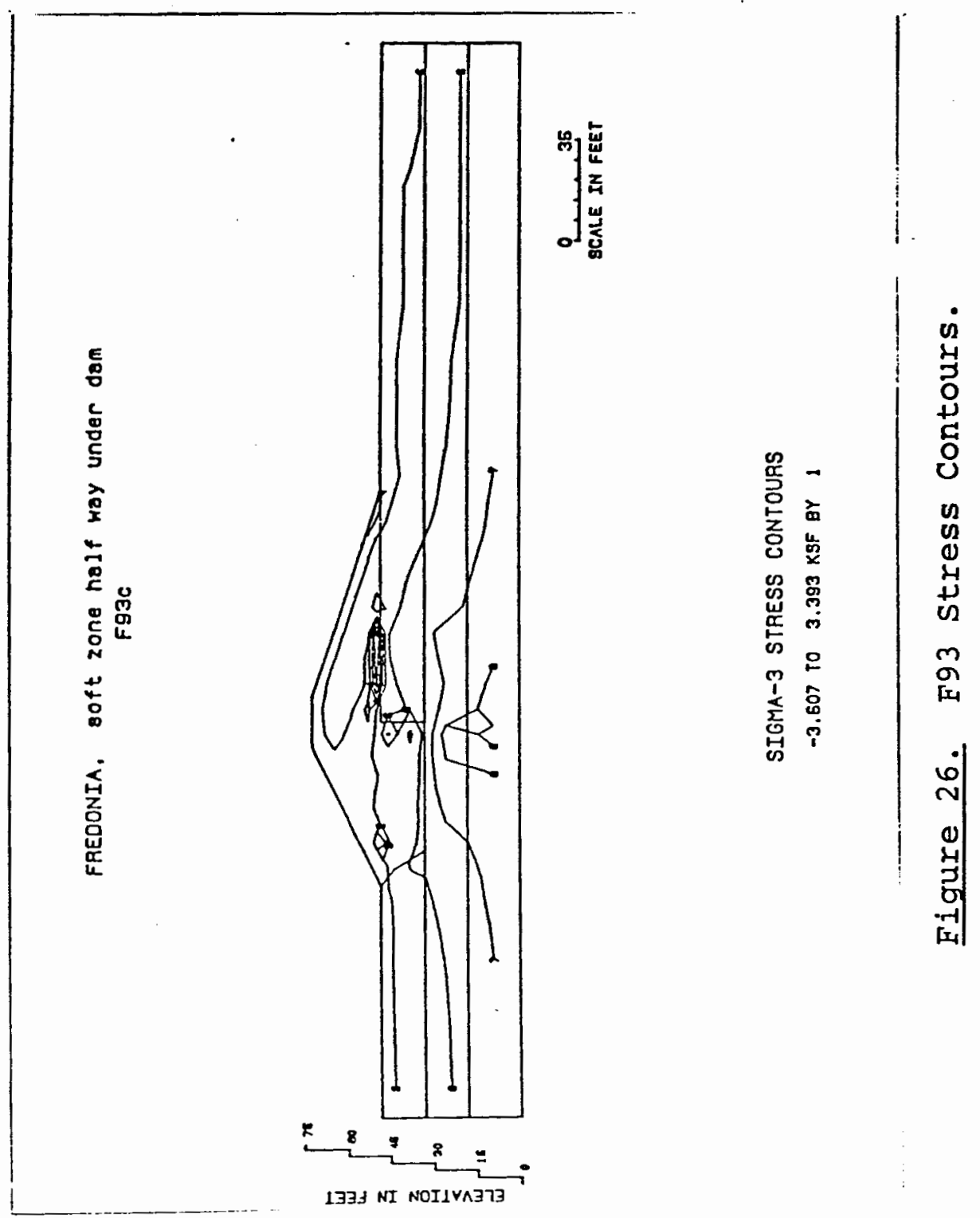
analogy might be a geophysical magnetic or seismic survey where background regional trends, or noise (the post construction state) must be removed or filtered out before the anomaly may be observed. Since FEADAM treats soil material in a hyperbolic sense, collapsible elements will not yield enough under the relatively low stresses imposed by the weight of the dam.

Thus the resulting plots, made on a scale the eye may decipher, may not show more subtle trends in the data. Several examples may be noted.

1) there is a definite anomaly created by every collapse model generated. This may be observed on Figures 25 and 26 where horizontal and vertical contours shift noticeably from the dry case.

2) the data itself (number output) may be looked at. In the case of F93, horizontal displacements may be noted to change in both sign and magnitude from the middle of the soft zone to the slope face. Thus, more information might be gotten from the saturated data if prepared differently. Saturated state stresses sigma-3, and tau-max shows an anomaly slightly above and in front of the saturated zone It appears that a tension zone forms ahead of the soft zone. 


\section{SATURATED STATE WITH A LOAD}

\section{Modeling Mechanisms}

In saturated models with loads, collapse is induced by adding a load to specified nodes. Figure 27 shows the mechanisms attempted. The first technique is the 'vector displacement model'. The vector model showed displacements well, but motion is confined to a very narrow vertical range. Next the distributed line load produced acceptable displacements. However, two problems arose. Firstly, the load had to be on the order of $30 \mathrm{ksf}$, or larger, to produce a foot of displacement. Secondly, the sigma-3 stress plots were highly distorted from the normal bell shape or bullseye anomaly described above. In the second case, results of incremental testing described in Chapter $v$ show an increase of displacement horizontally of about 1.5 times the first case, from 2 to about 4 inches. Vertical displacements increase from 3 to 6 or more inches. Sigma-3 increases from -1.0 to $2.0 \mathrm{ksf}$. The displacement pattern shifts more toward the dam centerline, while the sigma-3 low does the same, and the sigma-3 low anomaly on the upstream slope near the toe moves upslope towards the dam crest as the simulated wetted front moves towards the dam centerline.

Another mechanism tried was to compress an element from four sides, termed the 'compression element model'. This model consists of collapsing in the element from 4 
FREDOHIR. HYPERBOLIC CASE, vectar coll apse, $15 \mathrm{rt}$.

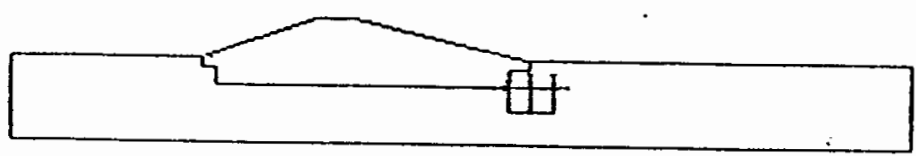

FREDOHIA, GYPERBOLIC CASE, mash element 87 fron 4 sides

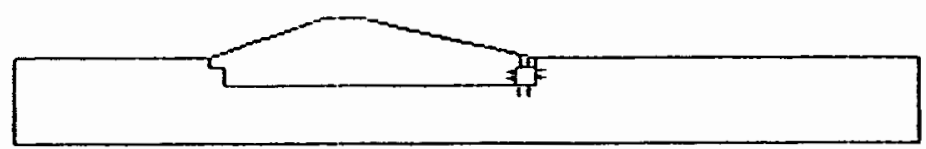

FREDONIA, HYPERBOLIC CASE load collapsible elements at the surf ace

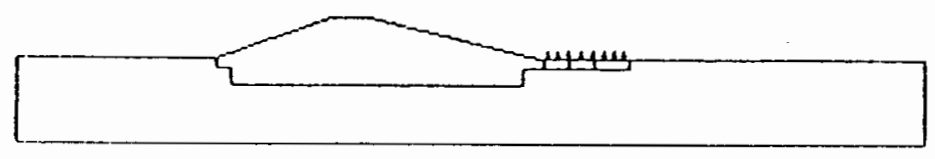

FREDONIA, HYPERBOLIC CASE collapse piston

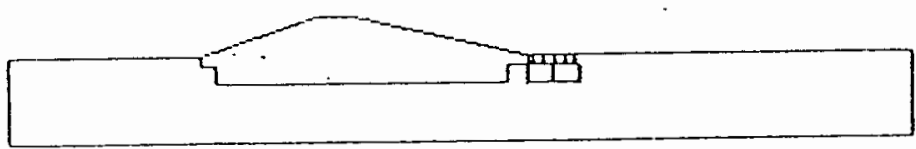

FREDOHIA, hYPERBOLIC CASE, IHCREKENTAL COLlaPSE PISION, S FT.

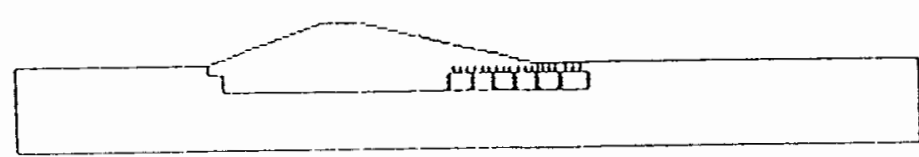

Figure 27. Collapse Model Mechanisims. 
sides much like a collapsible soil might do. This approach causes collapse, but it is difficult to calibrate where in terms of input force per unit of displacement produced. Stresses for the four-sides technique were quite distorted and not useful on the contour plots generated.

The next approach was to load elements across the upstream top surface of the model in an attempt to simulate sinkholes observed in the field. Results overall have been good, but displacements and strains tended to be constrained to the upper 10 feet or so of the model.

Then, elements with tops 5 feet below the basin surface were acted upon with a distributed load. One variation of this method was to impose a horizontal boundary constraint. The idea here was to fix nodes in a vertical section then add a distributed load across the top of the elements desired. This method creates a piston like effect on the loaded elements, termed the collapse piston. This method was introduced in an attempt to simulate the near vertical collapse observed in photographs and various field reports.

Finally, a hybrid approach was tried. The idea here was to fix nodes as above, then to lower modulus values until the desired amount of displacement was achieved by adding a distributed load in an incremental fashion across the top of 6 elements. This method has been termed the incremental collapse piston. Note that this lowering of 
the modulus was first tried with the line load method above, then calibrated to 3 or $4 \mathrm{ksf}$ using the fixed node or collapse piston technique just described. The last technique developed was a collapse piston model with incremented loads to simulate an advancing wetted front. This model was the most complex, but provided results very similar to the collapse piston above at any one point in the wetted front advance. Therefore, the most popular method to induce collapse was the 'collapse piston' technique.

As stated above, the collapse piston models the vertical displacement hydrocompaction process observed in photographs as in Figure 6. The idea is to produce approximately 1.5 feet of vertical collapse in a zone approximately 100 feet long. This zone of collapse is a two-dimensional representation of the sinkholes mapped, Figure 28. The assumption is made that the sinkhole continues under the toe of the dam.

Over 100 runs have been made using the collapse piston. Loads have varied from 1.0 to $30.0 \mathrm{ksf}$. All other hyperbolic parameters have been varied as well. Target vertical collapse is about one foot. This figure comes form an assumed $10 \%$ strain over a 5 to 10 -foot section of collapsible soil. To achieve the target collapse, modulus values were first lowered to $1.0 \mathrm{ksf}$. Experience shows 3.0 ksf to be the load that most consistently produced the 


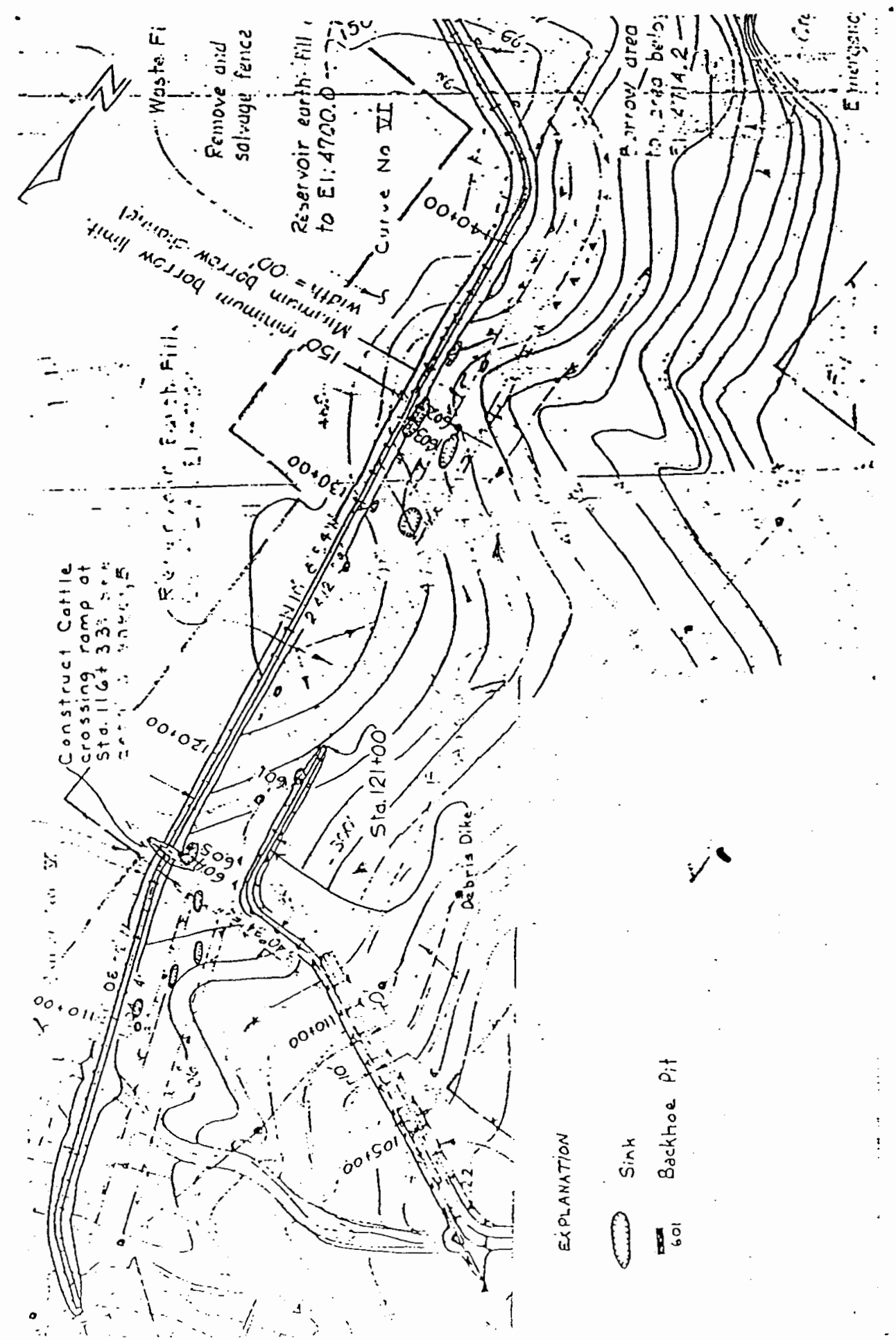

Figure 28. Fredonia Site Map. 
target range of displacement. Two examples discussed approach the target displacements given above.

\section{FEADAM Input, Model F66}

The first example is labeled F66 using the following saturated collapse zone parameters: $\mathrm{K}=\mathrm{Kur}=1.0, \mathrm{~Kb}=$ 0.10 . Other parameters equal zero.

\section{FEADAM Output, Model F66}

The resultant horizontal collapse is approximately 0.25 feet (Figure 29); vertical collapse, -1.4 feet. Sigma-3. ranges from -8.47 to $5.3 \mathrm{ksf}$ (Figure 30 ).

\section{Interpretation}

This model is the best way to overcome the limits of the hyperbolic model. Modulus values must be lowered to the $1.0 \mathrm{ksf}$ range before elements begin to respond in a collapse motion at all. The problem is that at $k=1$, elements are brought very close to failure, flags appear in the output, and the resulting interpretation may not be valid. Stresses below the $\mathrm{K}=1$ loaded elements show much higher than normal levels, an amount roughly equal to the amount of the applied $3 \mathrm{ksf}$. However this method does get nodal points to deflect downward, simulating collapse. This model may also help explain cracking. Many other. models very similar to $\mathrm{E} 66$ have been run using low modulus elements and a load. These models all show some degree of 
FAEDONLA. 1.6 FEET InOUCED COUAPSE. 3.0 KSF LONO F66AN $\mathrm{N}$

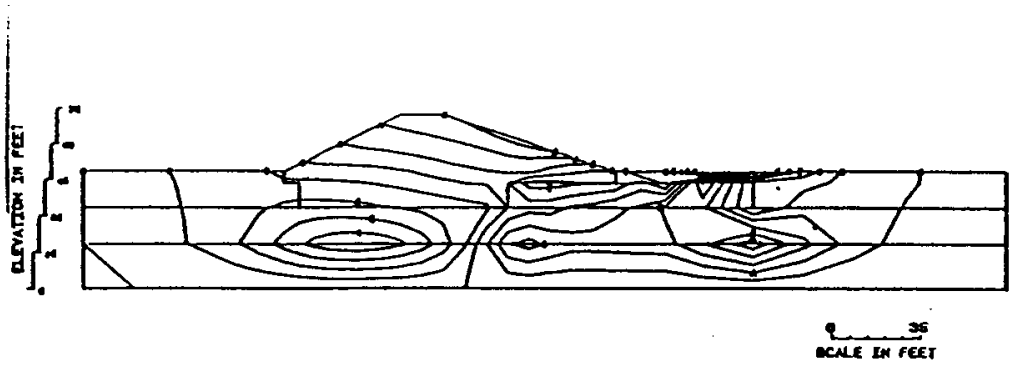

HORIZONIN OISPLACEHENT CONTOURS

-.20 to .2 rast ar .on

faEdonia, 1.6 fEet inouceo collarse, 3.0 kSF lOAO FGGB $\mu$

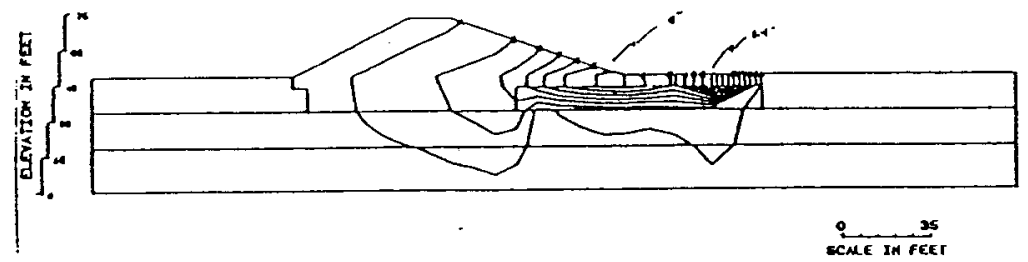

VEATICAL DISPLACEMENT CONTOUAS

-1.4 10-.0600004 reer or .16

Figure 29. F66 Displacement Contours. 


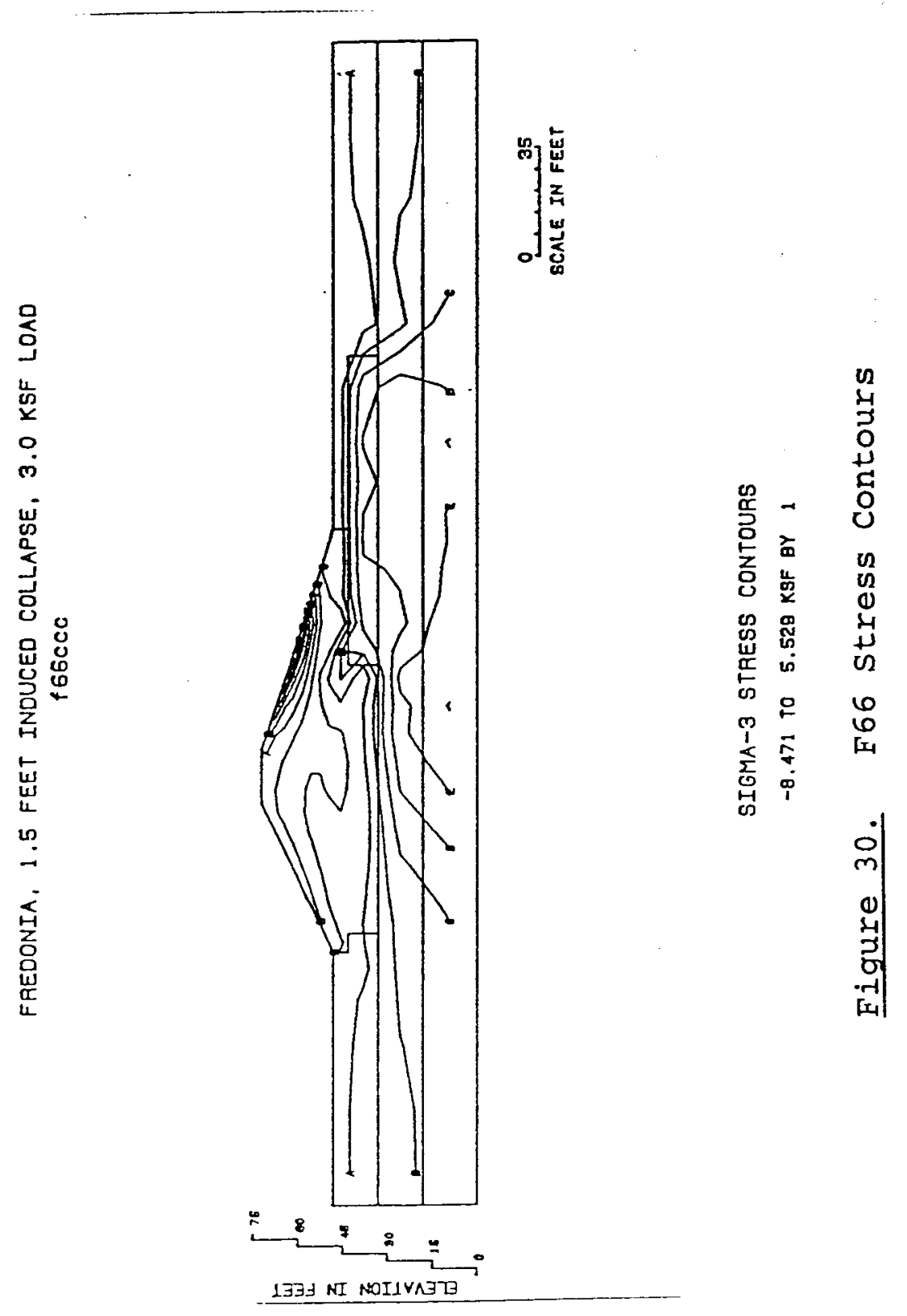


horizontal nodal displacement increasing toward the dam slope. The increase is slight, about 0.01 to 0.05 inches or so, but there appears to be a trend. At the same time, vertical nodal displacements decrease, though not always; there seems to be a trend here also. This type of nodal motion may support the unusual field measurements in which little vertical displacement is observed, but surface horizontal cracks are readily apparent.

FEADAM Input, Model F70

The model thus calibrated, the modulus values for the collapse zone are raised to $25 \mathrm{ksf}$, a value close to the 35 ksf obtained from pressuremeter test data.

\section{FEADAM Output, Model F70}

This example labeled F70 shows horizontal

displacements of approximately 0.20 feet, vertical displacements of -0.85 feet (Figure 31), and sigma-3 stress values range from -7.0 to $5.80 \mathrm{ksf}$ (Figure 32 ). Maximum shear stress values range from 0.1 to $4.9 \mathrm{ksf}$ to (Figure 32). Observations may be made with respect to the differences between the loaded and non-loaded results.

The loaded section produces displacements on the order of five times the unloaded section for the one ksf modulus value section. For the $25 \mathrm{ksf}$ to $35 \mathrm{ksf}$ modulus value sections tested displacements, a $3 \mathrm{ksf}$ load increases horizontal and vertical displacements about three times the 


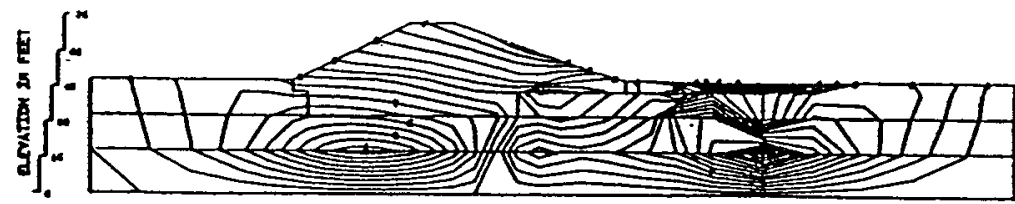

$\underset{\text { eCuE IN fEer }}{36}$

HOAIzONTAL OISPLACEnENT CONTOUPS

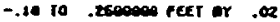

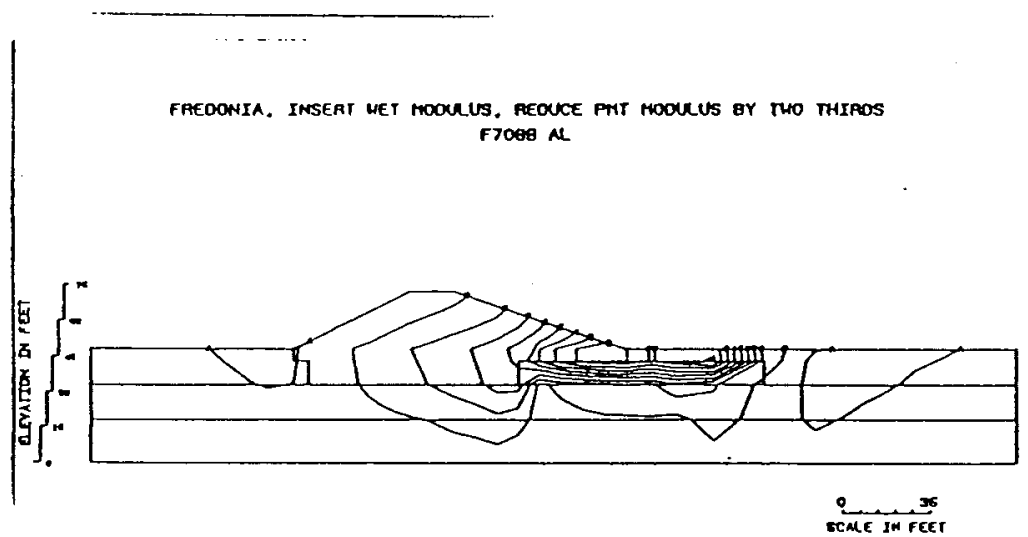

VERTICAL DISPLACEMENT CONTOUAS

- ob ro 5 -00000se-02 reet ar .I

Figure 31. F70 Displacement Contours. 


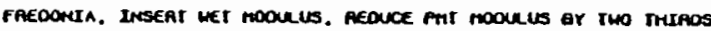
e 7oce

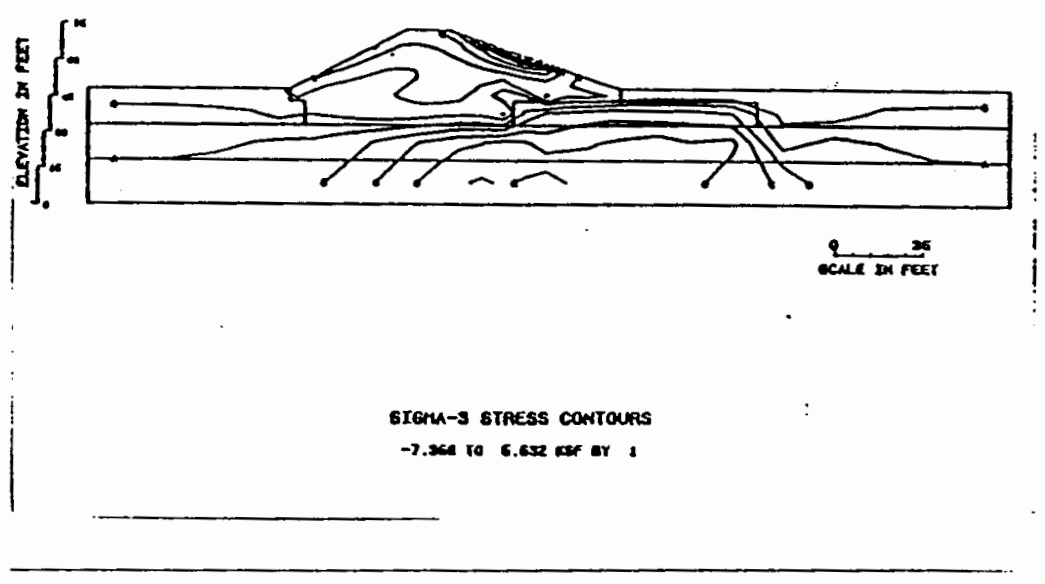

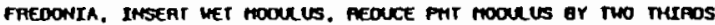
plodd

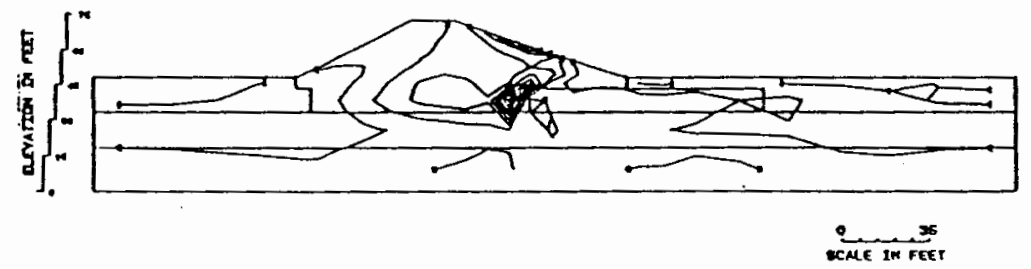

TAU-MAK SIRESS CONTONAS

.1 ro 1.0 rese or .te

Figure 32. F70 Stress Contours. 
unloaded displacements. Stresses increase slightly less than 3 to 1 , loaded compared to unloaded.

There is a distinct negative sigma-3 stress anomaly that developed on the upstream dam slope face about halfway upslope. The amount of negative stress varies with load and soil properties. The anomaly is $6.4 \mathrm{ksf}$ for $\mathrm{K}=1$ and 7.4 for $K=25 \mathrm{ksf}$. Tau-max contours show a similar anomaly on the dam slope. Note the bell-shaped pattern of stresses is shifted from beneath the dam center to beneath the loaded zone.

One other feature to note on Figure 32 is how the vertical collapse in the loaded section is concentrated in the area of the distributed load. This is in contrast to the dry and saturated non-loaded cases.

\section{Interpretation}

In the dry case, maximum vertical displacement is near the center of the dam. Stresses also tend to follow a pattern or centered tendency. When a lowered modulus, modified parameter section representing a saturated section is added, the pattern of post construction stress and displacement shifts to center more closely on the saturated zone itself, as described above. When loaded, the displacement contours tend to bunch together in the vicinity of the soft zone. This effect has not been subtracted out from the dry case background displacements at this time. The FEADAM code does not allow for anomaly 
definition in this way. The user is left with two distinct post construction cases from which to assume the correct state of displacement and stress caused by collapse. The load sequence is added after construction. However, for the load to be effective within the lower ranges ( 1 to 4 ksf), a saturated unit modulus needs to be in place. Thus, the load induced collapse is useful to determine magnitude and location of post collapse displacements and stresses. It must be realized that the locations and magnitudes are relative to a base state 'which, in the FEADAM code, is after the last construction increment. Note that displacements after load tend to concentrate in the soft zone, while stresses do the same. Stresses may show an anomaly either just above the zone of loaded soft material, and/or show an anomaly on the upstream slope itself. Displacements here have been limited to about 1.0 feet, with resulting sigma-3 stress in the range of -5.0 to $+5.0 \mathrm{ksf}$ and tau-max stress from 0.10 to $5.0 \mathrm{ksf}$ over many cases run. It appears that the downstream slope and dam are less affected moving away from the zone of collapse and the upstream dam face as described above, considering a zone of soft material projected about one quarter of the way under the upstream slope of the structure. 


\section{LONGITUDINAL SECTIONS}

\section{Longitudinal Meshes}

The longitudinal mesh reported for Fredonia is 300 feet long and ties into the center of the crest. Other longer meshes (2000 feet) were tried, but tended to take a very long time to compute, if they computed at all. The idea behind this mesh is to study transverse cracking indications through the center of the dam, which would be potentially catastrophic if a full impoundment arrives. Meshes for the longitudinal direction have been developed along the side slopes but not used here. As already noted, longitudinal lines suffer from geometric effects. It is not possible to model the three-dimensional nature of a dam in the longitudinal dimension using a two-dimensional line. The only true representation of the longitudinal section is the section running from dam crest edge to dam crest edge. It is not possible to model side slopes. One attempt to model slope change in the longitudinal direction has been made by decreasing element stiffness from the dam base up to a minimum stiffness at the crest. A soft collapse zone 50 feet wide has been placed in the top 15 feet of mesh foundation elements. An actual impoundment would probably be much wider to flood to a foot or more deep, given the generally gently dipping topography in the basin behind the dam. However, the aspect ratio ( 3 to 1 ) of the finite element mesh and height of basin and dam restrict mesh size 
to the dimensions above. So, a 50-foot wide soft zone has been used.

LONGITUDINAI SECTIONS, DRY STATE

\section{FEADAM Input, Model FL5}

Hyperbolic parameters for the longitudinal direction case are the same as the transverse direction. As stated the mesh is 300 feet long.

FEADAM Output, Model FL5

Horizontal displacement in the longitudinal direction is zero. The transverse section, using exactly the same input material hyperbolic parameters, shows one inch of horizontal displacement. Vertical displacement in the dry state longitudinal direction is 0.044 feet compared to 0.098 feet in the transverse direction. Sigma-3 ranges from 0.145 to $4.94 \mathrm{ksf}$ longitudinal compared to -0.3 to 3.6 ksf transverse. tau-max ranges from 0.1 to $1.1 \mathrm{ksf}$ longitudinal compared to 0.1 to $2.1 \mathrm{ksf}$ transverse.

\section{Interpretation}

The differences noted above are not directly explained since the geometric effect on the longitudinal section is not well defined at this time. It appears that horizontal displacement, vertical displacement and tau-max are highest in the transverse section model. Sigma-3 however, is lower in the transverse section with no tensional stress at all 
developed in the longitudinal section.

The longitudinal section has been scaled with

increasingly lower modulus values with height. Layer eight has a modulus of 100 compared to 500 at the base. Layer one of dam elements is 135 feet long at the base. Layer eight of dam elements is 30 feet long. The ratios are then $5: 1$ and $4.5: 1$. These results would seem to indicate a low or no tendency toward transverse cracking. However, this relationship is experimental at this point, and results should be viewed with caution.

\section{LONGITUDINAL SECTIONS, SATURATED STATE}

\section{FEADAM Input, Model FL6}

Hyperbolic parameters are the same as the saturated transverse model. A 50 foot wide soft zone is used.

\section{FEADAM Output, Model FL6}

Horizontal displacement is at a maximum -0.07 to +0.07 feet. Maximum horizontal displacement is symmetrical about the center of the soft zone with two lobes of maximum motion as seen on Figure 33. This line shows that one tenth of an inch or less displacement occurs in the embankment above the foundation. Vertical displacement is at a -0.37 foot maximum at the soft zone/dam interface on Figure 33. Vertical displacement is also symmetrical about the soft zone center. Note that essentially zero vertical displacement may be observed at the dam crest and is very 


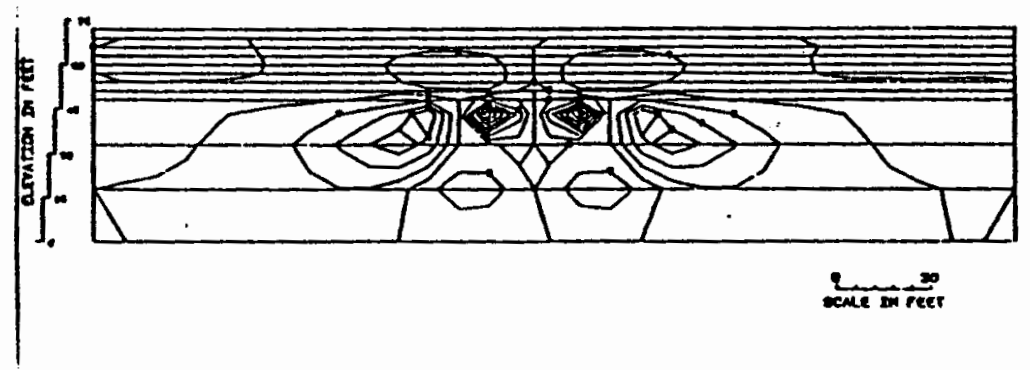

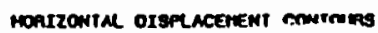

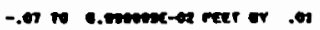

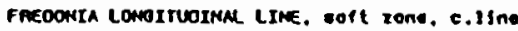
ejob bl

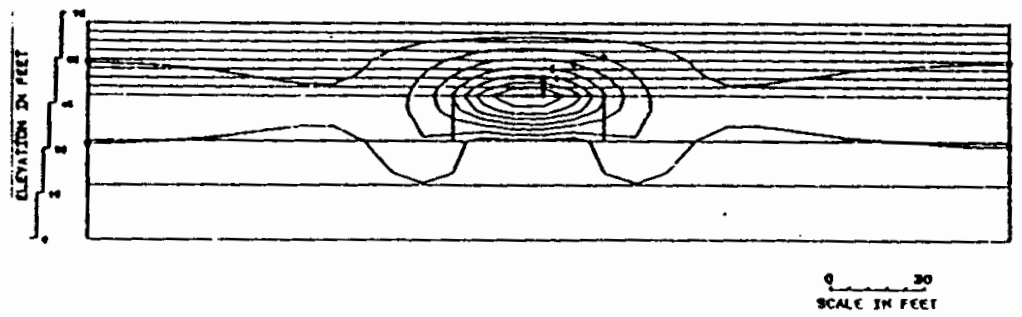

VEATICAL OISPA ACEMENT CONTOUAS

-.37 10 -1.00000e-02 fEet or .O6

Figure 33. FL6 Displacement Contours. 
close to zero more than 20 feet out from the soft zone. Sigma-3 stress is positive from 0.15 to $5.2 \mathrm{ksf}$ with a minimum near the top of the dam. The soft zone produces two small stress anomalies just above the soft zone. However, no negative values are produced. This is in contrast quantitatively to the transverse mesh where $-1.0 \mathrm{ksf}$ sigma-3 stress is produced.

\section{Interpretation}

Qualitatively, the transverse line shows low stress just above the saturated zone. This disagreement between sigma-3 values is also true of tau-max values and is probably related to the geometric problem described above. Note that the transverse line used for comparison has a soft zone only one quarter of the way under the dam. A soft zone fully to the center would only magnify the numerical stress disparity above. In this case longitudinal lines should be used with caution. Another problem pointed out by the longitudinal lines is the symmetrical nature of stress and displacements. This suggests that the location of various soft zones along the length of the dam may affect the dam about the soft zone centers out to an undetermined distance. This shows one serious drawback of the longitudinal line, assumed homogeneity i.e. a layer cake state, where in the field this is not so. If the field condition were of a layer cake geology and the dams were of a layer cake build, then 
the whole dam might be expected to strain with the collapsing foundation in equal amounts. As discussed in Chapter IV this is not the case in reality.

\section{MISCELLANEOUS MECHANISMS}

\section{Piping Experiment}

In the piping experiment an attempt has been made to simulate observed pipes in the Fredonia Dam (Figure 34). These pipes form by erosion and a few by animals burrowing. Pipes vary from a few inches to a few feet in diameter. The pipes at Fredonia have been measured by the author to 8 feet deep in the basin. The pipes probably pose the greatest risk to dam safety if they grow to a width greater than three feet or so.

In the piping experiment, the idea is to evacuate a cavity much like a large air void found in the field. This evacuation is simulated by lowering the hyperbolic parameters to those as close to air as possible in a set of elements of various heights. Results show that pipes do cause displacement of dam nodes. Figure 35 shows displacements from a pipe 1.5 feet high and 30 feet long under the upstream toe of the dam. Figure 36 shows stress caused by the pipe. Displacements are on the order of four to one vertical with maximum vertical displacement over twice that for a saturated layer only. Sigma-3 stress is not changed much from the normal saturated state. So, a 

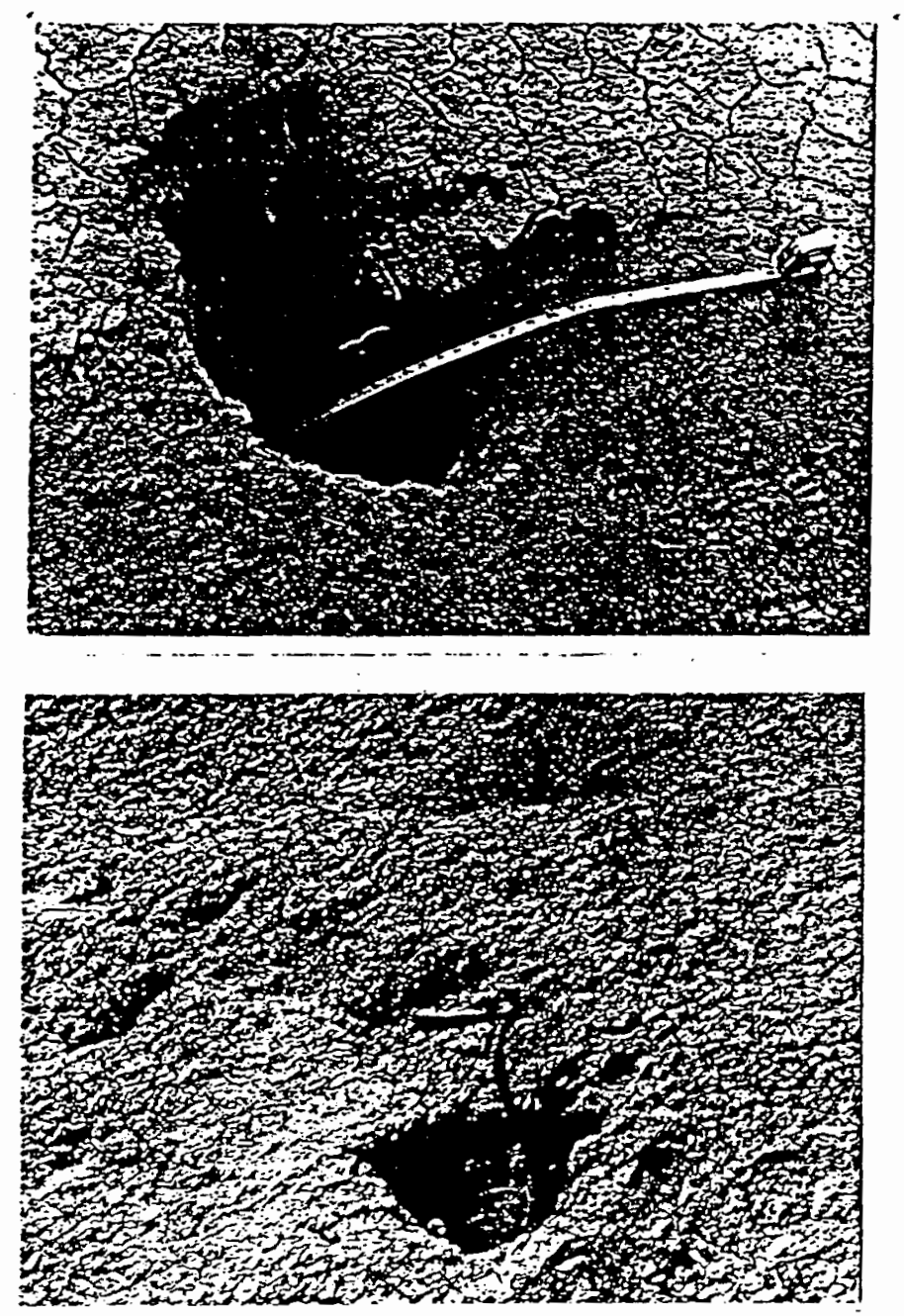

Figure 34. Solution Pipes at Fredonia. 
freconila. pipino exper imant

120.

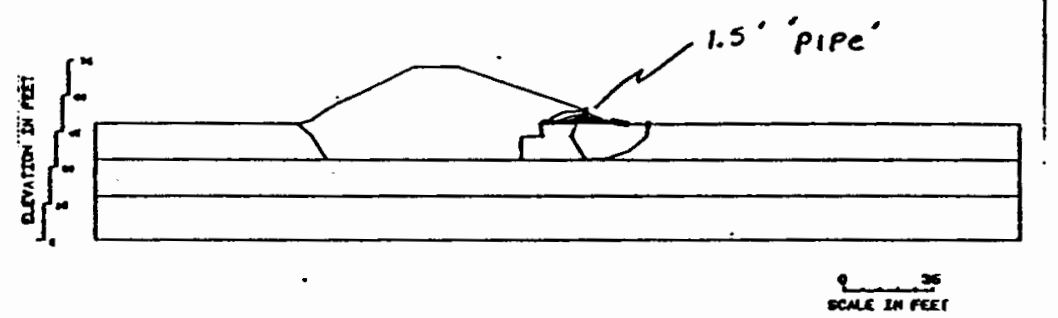

HORZZONIM OISPLACEENT CONTOUAS

-.1400 to 1.ecoj feet or .x6

fredowia. ploino experieant

1200

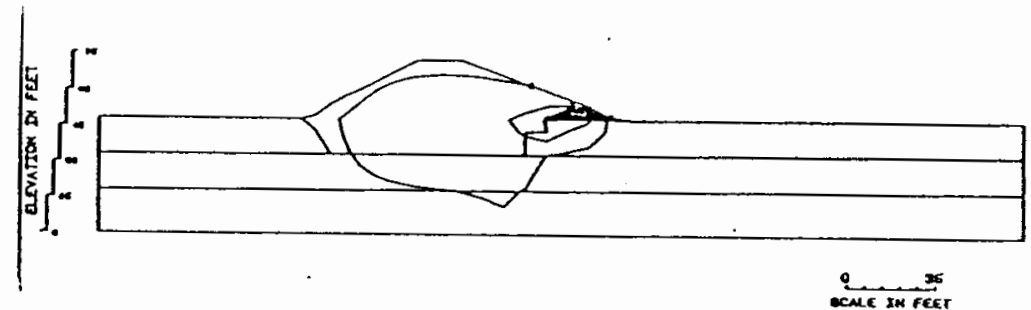

VEATICAL OISPLACERENT CONTOUAS

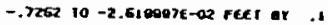

Figure 35. Piping Experiment Displacement Contours. 

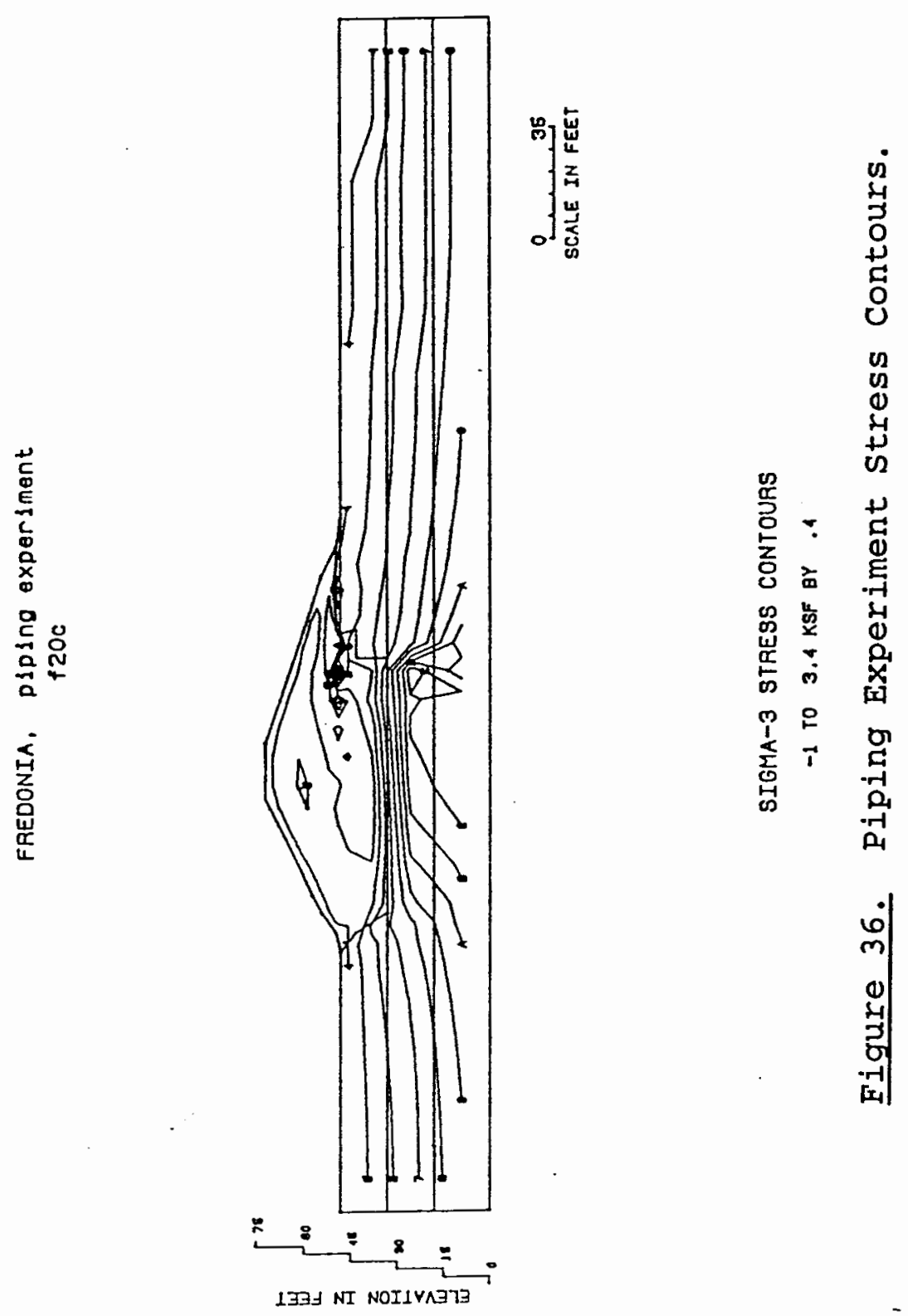
pipe that causes displacements near the pipe itself does not seem to affect the rest of the dam much, due to the elastic dam material composition in the model. This relation holds until the pipes reach about three feet. At this point, horizontal displacement becomes over twice the maximum vertical displacement in the area of the pipe. Still, at this point the displacement is concentrated mainly to within the area of the pipe.

The piping experiment may also be used to verify the block rotation mechanism introduced in Chapter II, since the area of very low modulus is: 1) 1.5 feet thick, similar to collapse sinkholes mentioned in Chapter II and 2) the 1.5 foot zone may be placed at desired discrete locations under the dam, simulating the location of a saturated front under the dam. Input parameters are the same as model F79 with the addition of the $K=1$ zone as in model F66.

Figure 37 shows hand-drawn displacement vectors as a result of the piping experiment. Note the reverse in displacement vectors vertically along a possible crack trace. Note also the distortion of displacements where nodes near the dam surface do not move as much as those deeper in the dam. This raises questions of model accuracy. 


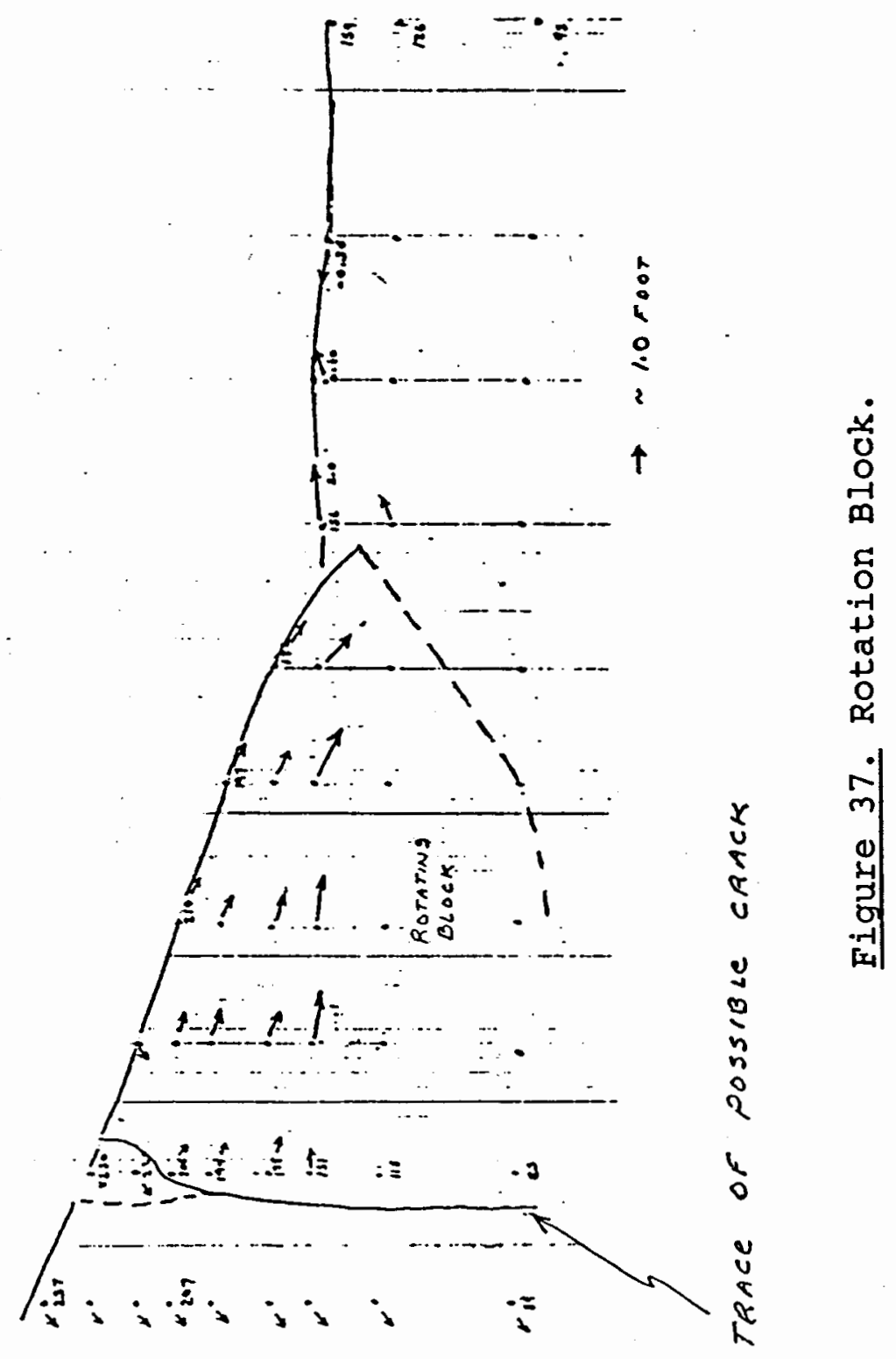




\section{Depth Experiment}

In the depth experiment the thickness of the saturated unit is varied to a maximum of 25 feet thick. The reason for doing this is to simulate a totally saturated condition, given the fact that collapse prone soils may extend to 25 feet in some cases.

The results of the depth experiment show an increase in vertical displacement from -0.40 feet to -0.85 feet using a 15-foot and 25-foot soft zone, respectively. This is a somewhat greater than linear increase of displacement with depth of soft zone. Sigma-3 increases more though. Minimum sigma-3 becomes $-5.6 \mathrm{ksf}$ with a 25 -foot soft zone compared to $2.0 \mathrm{ksf}$ for a 15 -foot soft zone. In the 25foot zone, negative sigma-3 contours begin to move up the upslope dam face (Figure 38). This movement is similar to after-load contours on the dam face upslope.

\section{STABILITY SUMMARY}

\section{$\underline{\text { Dam Safety }}$}

It appears from all slope stability and FEADAM explorations, calculations, and analyses that the cracking dam problem may be more of a nuisance than a danger at this point. However, a full impoundment behind any dam reported here may well lead to a piping problem of unknown magnitude. It is difficult to predict dam motion with any degree of accuracy using the hyperbolic model, yet some 
110
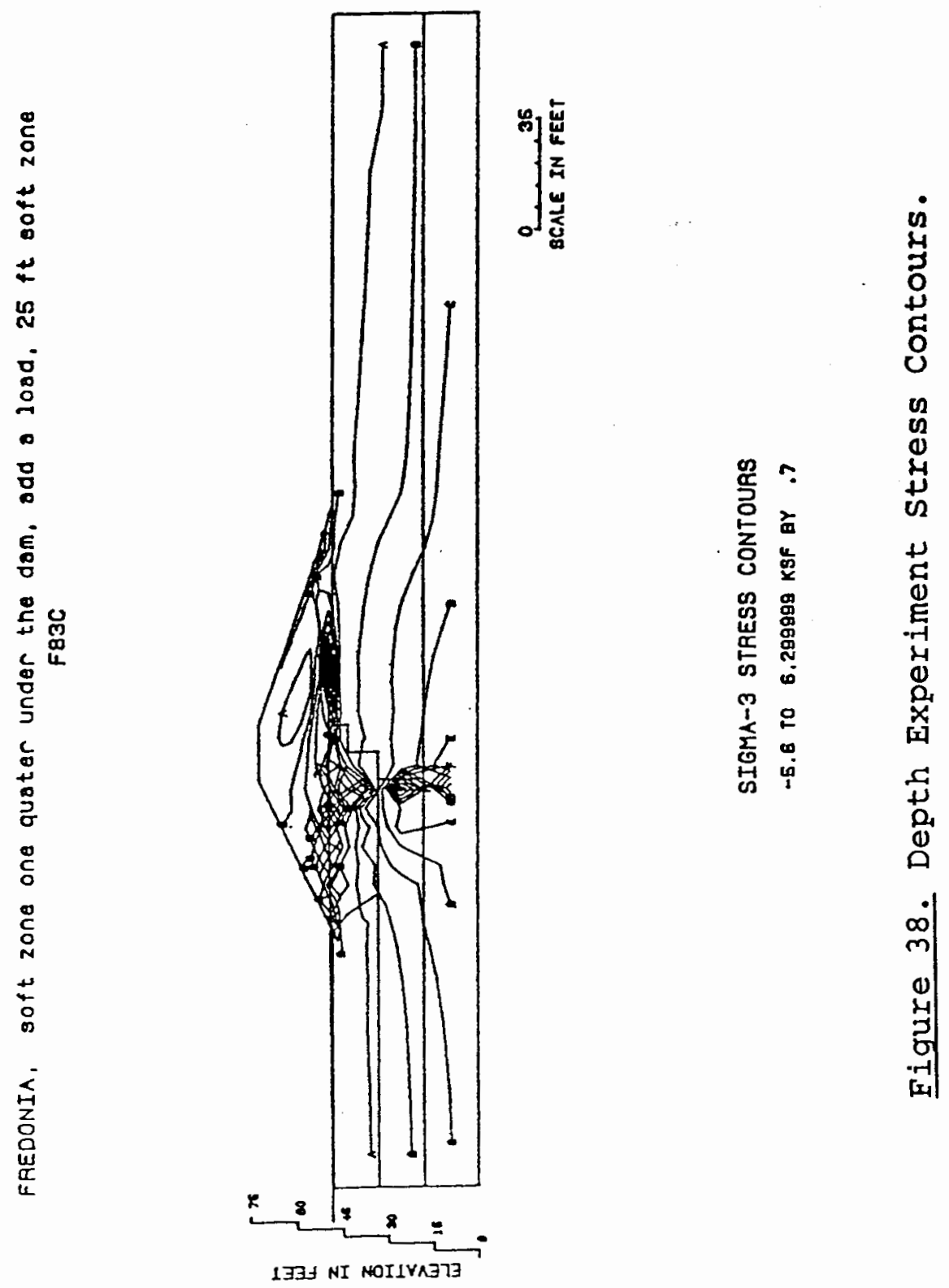
useful conclusions and relative magnitudes may be reported. The magnitude of displacements resulting from model F93 is expected to somewhat match those seen in the field. This is not the case. FEADAM underpredicts displacements by a foot or more. However, there is a noticeable difference between dry and saturated cases. If a ratio between wet/dry or model F93/F79 displacements are taken, the horizontal result is $2.85: 1$, and the vertical ratio is 4.15:1. This ratio is due to post construction settlement. In this case, post construction settlement would need to be 6 inches or so to bring horizontal displacements in line with the 12 to 18 inch wide cracks observed in the field. The sigma-3 ratio is $12: 1$, indicating a great increase in tensional stress after simulated saturation. The F70/F66 after load ratios are much lower at $1.6: 1$, both horizontal and vertical displacement. This may be due in part to the 10 foot thick F66 and F70 saturated units vs. the 15 foot thick F93 satrated unit. F70/F66 before load ratios are very nearly 1:1, displacement and stress. The main difference between $F 70$ and $F 66$ is that with F70 $K=25$, and with $\mathrm{F} 66 \mathrm{~K}=1.0$. However, the $\mathrm{K}=1.0$ section when loaded has the greatest nodal displacements, and highest stresses as a result. So, for absolute magnitude of displacements and stresses, it appears that loading an element of low stiffness produces those most like those found in the field. Model F79 shows only a few inches of displacement 
after original construction that compares fairly well with other dams on non collapsing soils. This comparison is used only in the dry state. Saturated state displacement may be double to four times the dry motions. However, it appears that given a dam stiffness of that measured by pressuremeter ( 4 to $600 \mathrm{ksf}$ ), the dams are able to stand up to foundation collapse with the main problem being a series of longitudinal cracks formed as the wetted front passes under the structure. This conclusion is reached after subjecting the dam to radical parametric studies. This type of study was found to be necessary since simply changing material property values in the FEADAM code produces barely noticeable results. The results of such alterations suggest over and over that as far as the FEADAM code is concerned, dams of the stiffness given will hold together well under extreme stresses. There are several numerical problems with this assessment.

FEADAM will not fail elements. So, any failure must be interpreted by the user. Secondly, the dams are already cracked. FEADAM is not able to show cracks at all. As discussed above, crack pattern indications are readily apparent but at a much lower magnitude than those observed in the field.

Given the above, the final impression left by FEADAM modeling at Fredonia is that producing an artificial hole in the mesh, or forcing nodal displacement equal to that 
observed in the field, causes mostly local distress in the dam, at a locale close to the leading edge of the wetted front. Catastrophic failure is not expected for a shallow impoundment. However, many varied pipes and sinkholes have been observed in the field, both on and off the dam. The most important factor here is probably the rate of pipe development. It seems that an impoundment of more than a few feet would be necessary to provide the driving head to enlarge pipes and fissures. Up to that point, evidence presented here suggests that the Fredonia dam is probably going to continue cracking in proportion to the impoundment, that the structure is probably serviceable in the short term, (4-5 years), and that four courses of action are suggested.

First the cracking phenomena needs to be documented, onsite, when it happens. Secondly, a better model like the SAMS model being developed at PSU needs to be employed at that site using input data of choice. Thirdly, a remedial course of action should be undertaken that works both with alluvial processes and dam repair. Fourth, a plan might be considered that utilizes small berms to reduce flow and impoundments in the case of relatively small events, saving the dam as it were for the larger 50 and 100 year events. This would help keep the dam from cracking after small events, giving more strength to withstand a larger event. After a large event, the dam 
might be repaired as has been done at the Greens Lake Dam, the next dam covered in this work. 
CHAPTER VII

FEADAM MODELING OF THE GREENS LAKE DAM \#3

\section{DAM STRUCTURE AND LOCAL GEOLOGY}

\section{Greens Lake Structure}

The Greens Lake Dam No. 3, located near Cedar City, Utah, is made of compacted basin fill material, similar to the Fredonia Dam. However, the Greens Lake structure is zoned, with a generally finer grained core and coarser shell. Core materials consist of clayey sandy silts and silty clays with some gravel compacted to at least $95 \%$ relative compaction, standard Proctor test procedure (Earth Science Associates, 1982). The shell is made of compacted soil, gravel and cobble with relative densities specified from $98 \%$ to $106 \%$. However, in situ density tests reveal compactions of $79 \%$ to $95 \%$; an upstream and downstream shell average of $86 \%$. Side slopes are 3:1 upstream, 2:1 downstream with core slopes of 1:0.5 upstream and downstream. The 5-foot deep cutoff trench side slope is specified inward at 1:1. The basin itself slopes at about 3 degrees. The dam is curved downslope and is nearly 0.40 miles long and 17.5 feet high (Figure 39). 


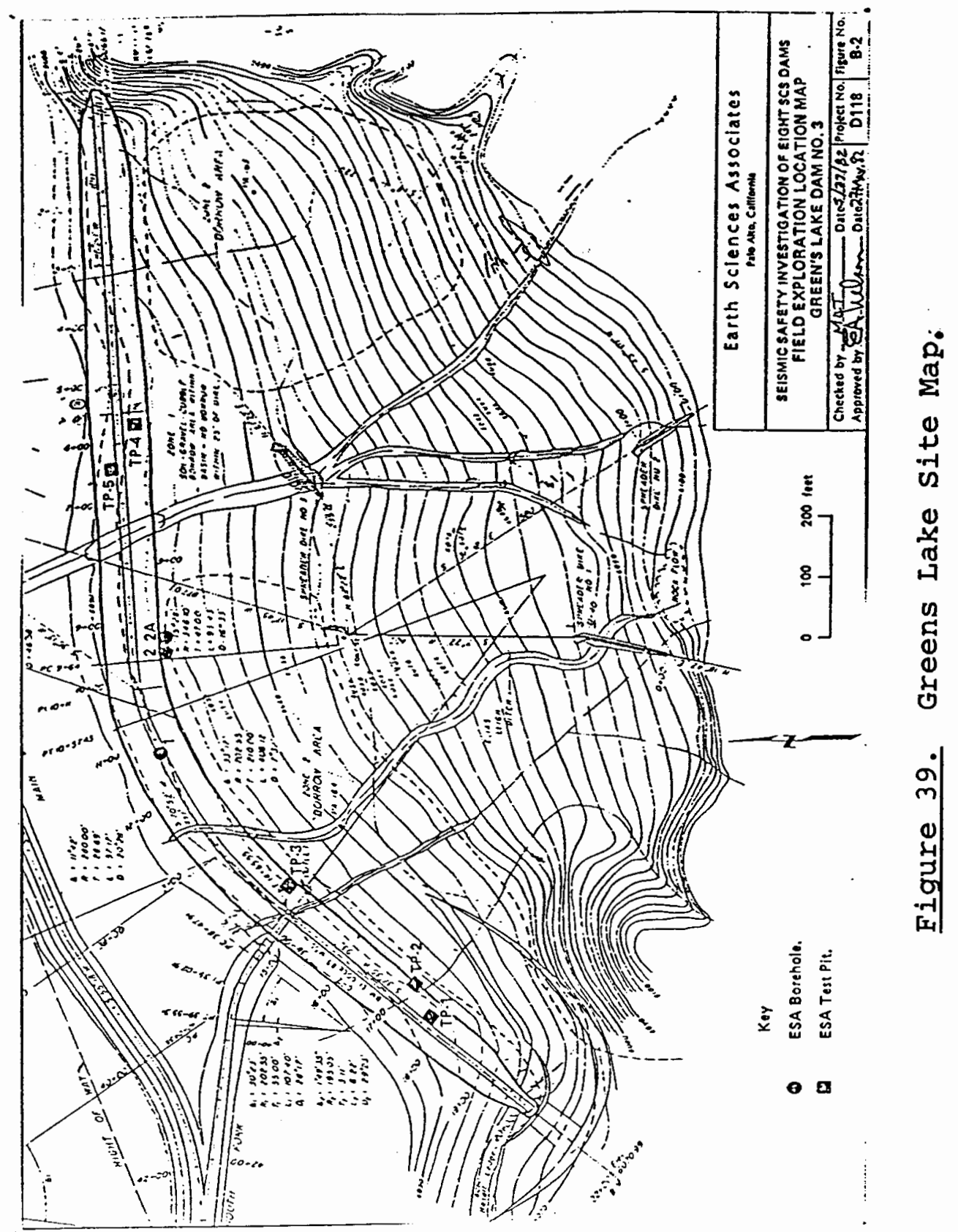


The Greens Lake Dam is also built on a shallow dipping alluvial apron filling in a shallow basin. Foundation materials consist of stratified sands, silts, clays and gravels. Much gypsum is reported (Earth Science Associates, 1982) with cobbles and boulders present. Blow counts in finer grained material are 15 to 30 blows per foot.

\section{Collapse History}

Subsidence of the circular depression type described in Chapter II had been first noticed after a 1963 debris flow. Total vertical displacement was on the order of two feet. The dam did not crack at this time, though the subsidence was described as "adjacent to the dam" (Earth Science Associates, 1982). Then, in 1967 the dam impounded water (to an unspecified depth) for three months. The basin near the east end of the dam collapsed five feet plus, with the collapsed zone continuing through the dam. Cracks widened to 15 to 20 feet deep. Block rotation was observed along the dam crest. Extensive grouting was carried out. The dam was more cracked than the foundation with 465 cubic yards of soil-slurry used to fill the dam cracks and 115 cubic yards used to fill foundation cracks. 
TRANSVERSE SECTIONS, DRY STATE

\section{FEADAM Input, Mode1 GL2}

A summary of models is given in Table $V$. FEADAM hyperbolic input is given in Table VI. The Greens Lake Dam has two materials of similar properties. The cutoff trench is centered beneath the crest. The trench cuts less than 10 feet into the foundation debris material.

\section{FEADAM Output, Model GL2}

Horizontal displacement contours show two centers of horizontal maximum motion centered about three feet deep near each toe. Maximum displacement is less than 1.0 inch. Motion to the upstream is slightly greater. Vertical displacement is centered about the cutoff trench with maximum motion at about -1.0 inch. Sigma-3 contours show some small anomalies about the core. Tau-max contours show maximum shear stress at the core/shell/foundation transition. Maximum shear stress is $3.0 \mathrm{ksf}$. Tau-max contours show a maximum shear stress at the same junction as sigma- 3 contours above. Figures 40 and 41 show the displacement and stress contours, respectively.

\section{Interpretation}

Displacements on model GL2 are quite low, at no more than a few inches. These low values are probably due to the relatively stiff $k$ values of the foundation. It has 


\section{TABLE V \\ GREENS LAKE MODEL FIGURE SUMMARY}

Model Figure

$\mathrm{GI2A}, \mathrm{b} \quad 40$

G12C

GL11A,B 42

GL11C

43

G118C Not Shown
Display

Displacement Contours

Stress

Contours

Displacement Contours

Stress

Contours
Conditions

Dry State 3 layer

Foundation 2 zone dam

Dry state

Sat. zone one quarter under dam

Sat. zone one quarter under dam

Loaded section one quarter, one half under dam 
TABLE VI

GREENS LAKE HYPERBOLIC PARAMETERS

HYPERBOLIC INPUT MODEL GL2

$\begin{array}{ccccccccccccc}\text { MATERLAL } & \mathrm{c} & \gamma & \phi & \mathrm{K} & \Delta \phi & \mathrm{KUr} & \mathrm{K}_{\mathrm{o}} & \mathrm{n} & \mathrm{R}_{f} & \mathrm{~K}_{\mathrm{b}} & \mathrm{m} & \text { NOTES } \\ 1 & 0 & .121 & 0 & 120 & 0 & 120 & .5 & 0 & 0 & 2000 & 0 & \\ 2 & 0 & .111 & 0 & 160 & 0 & 160 & .5 & 0 & 0 & 1800 & 0 \\ 3 & 4.2 & .09 & 15 & 225 & 0 & 225 & .5 & .85 & .15 & 200 & 0 \\ 4 & 0 & .115 & 0 & 600 & 0 & 600 & .8 & 0 & 0 & 500 & 0 \\ 5 & 0 & .115 & 0 & 450 & 0 & 450 & .8 & 0 & 0 & 400 & 0\end{array}$

HYPERBOLIC INPUT MODEL GL11

$\begin{array}{ccccccccccccc}\text { MATERIAL } & c & \gamma & \phi & K & \Delta \phi & . K u r & K_{b} & n & R_{f} & K_{b} & m & \text { NOTES } \\ 1 & 0 & .121 & 0 & 120 & 0 & 120 & .5 & 0 & 0 & 2000 & 0 & \\ 2 & 0 & .111 & 0 & 160 & 0 & 160 & .5 & 0 & 0 & 1800 & 0 & \\ 3 & 4.2 & .090 & 15 & 225 & 0 & 225 & .5 & .85 & .15 & 200 & 0 & \\ 4 & 0 & .115 & 0 & 600 & 0 & 600 & .8 & 0 & 0 & 500 & 0 & \\ 5 & 0 & .115 & 0 & 450 & 0 & 450 & .8 & 0 & 0 & 400 & 0 & \\ 6 & 2.0 & .121 & 35 & 15 & 0 & 15 & .3 & .45 & .7 & 15 & 0 & \text { COLLAPSIBLE MATERIAL }\end{array}$




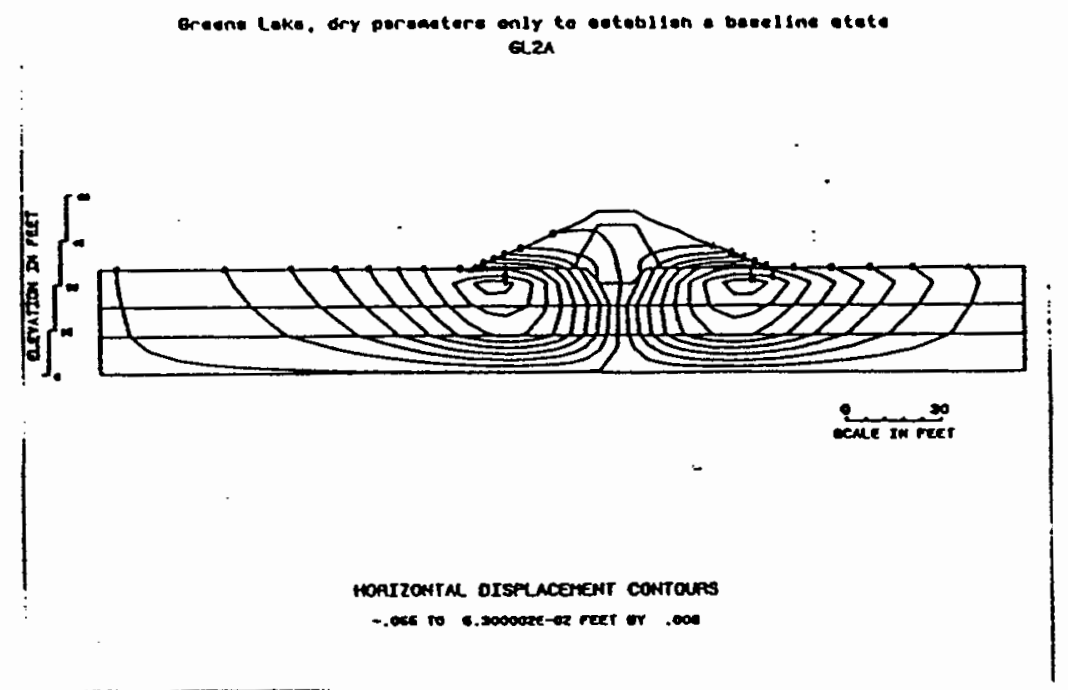

Graene Loke. dry perantere only to eatublian o beetilne etate a28

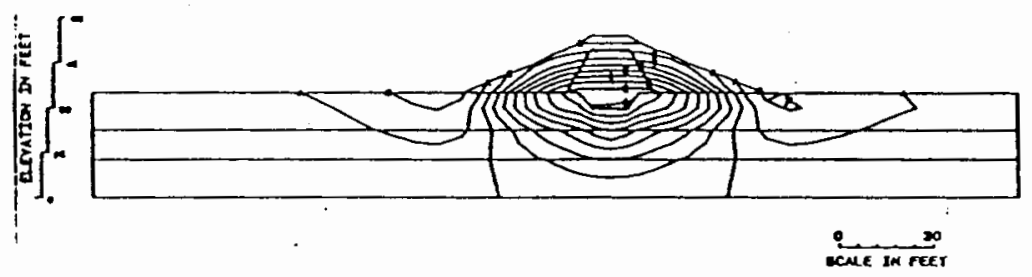

VEATICN OISPLACEMEHT CONTOURS

-.00 so $1.000000-02$ feet or .ot

Figure 40. GL2 Displacement Contours 

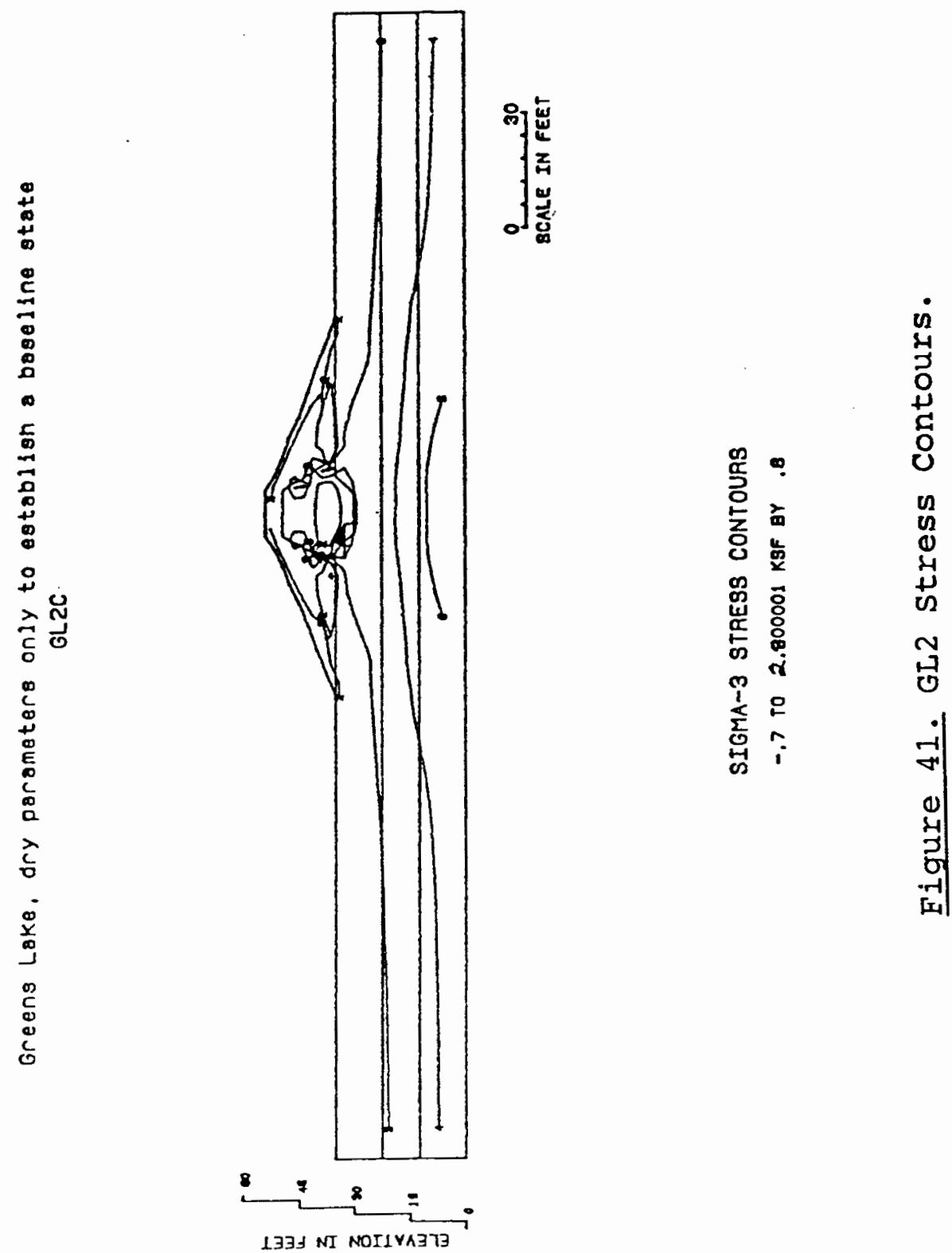
been found from experience that foundation values greater than $100 \mathrm{ksf}$ at greater than about 20 feet will cause the entire dam/foundation system to displace much less than $K$ values of $50 \mathrm{ksf}$ or so. The lowest Greens Lake foundation value is $120 \mathrm{ksf}$, and this value is on the low end of possible $K$ values assigned to the deepest layer of the Greens Lake mesh. Cohesion in the upper layer is also somewhat high at $2.0 \mathrm{ksf}$, as well as a phi angle of 35 degrees. Greens Lake displacement contours are symmetrical about the center in the horizontal plot, with the vertical displacement contours centered on the lower part of the dam core. So, though the displacement values seem low, the displacement patterns seem to be even with no anomalous features. Sigma-3 values range from $-0.7 \mathrm{ksf}$ to $3.0 \mathrm{ksf}$. The stress contours tend to be unevenly distributed in and around the core/shell interface. The reason for this is not known.

TRANSVERSE SECTIONS, SATURATED STATE

FEADAM Input, Model GL11

Saturated hyperbolic input is given in Table VI. The saturated zone is placed about one quarter of the way under the dam. The saturated Young's modulus is $15 \mathrm{ksf}$. 
FEADAM Output, Model GL11

Horizontal $=$ vertical displacement at about 2 inches. Most of the displacement is in the basin, not on the dam. Horizontal displacement contours show double the dry motion in the upstream section just below the toe at -5.0 feet. The locus of maximum displacement has not changed from the dry case. Vertical displacement is at a maximum -0.1711 feet near the leading edge of the soft zone, Figure 42 . Sigma-3 stress ranges from -0.66 to $2.8 \mathrm{ksf}$. Tau-max stress ranges from 0.1 to $1.1 \mathrm{ksf}$, Figure 43 .

\section{Interpretation}

Saturated displacements are about two inches horizontal and vertical. Maximum horizontal displacement is centered in the basin; the dam does not displace much horizontally. The vertical displacement contours shift more towards the leading edge of the saturated unit from the center of the core. Displacement is much less than the values reported above. The reason for this is probably the stiff foundation values as in the dry case. Apparently, a saturated zone itself does not cause much displacement in the dam. Sigma-3 stress of $-0.66 \mathrm{ksf}$ may also be a result of foundation stiffness great enough to lower dam displacements and reduce tensional stresses. 

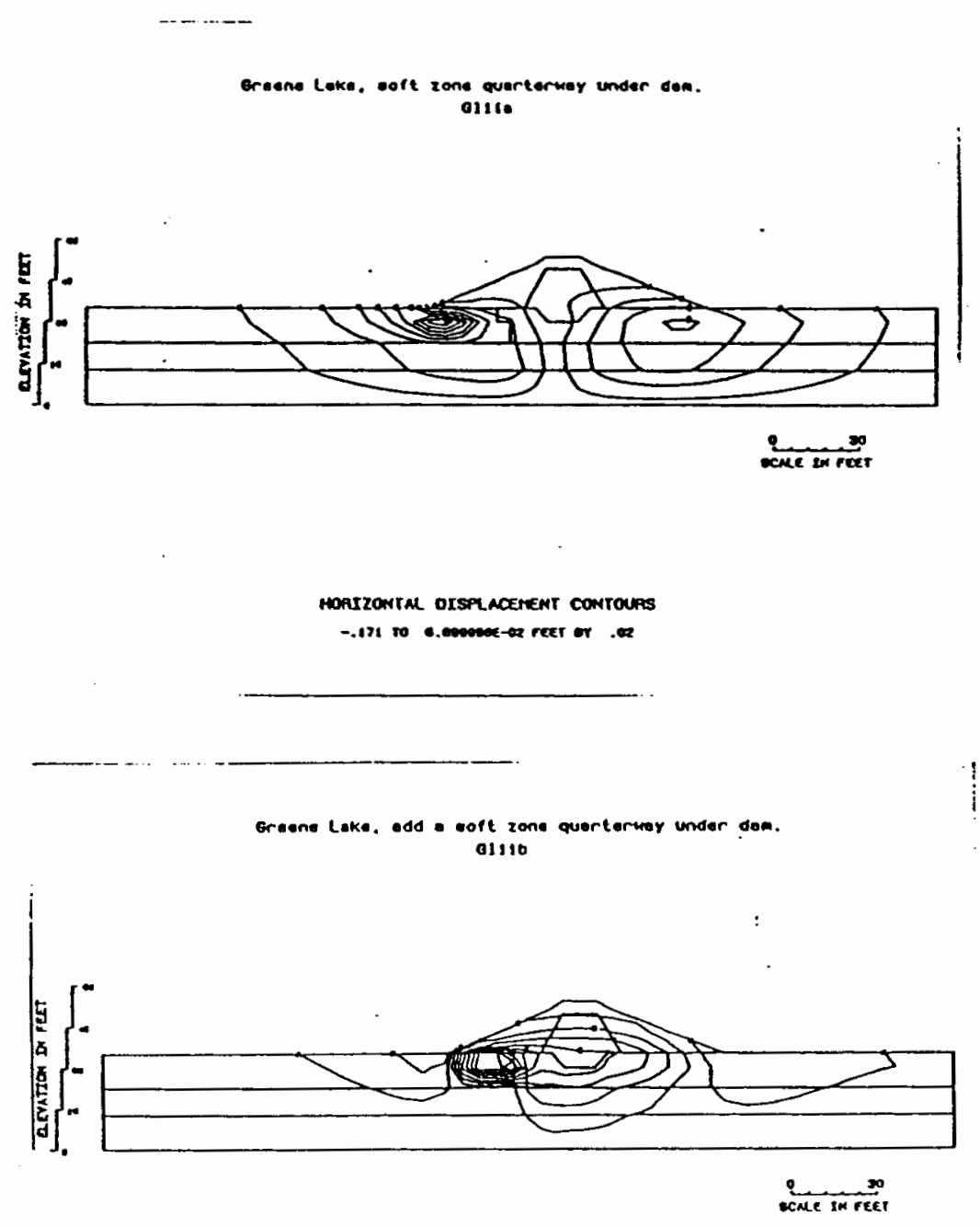

VEATICAL OISPLACETENT CONIOUAS

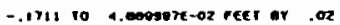

Figure 42. GL11 Displacement Contours. 


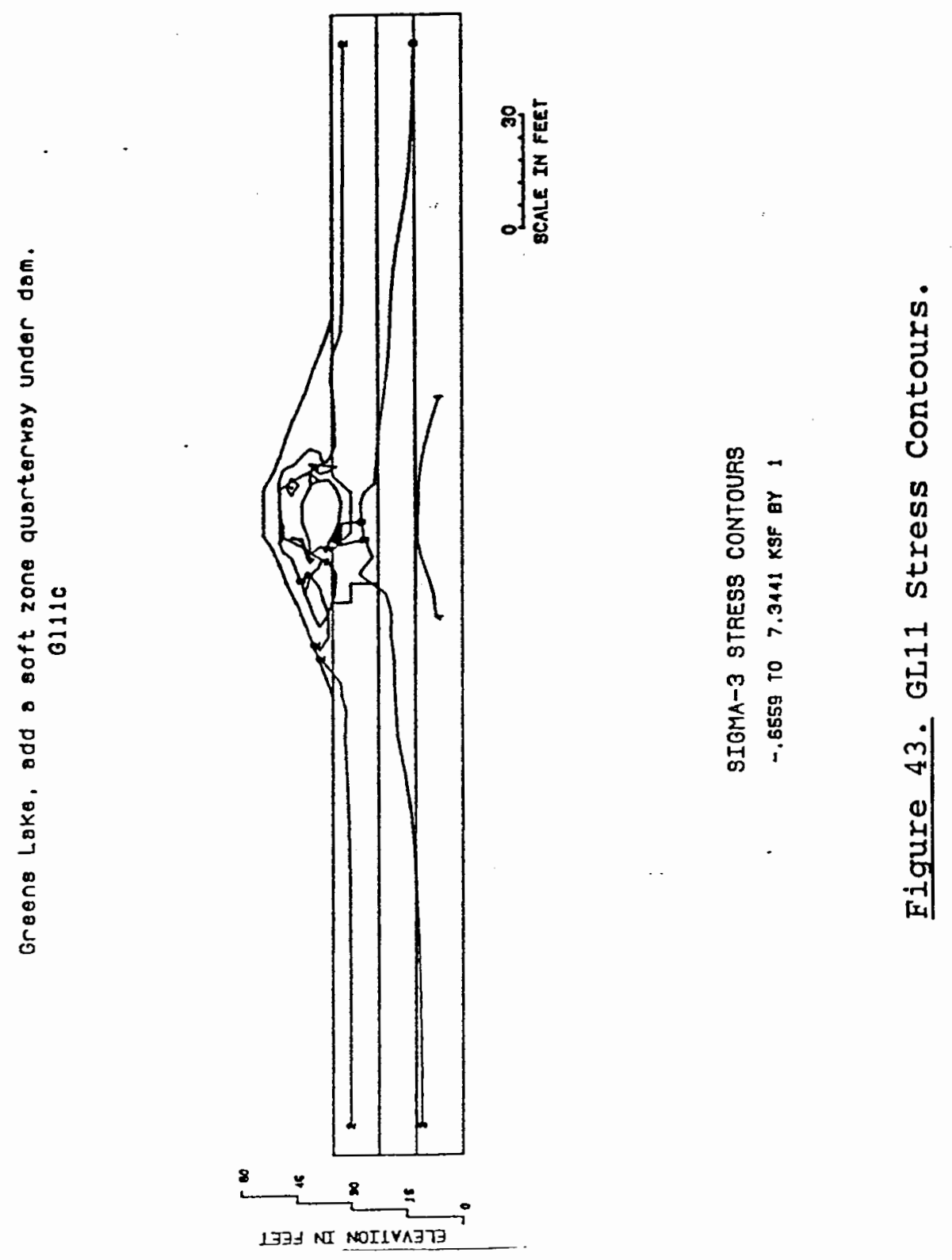


SATURATED STATE HALFWAY UNDER THE DAM

FEADAM Input, Model GL18

Input is the same as model GLII above, except for extending the saturated zone to halfway through the cutoff trench. This extension is done to simulate the advance of a wetted front. Field reports (Earth Science Associates, 1982) indicate five feet of basin subsidence extending into the dam. It is inferred that a wetted front proceeded under the dam causing dam damage. After the construction increment, a $1.5 \mathrm{ksf}$ load is applied to induce moderate ( 1 to 2 feet) of vertical displacement in the basin, as reported above.

FEADAM Output, Model GL18

output from the saturated increment only shows horizontal displacements of -0.27 feet, approximately twice the values with a saturated zone one quarter under the dam in model GL11 above. Vertical displacements increase to three times model GL11, with sigma-3 decreasing to -2.5 ksf, four times the tensional stress developed in model GL11 above. Output from the loaded increment drives displacements to about twice the unloaded increment above. Sigma-3 stress also doubles to $5.0 \mathrm{ksf}$. 


\section{Interpretation}

The saturated case does not displace near the amount of reported field displacements, except after loading the halfway under the dam model GL18, where vertical displacements reach -2.5 feet. For this case, the stress is $-5.0 \mathrm{ksf}$, the same as the quarterway model GL11 (after load) but GL18 displacements are four times the GL11 displacements. Thus, loading the halfway under the dam section creates the same amount of stress for a lower load, but more displacement than an equivalent quarterway under saturated, loaded section. Model GL18 has not been loaded to $3.0 \mathrm{ksf}$. The resulting sigma-3 $\max$ stresses are 4.0 ksf. It is probable that the addition of another $1.5 \mathrm{ksf}$ will increase the GL18 sigma-3 max value to greater than the $5.5 \mathrm{ksf}$ GL11 value above.

\section{LONGITUDINAL SECTIONS}

\section{FEADAM Input, Model GLO6}

Though dry and saturated cases have been run, they are not displayed here. It is found that longitudinal sections are not good indicators of dam damage due to reasons outlined in Chapter VI. FEADAM input parallels transverse model input summarized in Table V. Hyperbolic parameters are given in Table VI for models GL2 and GL11. Saturated state transverse parameters are the same as saturated state longitudinal parameters. 
FEADAM Output, Model GLO6

only saturated results are reported. Dry state plots show no significant displacement or induced stress without the addition of a soft zone. Therefore, output shows that saturated state contours vary from -0.0714 to 0.068 feet. in a symmetrical pattern about the soft zone center. output plots show vertical displacement contours at a maximum near the top of the soft zone, at -0.4135 feet. Sigma-3 varies from 0.0726 to $3.5726 \mathrm{ksf}$, and no tension stress is indicated.

\section{Interpretation}

Although no tensional stress is indicated on output plots, these data may be in serious error for reasons discussed in previous chapters. It is suggested at this time that these data be considered as very experimental. True longitudinal model representation has probably not been achieved.

\section{STABILITY SUMMARY}

\section{Dam Safety}

As noted previously, the Greens Lake dam has already been damaged. The damage is not completely qualified, or quantified. For discussion, it is assumed that a collapsible part of the basin is inundated.

It seems from models GLII and GL18 that, if a wetted front were to proceed to the midale of the dam, then 
maximum displacements would begin to occur. Displacements on the order of several feet do seem realistic at some future point in time.

Ratios of displacement and stress are: GL11/GL2 horizontal displacement $=2.6: 1$, vertical displacement $=$ 2.1:1, and Sigma-3 = 1:1. So, if these ratios are correct, post construction settlements need to be on the order of 6 inches or so for the model to work in most cases. However, for the large displacements noted above ( 5 feet), the model will underpredict displacements by over $100 \%$. At least 25 runs have been made in an attempt to duplicate 5 feet of vertical displacement, without success.

Since the dam has been grouted, the dam might be presumed safe, depending on the effectiveness of the grout in slowing down a moisture front and adding tension strength to the dam soil. Monitoring the dam might tell how effective the grout is in preventing dam collapse.

There is a question of repeatability of the foundation collapse phenomenon that might begin to be answered at the Greens Lake site. The question is: will the foundation keep on collapsing with each critical saturation, or has it used up its collapse potential as it were? This site has had repeated documented sinkholes and cracking. Though it is beyond this study, a collapse sequence through time might be developed, similar to seismic gap theory. It seems that cracking has gone on since at least 1966. 
CHAPTER VIII

FEADAM MODELING OF THE SOUTH STRAIGHT HOLLOW DAM

DAM STRUCTURE AND LOCAL GEOLOGY

\section{Dam Structure}

The South Straight Hollow Dam is made of compacted basin fill material, similar to the Fredonia and Greens Lake dams. This dam is one of a series of structures in the Ferron Watershed in Emery County, Utah, including the North Straight Hollow, Diversion Hollow, Zwahlen Wash, and Ely structures. The South straight Hollow dam is a quarter mile long, 22 feet high at the highest point, and has side slopes of 3:1 upstream, and 2.5:1 downstream. The dam is zoned with a compacted core, rockfill slopes, and a cutoff trench 10 feet deep has been placed at the upstream toe. Original as-built plans show a 5 to 8 foot deep cut in the basin where fill was to be removed for dam construction. Field investigations in 1991 reported a continuous surface in the upstream basin with no evidence of the cut depicted on the as-built plans.

\section{Local Geology}

The South Straight Hollow dam is built on a shallow dipping alluvial apron filling a shallow basin, much like 
the Fredonia and Greens Lake basins. The basin is approximately 35 feet deep at its central axis with a drainage area of 2.1 square miles. Steep, homogeneous, fine grained siltstone units flank the basin. Silt derived from this Bluegate member of the Mancos formation had been recognized and tested for its collapse potential in 1967 (USDA, 1967). In fact, all Ferron watershed basins have been similarly recognized. In a series of reports, geologist W.F. Mildner (USDA, 1967) reports sinkholes in the basin 1.5 feet deep, and that sandy silts (ML) from sta. $11+00$ to $18+00$ are collapsible if saturated, causing possible failure of the dam. The same report states an egg shaped sinkhole approximately 20 x 30 feet, 1.5 feet deep at sta. 15+30. The material reported from station $18+50$ to $21+50$ is a sandy clay, (CL). No mention of collapse related features is made in the CL area; however, crystalline gypsum is reported in this area, Figure 44. Crystalline and disseminated gypsum is reported in the basin, so much that a separate borrow area had to be established. Figure 45 shows the subsurface data.

\section{TRANSVERSE SECTIONS, DRY CASE}

FEADAM Input, Model ST1

South Straight Hollow models are summarized in Table VII. Hyperbolic input is given in Table VIII. Values are very similar to Fredonia, and Greens Lake. 


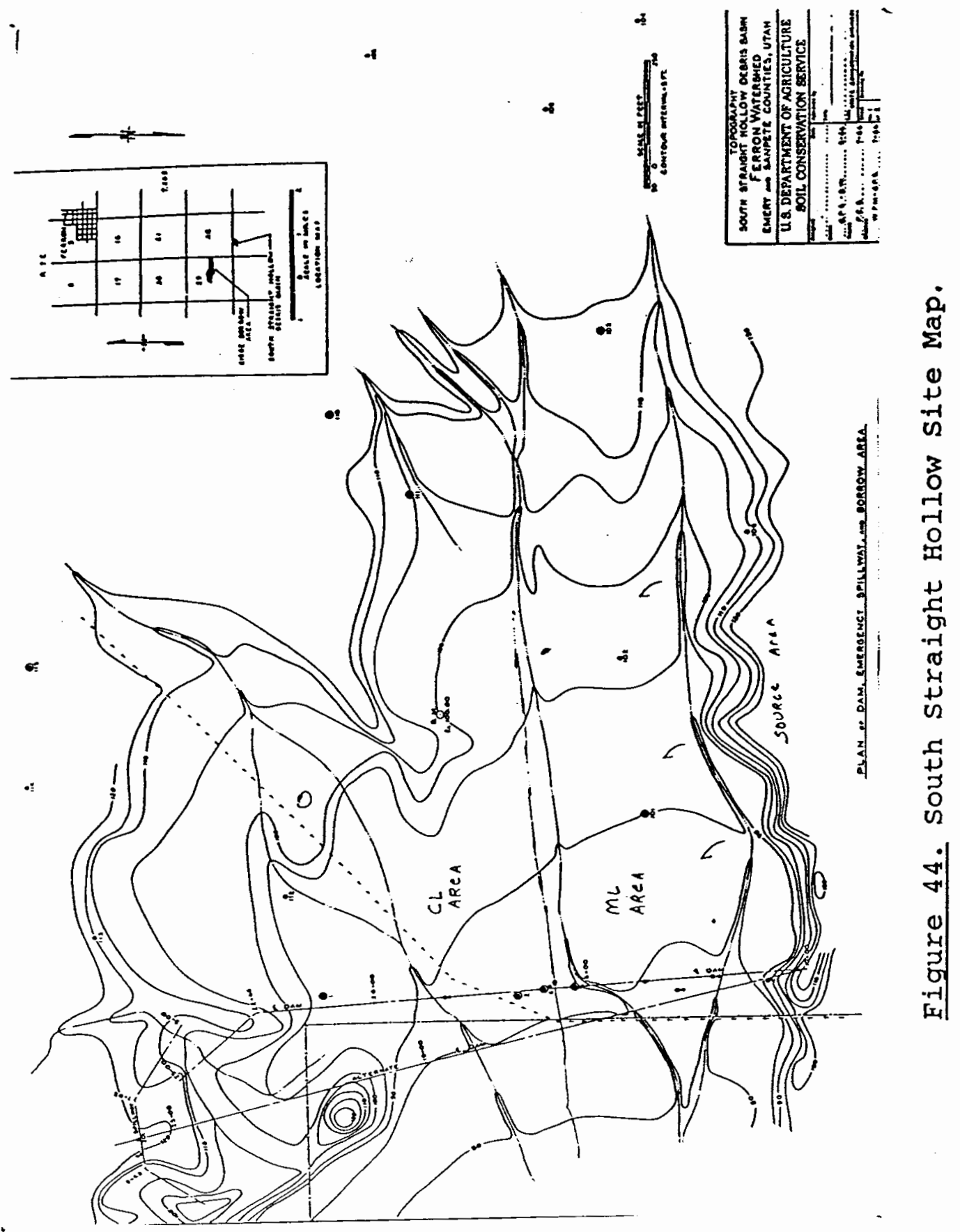




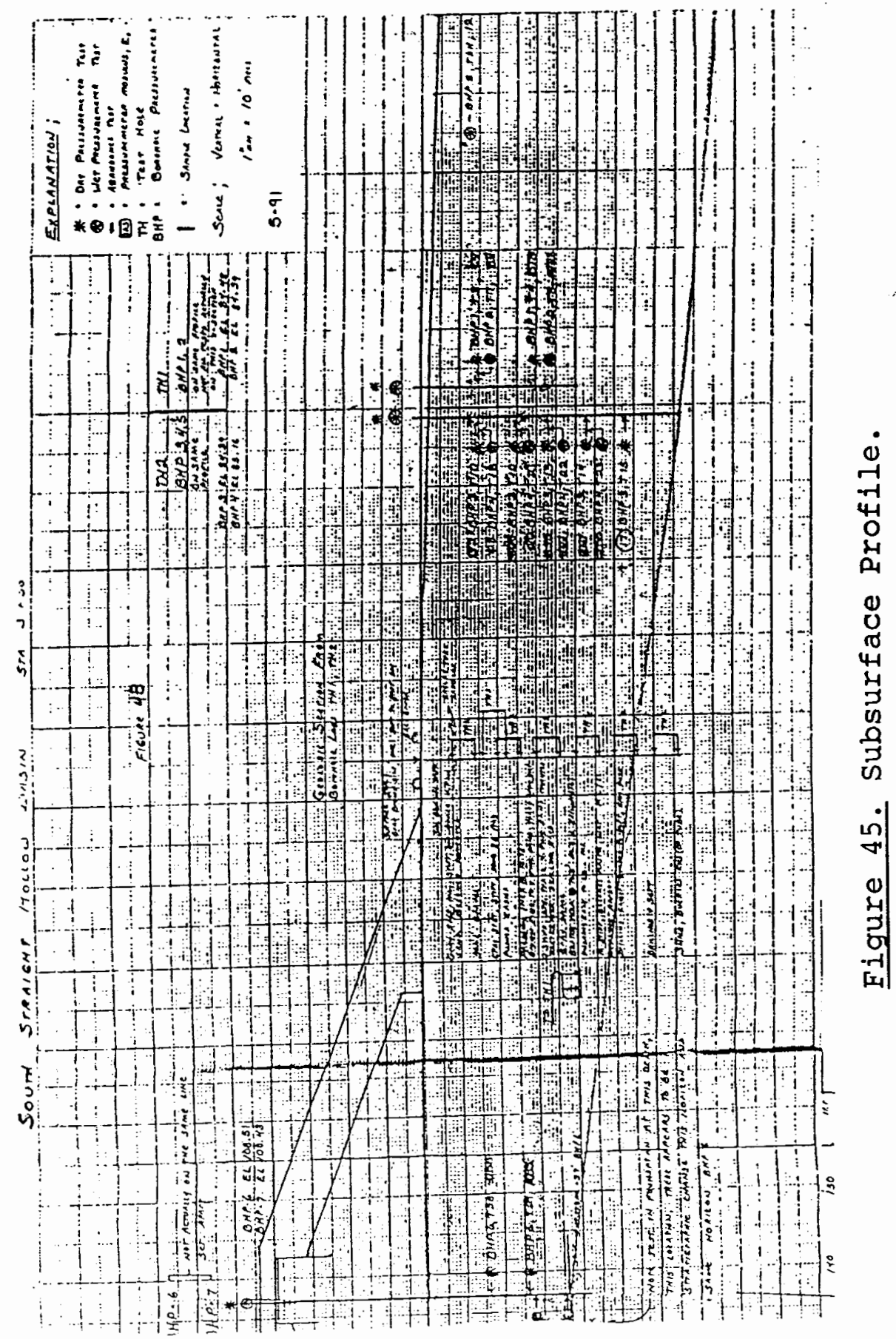


TABLE VII

SOUTH STRAIGHT HOLLOW MODEL FIGURE SUMMARY

Model Figure Display

Conditions

$\begin{array}{llll}\text { ST1C } & 46 & \begin{array}{l}\text { Stress } \\ \text { Contours }\end{array} & \begin{array}{l}\text { Dry State } 3 \text { layer } \\ \text { foundation 2 layer dam }\end{array} \\ \text { ST2A, B } 47 & \begin{array}{l}\text { Displacement } \\ \text { Contours }\end{array} & \begin{array}{l}\text { Sat. zone one quarter } \\ \text { under dam }\end{array} \\ \text { ST2C } & 48 & \begin{array}{l}\text { Stress } \\ \text { Contours }\end{array} & \begin{array}{l}\text { Sat. zone one quarter } \\ \text { under dam }\end{array}\end{array}$




\section{TABLE VIII}

SOUTH STRAIGHT HOLLOW HYPERBOLIC PARAMETERS

HYPERBOUC INPUT MODEL ST1

$\begin{array}{ccccccccccccr}\text { MATERLAL } & c & \gamma & \phi & K & \Delta \phi & K U K_{b} & n & R_{f} & K_{b} & m & \text { NOTES } \\ 1 & 0 & .121 & 0 & 120 & 0 & 120 & .5 & 0 & 0 & 2000 & 0 & \\ 2 & 0 & .111 & 0 & 500 & 0 & 500 & .5 & 0 & 0 & 400 & 0 \\ 3 & 0 & .095 & 0 & 160 & 0 & 160 & .5 & 0 & 0 & 150 & 0 \\ 4 & 3.0 & .095 & 10 & 150 & 0 & 150 & .5 & 0 & .7 & 100 & 0 \\ 5 & 0 & .121 & 0 & 600 & 0 & 600 & .8 & 0 & 0 & 500 & 0 \\ 6 & 0 & .135 & 0 & 500 & 0 & 500 & .5 & 0 & 0 & 400 & 0\end{array}$

\section{HYPERBOLIC INPUT MODEL ST2}

$\begin{array}{ccccccccccccc}\text { MATERIAL } & c & \gamma & \phi & K & \Delta \phi & \text { KUr } & K_{b} & n & R_{f} & K_{b} & m & \text { NOTES } \\ 1 & 0 & .121 & 0 & 120 & 0 & 120 & .5 & 0 & 0 & 2000 & 0 & \\ 2 & 0 & .111 & 0 & 500 & 0 & 500 & .5 & 0 & 0 & 400 & 0 & \\ 3 & 0 & .095 & 0 & 160 & 0 & 160 & .5 & 0 & 0 & 150 & 0 \\ 4 & 3.0 & .095 & 10 & 150 & 0 & 150 & .5 & 0 & .7 & 100 & 0 \\ 5 & 0 & .121 & 0 & 600 & 0 & 600 & .8 & 0 & 0 & 500 & 0 \\ 6 & 0 & .135 & 0 & 500 & 0 & 500 & .5 & 0 & 0 & 400 & 0 \\ 7 & .3 & .120 & 20 & 12 & 0 & 12 & .3 & 0 & .2 & 12 & 0\end{array}$


FEADAM Output, Model ST1

The dam moves 0.006 feet horizontally. Maximum vertical motion in this case is -0.02 feet. Sigma-3 stress ranges from -0.057 to $3.43 \mathrm{ksf}$, Figure 46 . A complex zone of stress anomalies develop near the compacted core/rockfill interface near the upstream and downstream toes of the dam. Tau-max ranges from 0.007 to $1.41 \mathrm{ksf}$.

\section{Interpretation}

The displacement magnitude is smaller than expected. The zone of $500 \mathrm{ksf}$ modulus material at -16 feet probably reduces displacement. This zone corresponds to a very stiff, cemented very fine sand, through which drilling is hard, from field data, Figure 45. However, this stiff zone may actually be a local anomaly. Sigma-3 stress anomalies show up, Figure 46, which may be the result of the modeling technique in part. The material zone break between rockfill shell and core material is not a straight line but rather a series of stepped elements to approximate a straight line boundary. This was done to minimize the number of elements. This break is also where the anomalies occur. So, either the foundation actually is stiff enough in the dry state to prevent any significant settlement, or the hyperbolic model is quite conservative in its calculations. It seems most likely a combination of both. It offers from experience that the hyperbolic model tends to underestimate settlements given a stiffness of 500 


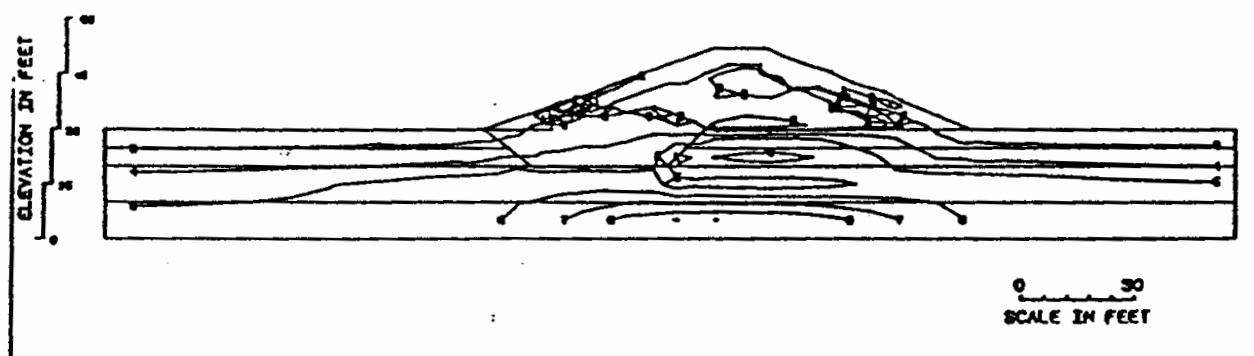

SIGHA-3 STRESS CONTOURS

-.67 10 3.40 nst or .5

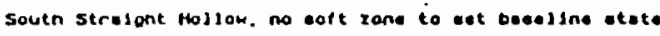
siso

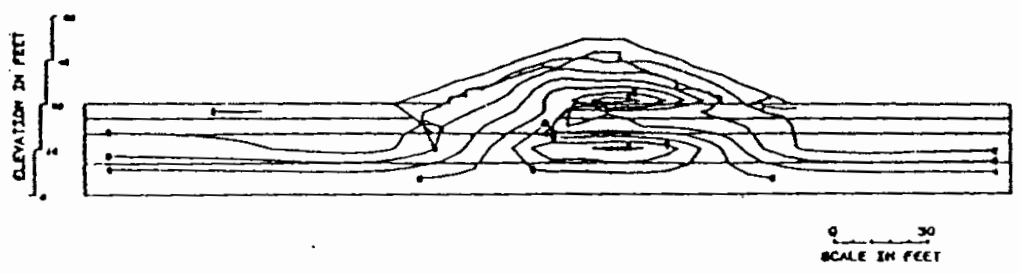

IAU-mX STRESS CONTOUAS

.04 to $1.41 \mathrm{cer}$ or -2

Figure 46. ST1 Stress Contours. 
ksf, and 2-3 ksf cohesion value. From experience with the FEADAM code, a cohesion of $>1.0 \mathrm{ksf}$, a phi angle of 5 degrees or more, and stiffness of over $100 \mathrm{ksf}$, at the range of depths considered, FEADAM will consistently produce horizontal and vertical displacements in the 0.01 to 0.15 foot range. It has not been possible to fine tune either the model parameters or mesh much more. South Straight Hollow results are even more conservative than the range above. This is probably due to the $500 \mathrm{ksf}$ zone. This numerical value is backed up by field notes, where gypsum and cemented zones are commonly reported.

TRANSVERSE CASE, SATURATED STATE

FEADAM Input, Model ST2

In this case, a zone of low modulus material is placed at about halfway through the cutoff trench. The modulus value of this material is the lowest of any used at $12 \mathrm{ksf}$.

FEADAM Output, model ST2

Horizontal displacement contours show a maximum of 0.13 feet near the upstream toe, about 5 feet deep. This pattern and magnitude is very similar to the other collapsible sites above. Vertical displacement is 0.10 feet, Figure 47. This value is low compared to the above sites. Sigma-3 stress ranges from -1.6 to $3.2 \mathrm{ksf}$, while tau-max goes from 0.1 to $1.45 \mathrm{ksf}$, Figure 48 . 


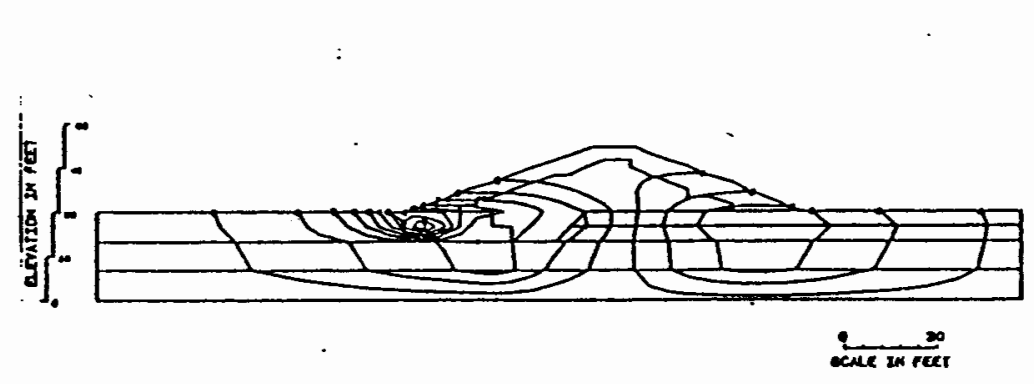

HORTONIM OISFLCERENT CONTOURS

-.1s to a.c0000se-oz reer or .016

South Strulont Mallow. waft zom Included 8129

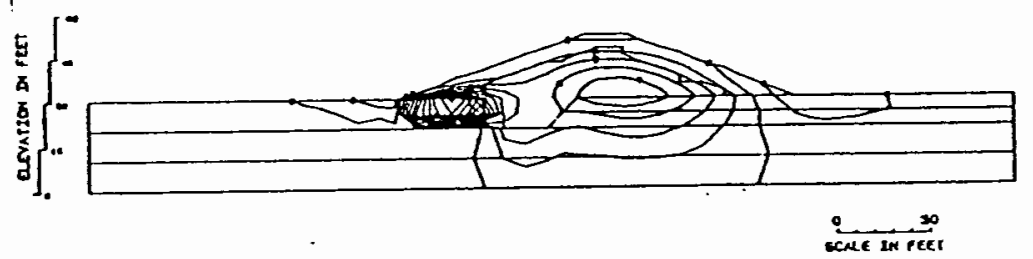

VEATICM DISPRACERENT CONTOUAS

-.1 so $2.0000000-02$ feer or $=0$ s

Figure 47. ST2 Displacement Contours. 


\section{Interpretation}

The saturated displacements double from the dry case. However, the range reported is conservative due to causes discussed above. The range of values used to simulate a saturated state is not low enough for the hyperbolic model to cause elements to yield as a collapsible soil would. The problem is that by lowering element stiffness, $C$, or phi to a value to initiate element displacements observed in the field violates field data values and gives

erroneous values the closer elements get to failure. Thus the output becomes unreliable. The South Straight Hollow case is made more difficult because of the stiff values discussed above.

\section{STABILITY SUMMARY}

\section{Dam Safety}

If the displacements are noted to double from the dry to the saturated case then, as a qualitative guide, saturated displacements may be expected to at least double from post construction displacements. No noticeable damage has been reported to this structure as of spring 1991, and no impoundment history has been available. In 1966, 1.5 foot basin settlements (sinkholes) had been reported. FEADAM modeling shows very conservative displacements and Low associated stresses. Several possibilities exist. 

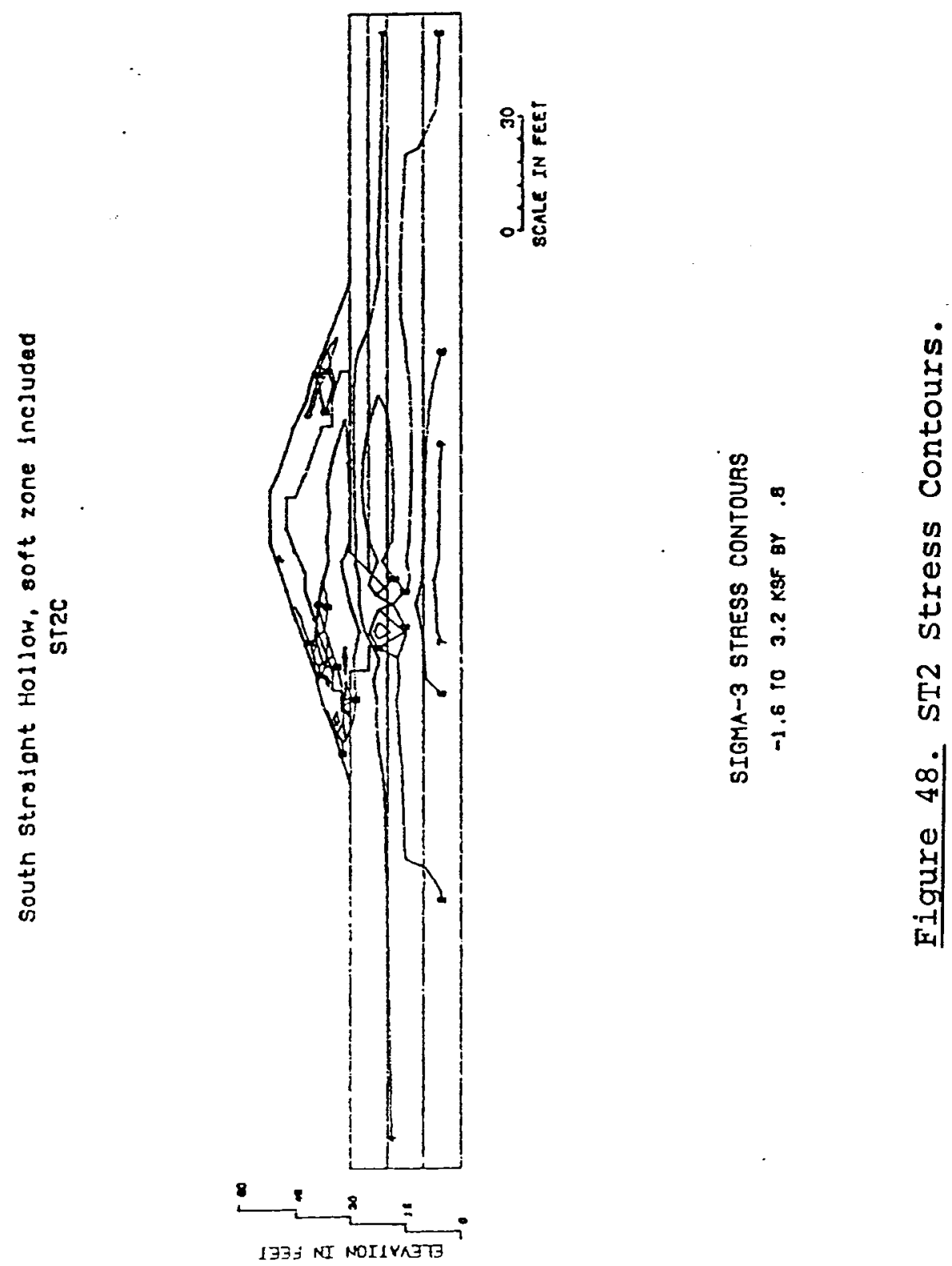
An impoundment of appreciable size may have dissipated from this dam. If the dam had an impoundment, it did not do noticeable damage, however it may be hidden due to the rockfill sideslopes. Another possibility is that since material for this dam is from a remote borrow location, it is a more competent material than basin borrow fill used at Fredonia and less susceptible to ion bond dissolution problems as the sulfates of the basin material. The ML material shown on Figure 44 is most affected by bond dissolution. Collapse in this case might be localized to the area of collapse prone material and area of impoundment. Note that the area of impoundment is likely to be determined by both the amount of rain and particular. debris flow channel, neither of which is predictable.

Thus it is likely that give an event of 0.5 inch or so rain, local collapse still is likely. It appears that the South Straight Hollow dam would suffer less than Greens Lake or Fredonia due to a stiffer subsurface profile. However, the dam slopes would experience high tensional stresses ( $-4 \mathrm{ksf})$, and cracking should be expected. The main problem is piping of erodible material once cracking has started. The amount of piping depends on the cutoff trench effectiveness and how competent the dam is. 
CHAPTER IX

\section{CONCLUSIONS AND RECOMMENDATIONS}

\section{STABILITY CONCLUSIONS}

The problem of cracked dams on collapsing soils has been examined here from the point of view of dam stability. The stability approach has been divided into classic slope stability and finite element method categories. The slope stability methods have been used to examine a generic dam, with the FEM used to examine four debris dams. In drawing conclusions, it is helpful to present slope stability limits and a possible stability mechanism, though finite element results may be used to help delineate a possible mechanism. Then, FEADAM capabilities and limits may be shown.

\section{Slope Stability Summary}

Slope stability methods seek to define and quantify dam slope safety through a factor of safety. The particular stability approach chosen defines the failure plane; limit. equilibrium calculations determine the factor of safety. For the problem of cracked dams on collapsing soils, stability methods do not produce a factor of safety below 1.0 except under unlikely hypothetical conditions such as 
zero cohesion.

Probable reasons for the high factor of safety results are twofold. 1) In a collapsing foundation soil, saturated soil reduces in volume. This means placement of a single failure plane through the foundation is not possible. 2) A collapsing soil changes material properties by up to 1008 or more. This means that assignment of average material properties across the collapsing foundation soil is not accurate, since the properties are changing.

These conclusions have been reached after over 100 calculations and some of the results presented in chapter II. The results of slope stability calculations, field reports, crack mapping, photographs, and office study have led to a possible failure mode termed the block with rotation mechanism.

The block with rotation mechanism, outlined in chapter II, tentatively explaines the dam cracking with collapse phenomenon. The mechanism is not rigorously tested. Finite element results displayed on Figure 36 indicate possible block behavior under simulated collapse conditions.

\section{FEADAM Summary}

After stability methods, the finite element code FEADAM has been used to define and quantify the problem of cracked dams on collapsing soils. This code has been more 
accurate than stability methods in solving the problem but has limitations.

The main limitation with the FEADAM code is that it does not predict the magnitude of dam crack displacements as observed in the field. FEADAM displacement output is consistently only about one tenth of actual field displacement. The main suspected reason for this disparity is the consistent failure of the hyperbolic model to respond to the sudden soil failure caused by saturation and collapse of foundation soils. A number of techniques have been tried to overcome this limitation, with varied success. The main problem with forcing collapse in FEADAM models is the resulting distortion of displacements and stresses. As listed, the sources of distortion and error are probably:

1) The hyperbolic model itself relates increasing soil strength with increased confining stress up to some plastic limit. Collapsible soils deform with the addition of moisture and perhaps without the addition of increased confining stress.

2) FEADAM is designed to quantify post construction stresses and strains. The problem of cracked dams on collapsing soils occurs after construction. The chronological sequence is saturation then strain (the stress is already present, not construction induced), then stress and strain. 
3) The hyperbolic model is designed for use with triaxial data. Pressuremeter data has been used in much of this study since in-situ testing is perhaps the best way to measure field collapse properties at the present time. BY way of example, pressuremeter moduli have been substituted for triaxial moduli for in depth plots to obtain the change in modulus with depth parameter, $n$.

4) Discretization of the FEADAM mesh is not accurate. As noted in Chapter IV, and shown on Figures 14 and 15, the alluvial fan/ debris basin foundation system is of various lenticular shapes of various material properties that are not accurately defined or quantified by the simplified models in this study. Sloped layer surfaces in FEADAM input are permitted; however, complex surfaces are not, except when stresses are pre-calculated. FEADAM then is not designed to model the complex debris fan systems encountered here, though best-case, worst-case scenarios may be modeled as an indication of possible foundation-dam changes from the dry to wet state.

5) mesh size limitations (550 elements, 550 nodes) prevent accurate discretization of long longitudinal sections, as noted in Chapter $V$, or detailed discretization of the debris fan system in 4 ) above.

6) Element failure is not permitted in either tension or shear failure. For example, shear failure does not occur, and 0.95 moduli are the maximum values used. 
7) Saturation values as available are not employed. Saturation is indirectly simulated through the use of saturated moduli. This assumes discrete saturation boundaries of, in reality, uncertain placement under the dams.

FEADAM however, does give some useful output concerning the problem of collapsing soils and cracked dams. The main pieces of useful output are given.

1) FEADAM shows useful qualitative displacement differences between saturated and non-saturated sections. Ratios in Chapters VI, VII, and VIII show an increase in post-construction collapse of from $2: 1$ to $5: 1$, saturated/ dry displacements.

2) FEADAM shows saturated/dry sigma-3 (tension) stresses ratios of up to $12: 1$. FEADAM consistently shows increases in tension stress in all saturated models. Thus, though displacements do not at all match field crack offsets, tensional stresses associated with cracking are regularly predicted by FEADAM.

3) Saturated models, with an applied load, reproduce field displacements and show tensional stresses developing on dam slopes, as in Figures 31 and 32 .

4) FEADAM output shows that the advance of a wetted front to halfway under the dam affects displacements less than stresses. As discussed in Chapter VII, displacements double upon the advance of a wetted front from one quarter 
to halfway under the dam. At the same time, tension stresses decrease appreciably (become more negative) by four to five times. By way of example, when a simulated wetted front is advanced from one quarter to one halfway under the dam at Fredonia, tensional stresses increase four times, from $-0.90 \mathrm{ksf}$ to $-3.6 \mathrm{ksf}$. At Greens Lake, tensional stresses also increase about four times from -0.66 to $-2.5 \mathrm{ksf}$ as the wetted front advances.

5) FEADAM output has been used to create Figure 37. This figure, while not conclusive, does give indications of the proposed block rotation mechanism from bearing failure.

6) These FEADAM analyses have been used as a guide in developing a more sophisticated collapse program. The program Metastable Analyses of Dams, or MADAM, now being developed at PSU, has employed FEADAM meshes, stresses, and displacements as a guide.

7) FEADAM longitudinal section output has shown the necessity for more than a 'layer cake system' to properly represent the debris fan subsurface system. This has been observed from the nearly perfectly symmetrical contours about a soft zone placed in a layer cake foundation. Future models will probably produce more accurate output as the meshes used more accurately reflect field conditions, recognizing that more time and study might be spent on accurately collecting data for, and modeling of the dam foundations. 


\section{FEADAM ACcuracy}

One of the most outstanding conclusions of FEADAM work is that the models run consistently predict lower than expected displacements. In order to make results as useful as possible, the magnitude of field offsets vs. magnitude of model offsets is given. FEADAM results might then be interpreted in a consistent manner. Table IX gives a summary of dry to wet displacements for the four sites.

As mentioned, WHD, and WVD show very conservative displacements compared to field conditions. These results are after many trials to accurately represent field parameters, and in some cases to actually replicate field offsets given any input parameters.

White Tanks models show a maximum 1.2 inches displacement increase after addition of the soft zone. Field conditions show one to two feet of displacement, after the soft zone. Sigma-3 (tension) however increases five times, indicating a much weaker soil state.

Fredonia non-loaded models show a maximum 4.6 inch displacement increase dry to wet state. Loaded models show up to a foot of after load displacement. Sigma-3 stresses increase nine to one, dry to wet, non-loaded; 25 to one or greater, dry to wet, loaded.

Greens Lake models show 2.8 inches maximum displacement dry to wet, with sigma-3 increasing four to one. Five feet of field displacement has been reported. 
South Straight Hollow models show about an inch of displacement dry to wet. Sigma-3 increases sixteen to one, in one case.

Given the above, FEADAM usually predicts about one tenth or so of actual field offsets. FEADAM does however show a marked sigma-3 stress in all cases, except longitudinal lines. In this case FEADAM is not an accurate tool to predict field displacements in the case of earth dams on collapsing foundations. FEADAM may be a good tool to predict tension zones associated with the collapse phenomenon. 
TABLE IX

MODEL DISPLACEMENT SIGMA-3 SUMMARY

Model DHD DVD DS3 WHD WVD WS3 $\frac{\text { WHD }}{\text { DHD }} \frac{\text { WVD }}{\text { DVD }} \frac{\text { WS3 }}{D S 3}$

WT9 $\quad 1.7 \quad 5.5 \quad 0.1$

$\begin{array}{lllllll}\text { WT10 } & 1.7 & 5.5 & 0.6 & 1.0 & 1.0 & 5.3\end{array}$

WL14 $\quad 0.5 \quad 4.2 \quad$ POS

$\begin{array}{lllllll}\text { WL15 } & 0.6 & 5.4 & \text { POS } & 1.2 & 1.3 & 1.0\end{array}$

$\begin{array}{llll}\text { F79 } & 1.0 & 1.4 & 0.3\end{array}$

$\begin{array}{lllllll}\text { F93 } & 2.7 & 6.0 & 3.6 & 2.7 & 4.3 & 9.0\end{array}$

$\begin{array}{lllllll}\text { F70 } & 2.2 & 10.0 & 7.4 & 2.2 & 7.1 & 24.5\end{array}$

FL5 $\quad 0.1 \quad 0.5 \quad$ POS

$\begin{array}{lllllll}\text { FL6 } & 0.8 & 4.4 & \text { POS } & 8.0 & 10.0 & 1.0\end{array}$

GL2 $\quad 0.8 \quad 1.0 \quad 0.7$

$\begin{array}{lllllll}\text { GLI8 } & 2.3 & 3.8 & 2.5 & 2.9 & 3.8 & 4.2\end{array}$

ST1 $\quad 0.1 \quad 0.3 \quad 0.1$

$\begin{array}{lllllll}\text { ST2 } & 1.6 & 1.2 & 1.6 & 16.0 & 5.3 & 16.0\end{array}$

$$
\begin{array}{ll}
\text { DHD }=\text { Dry horizontal Displacement } & \text { DS3 }=\text { Dry Sigma-3 } \\
\text { DVD }=\text { Dry Vertical Displacement } & \text { WS3 }=\text { Wet Sigma-3 } \\
\text { WHD }=\text { Wet Horizontal Displacement } & \text { POS }=\text { Positive }
\end{array}
$$$$
\text { WVD }=\text { Wet Vertical Displacement WT \& WL models, } W=\text { soft }
$$ 


\section{REFERENCES}

Alberro, J., Macedo, G, Montanez, L., and GonzalezValencia, F., "Penitas Dam-In Situ Stress-Strain Characteristics of Materials," Proceedings of the Second International Conference on case Histories in Geotechnical Engineering, St. Louis., Missouri, 1988.

Baquelin, F., Jezequel, J.F., and Shields, D.H., The Pressuremeter and Foundation Engineering, Trans Tech Publications, Clausthal, Germany, 1978.

Beckwith, G.H., and Hansen, M., "Identification of The Collapsing Alluvial Soils of the Western United States," Foundation Engineering, Proceedings of the Congress sponsored by the Geotechnical Engineering Division, ASCE, Evanston, Illinois, 1989.

Bishop, A.W., "The Use of the Slip Circle in Stability Analysis of Earth Slopes," Geotechnique, Volume 5, 1955, pp. 7-17.

Carter, J.P., "CAMFE, A Computer Program for the Analysis of a Cylindrical Cavity Expansion in Soil," Cambridge University Internal Report, CUED/C-soils-TRS.

Dekker, J., "Evaluation of the Failure of an Important Dike in the Netherlands," Proc of the Second International Conference on Case Histories in Geotechnical Engineering St. Louis, Missouri, 1988.

Cheney, R.S., and Chassie, R.G., Soils and Foundation Workshop, Federal Highway Administration, Geotechnical and Materials branch, HHO-33, 1982.

Das, B.M., Principles of Geotechnical Engineering, PWS-KENT Publishing Company, Boston, Massachuttes, 1985.

Duncan,J.M., and Chang, C-Y.," Nonlinear Analysis of Stress and Strain in Soils," Journal of the Soil Mechanics and Foundation Division, ASCE, September, 1970.

Earth Science Associates, "Greens Lake Dam No. 3," Seismic Safety Investigation of Eight SCS Dams, Project G118, Palo Alto, California, 1982. 
French, R.H., Editor, Hydraulic processes on Alluvial Fans, Elsevier Developments in Water Science \#31, 1987.

Graf, W.L., Fluvial Processes in Dryland Rivers, SpringerVerlag Geobooks, England, 1988.

Gibbs, H.J., and Bara, J.P., "Stability Problems of Collapsing Soils," Journal of the Soil Mechanics and Foundations Division, ASCE, JulY, 1967.

Horton, R.E., "The Role of Infiltration in the Hydrologic Cycle," EOS Transactions of the American Geophysical Union, Vol.14, 1933 .

Houston S.L., and El-EhwanY, M., " Settlement and Moisture Movement in Collapsible Soils," Journal of Geotechnical Engineering, ASCE, 1990.

Houston, W.N., and Houston, S.L. "State of the Art Mitigation Measures for Collapsible Soil Sites," Foundation Engineering, Proc. of the Congress sponsored by the Geotechnical Engineering Division, ASCE, Evanston, Illinois, 1989.

Jacobson, R. "Finite Element Study of Earth Dams Founded on Collapsible Soils Utilizing Abaqus and Madam" SCS Project Report, GE-SCS-04-91, 1992.

Kondner, R.L., "Hyperbolic Stress-Strain Response: Cohesive Soils," Journal of the Soil Mechanics and Foundations Division, ASCE, 1963.

Mildner, W.F., "Report of Geological Investigation South Straight Hollow Debris Basin Dam, Ferron Watershed, Emery County Utah," USDA SCS Engineering and Planning Unit, Portland, Oregon, 1966.

Mildner, W.F., "Report of Geological Investigation, Indian Hollow Debris Basin Dam," Ferron County Watershed, EmerY County Utah," USDA SCS Engineering and Planning Unit, Portland, Oregon, 1966.

Mildner, W.F., "Report of Geological Investigation, Diversion Hollow Debris Basin Dam," Ferron county Watershed, Emery County Utah, USDA SCS, Engineering and Planning Unit, Portland, Oregon, 1966. 
Neumann, D., "Hyperbolic Soil Parameters for Granular Soils Derived From Pressuremeter Tests for Finite Element Programs," A Thesis Submitted in Partial Fulfillment of the Requirements For the Degree of Master of Arts, Portland State University, Portland, Oregon, 1987.

Ritter, D.F., Process Geomorphology, Wm. C. Brown Publishers, Dubuque, Iowa, 1978.

Rollins, K.M., and Williams,T., "Collapsible Soil Hazard Mapping for Cedar City Utah," Proceedings of the 27th Symposium on Engineering Geology and Geotechnical Engineering, Utah State University, Logan, Utah, 1991.

Sanders, A.C., "Crack Investigation," Fredonia FRS Fredonia Watershed, SCS, USDA Dam Safety Report, Phoenix, Arizona, 1981.

Smith, T.D., and Deal, C.E., "Cracking Studies at Sand $H$ Básin by the Finite Element Method," Proceedings of the second International Conference on Case Histories in Geotechnical Engineering, St. Louis, Missouri, 1988.

Talbot, J., Seepage and Leakage from Dams and Impoundments Proceedings of the of the ASCE Geotechnical Engineering Division ASCE National Convention, ASCE, Denver. Colorado, 1985.

Turnbull, W.J., and Hvorslev, M.J., "special Problems in Slope Stability," Journal of the Soil Mechanics and Foundations Division, ASCE, 1967.

Uhacz, K., "Evaluating the Role of Geogrids in the Rehabilitation of Cracked Dams via Numerical

Techniques," SCS Project Report, GE-SCS-01-91, 1991.

USDA SCS, Materials Testing Section Report, South straight Hollow Debris Dam, Ferron Watershed, Utah, Portland, Oregon, 1966.

USDA SCS, Materials Testing Section Report, Fredonia, Fredonia Watershed, Az., Portland, Oregon, 1970.

Werle, J.L., and Stilley, A.N., and R.G., "Effects of Ground Fissures on Development in the Las Vegas Valley, Nevada," Proceedings of the of the $27 \mathrm{th}$ Symposium on Engineering Geology and Geotechnical Engineering, Utah State University, Logan, Utah, 1991. 
Wright, A.C., "A Stochastic Distributed Model of Soil Erosion by Overland Flow," Earth Surface Processes and Landforms, Volume 16, 1991.

Wright, S.G., and Edris, E.V., UTEXAS2 Slope Stability Package, Department of the Army, Corps of Engineers, Vicksburg, Mississippi, 1987.

Yair, and Rorke, B., Badland Geomorphology and piping, GeoBooks, Norwich, England, 1982. 
APPENDIX A

REPAIR POSSIBILITIES 


\section{REPAIR POSSIBILITIES}

\section{Suggested Repair Methods}

There are many suggestions as to repairing cracked dams, and attempting to prevent further cracking. Some of these ideas are given. Calculating repair cost, timing, effectiveness, etc., is beyond the scope of this thesis. Therefore, ideas listed below are given on a preliminary basis only. Detailed repair proposals should be treated as continuing parts to work done here.

1) Re-compacting of the dam foundation. This technique has been used at Fredonia with some success in that the Fredonia dam while cracked, has not seen near the damage reported at Greens Lake. Records of impoundment depths have not been available for direct comparison.

2) Placing of geosynthetics in damaged dam sections. This idea has been studied at PSU (Uhacz, 1991).

3) Rockfill on dam slopes. This method, used at South straight Hollow, has been discussed in Chapter VIII. Field researchers in 1991 reported no evidence of cracks on this dam. It is unknown if the rockfill merely hides the cracks .

4) Place a bentonite blanket in the upstream basin. This idea may work, providing the dam does not crack to an extent that splits the bentonite blanket. 
5) Keep the water table low. Sanders (Sanders, 1981), reports possible damage at Fredonia from a rising water table saturating collapsible soils.

6) Place an impervious core. This idea may keep moisture from flowing through the dam, but as reported above, tensional stresses may maximize before the wetted front reaches one quarter way, possibly less, under the dam.

7) Place water/debris flow barriers or trenches in the basin. This may slow runoff enough to allow infiltration into the basin instead of rapid runoff associated with debris flows. Figure 49 shows this possibility. This idea sounds workable in principle, but is untested, and would require more study of alluvial processes.

It seems likely that at some point during or after a rainstorm that runoff exceeds infiltration. This flow may for a time act as Horton overland flow (Horton, 1933). At some point, basin soil particles become entrained in the flow. The result may be a debris flow, other basin conditions being right for debris flow formation.

French (French, 1987) reports that 1-2 inches of 4-8 inches/hour rainfall may be required for debris flow formation, though debris flows have been reported occuring after 0.85 inches of precipitation.

It seems possible that if hydraulic conductivity in 


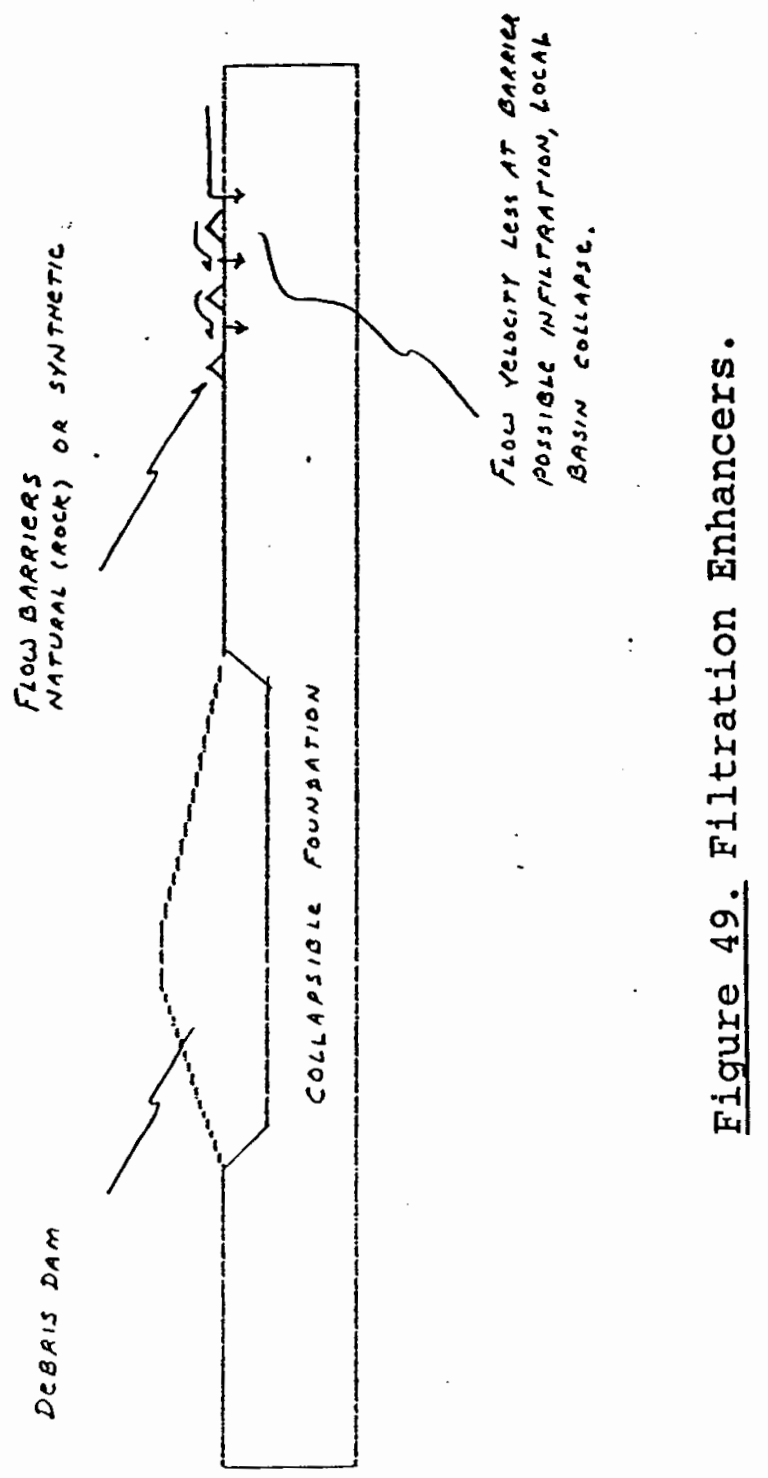


the basin may be increased, infiltration might exceed runoff. Hydraulic conductivity at South Straight Hollow has been measured at a first 15 minute value of 0.63 inches $\backslash$ second. The second, slower infiltration rate, after 23 minutes, is 0.12 inches $\backslash$ second. In a recent computer modeling study (Wright, 1991), it has been noted that at a hydraulic conductivity of 1.2 inches per second, on a 17 degree slope, with 60 minutes of 0.15 to 0.40 inches lhour of (simulated) rainfall falling for one hour will not cause any overland flow to occur, though several elements in the model do saturate. In contrast, the debris basin may have a much lower slope, and one half the 1.2 inches $\backslash$ second conductivity of the computer model. Rainfall intensities and durations have not been used in the study of debris dams here.

8) Place a moisture barrier as shown on Figure 50. This idea would work in principle if the impervious material were placed deep enough in the basin to prevent critical saturation, and also placed on dam slopes to keep them dry.

In a dozen or so FEADAM runs made so far, it appears that displacements, and stresses may be lowered by placing a moisture barrier as described. 
162
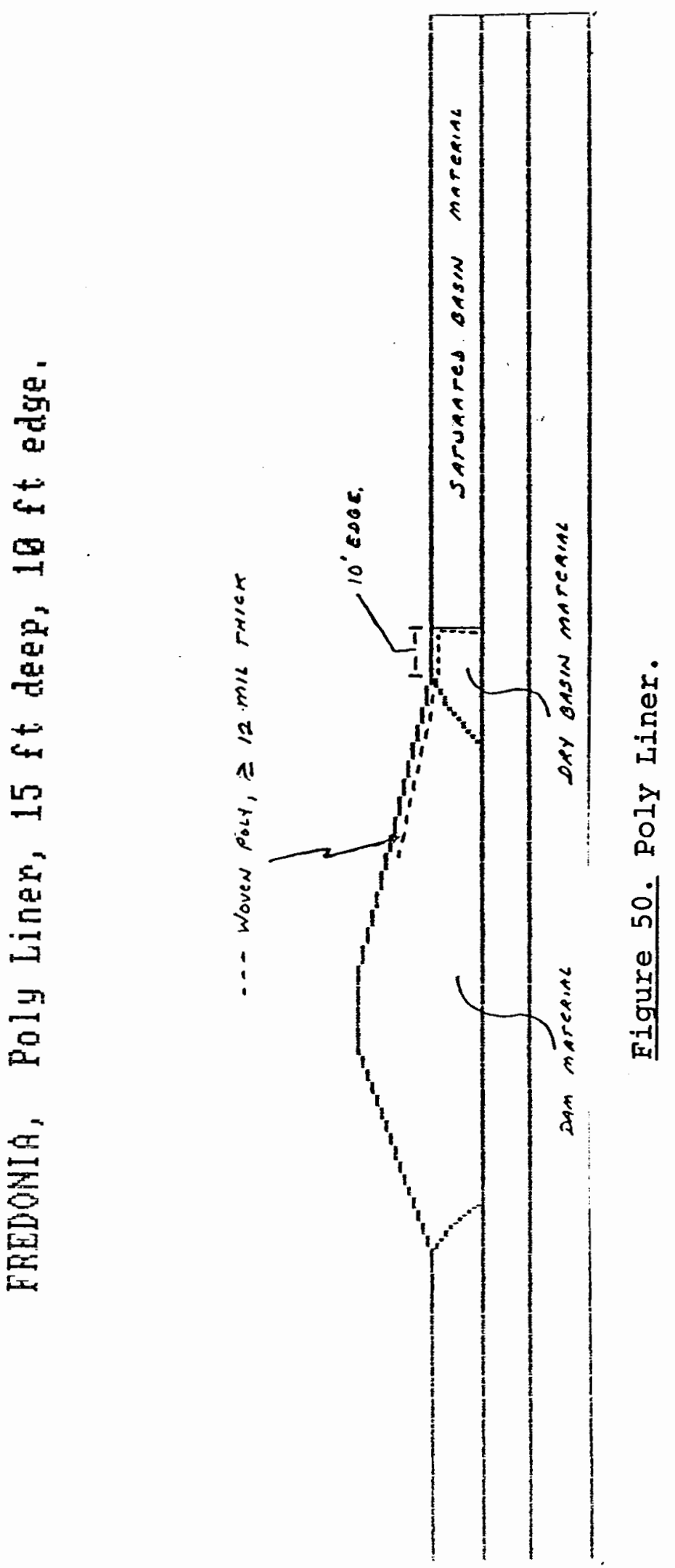


\section{RECOMMENDED AREAS FOR FUTURE STUDY}

\section{Process and Form}

Areas of possible future study include areas of process and form. Suggestions are given.

1) In the area of process, alluvial processes might be studied. An understanding of where debris materials might suddenly issue forth from in the debris fan area would show the area of most likely deepest impoundment.

one place to begin might be to delineate as closely as possible the debris flow formation process. Then steps might be taken to re-direct, slow, or stop undesired flow in the early stages of an event.

2) Specific field studies might be made. The idea here is to make as detailed as possible observations of actual dam cracking in a changing environment. As noted in Chapter VII, as-built plans (1966) at South Straight Hollow show a near 5 foot deep basin cut upstream of the dam. Field researchers report a level basin in 1991. Therefore, it would seem important to acquire as to date as possible crack data, basin conditions, etc. before an event at one or more dams. Then right after an event, make detailed field measurements of cracking, etc.

An alternative to waiting for a storm might be to artificially pond a smaller structure, if sufficient water were available. It would require on the order of one 
like the Diversion Hollow Dam in The Ferron Watershed, Utah. This ponding could then be developed as a carefully controlled case study.

3) Future models should include more realistic material unit shapes, or more, smaller elements so as to more closely depict actual chaotic alluvial fan subsurface conditions. 
APPENDIX B

MINI-DAMS 
MINI-DAMS

\section{Heating Mini-Dams}

One feature of the debris dams is their homogeneous nature. On this basis, and the idea of constructing an actual model embankment, it was decided to make miniature embankments from Fredonia soil samples. The miniature dams are about one inch high by six inches long, to approximate Fredonia side slope geometry. These models are then heated in a microwave oven for five to ten minutes until visually dry, and in a regular heat-coil oven for twenty four hours at 150 degrees. Table $\mathrm{X}$ shows moisture parameters.

Longitudinal cracks form along embankment slopes, looking to the eye at least like those at the Fredonia site. After heating, the soil increases a lot in porosity, again to the eye. No actual porosity measurements were made. The heated samples also crumble under finger pressure. Soil in the field near the dam tends to be much more compact, except along stream banks 1500 feet or so upstream of the dam. This stream cut most probably displays original, undisturbed deposition in the area. The soil here is of an open framework, with less grain-grain contact than a more compact soil typifying the basin floor near the dam. Whether this type of unit forms a signifigant part of the dam foundation is not known.

Transverse cracks do form near the ends of the minidams. However, transverse cracking is not apparent along 
much of the dams length, also similar to field conditions. The slow-cooked mini-dams look somewhat different. The soil seems overall more compact, with less longitudinal cracking than the microwave samples. The soil is still openwork relative to field basin soil, but less so than the microwave dams.

For comparison, the diatomite and Fredonia soils show very similar structure (open) and crack patterns. So, it seems that crack potential at least may be independent of collapsible soil type, at least as shown here.

In conclusion, there is a similarity in crack pattern between oven cooked mini-dams and the Fredonia, Az. dam. This similarity is strongest in the case of microwaved mini-dams of Fredonia soil, and diatomaceous composition. Heating of mini-dams causes the soil to attain an open framework. Any other conclusions or analogies are beyond the scope of this paper. 


\section{TABLE $\mathrm{X}$ \\ MINI-DAMS}

\begin{tabular}{|c|c|c|c|}
\hline \multicolumn{4}{|c|}{ Microwave Parameters } \\
\hline Material & Weight wet & Weight DrY & $w \%$ \\
\hline Fredonia & 81.29 & $63.3 g$ & 28.0 \\
\hline \multicolumn{4}{|l|}{ Silt } \\
\hline Diatomite & $61 \cdot 2 \mathrm{~g}$ & $26.6 \mathrm{~g}$ & 130.0 \\
\hline \multicolumn{4}{|c|}{ Oven parameters } \\
\hline Material & Weight wet & Weight DrY & woํํำ \\
\hline Fredonia & $77.2 \mathrm{~g}$ & $53.5 \mathrm{~g}$ & 44.0 \\
\hline \multicolumn{4}{|l|}{ silt } \\
\hline Diatomite & $58.6 \mathrm{~g}$ & $23.0 \mathrm{~g}$ & 154.0 \\
\hline
\end{tabular}

